\title{
Cochrane
}

Library

Cochrane Database of Systematic Reviews

\section{Radiotherapy for neovascular age-related macular degeneration} (Review)

Evans JR, Igwe C, Jackson TL, Chong V

Evans JR, Igwe C, Jackson TL, Chong V.

Radiotherapy for neovascular age-related macular degeneration.

Cochrane Database of Systematic Reviews 2020, Issue 8. Art. No.: CD004004.

DOI: 10.1002/14651858.CD004004.pub4.

www.cochranelibrary.com 
TABLE OF CONTENTS

HEADER 1

ABSTRACT

PLAIN LANGUAGE SUMMARY

SUMMARY OF FINDINGS

BACKGROUND

OBJECTIVES

METHODS

RESULTS

Figure 1.

Figure 2.

Figure 3.

Figure 4.

DISCUSSION

AUTHORS' CONCLUSIONS

ACKNOWLEDGEMENTS

REFERENCES

CHARACTERISTICS OF STUDIES

DATA AND ANALYSES

Analysis 1.1. Comparison 1: Radiation therapy versus control, Outcome 1: Loss of 3 or more lines best-corrected visual acuity lost at 12 months

Analysis 1.2. Comparison 1: Radiation therapy versus control, Outcome 2: Three or more lines visual acuity lost at 24 months ..

Analysis 1.3. Comparison 1: Radiation therapy versus control, Outcome 3: Change in BCVA at 12 months

Analysis 1.4. Comparison 1: Radiation therapy versus control, Outcome 4: Change in BCVA at 24 months

Analysis 1.5. Comparison 1: Radiation therapy versus control, Outcome 5: Change in contrast sensitivity

Analysis 1.6. Comparison 1: Radiation therapy versus control, Outcome 6: Contrast sensitivity raw data

Analysis 2.1. Comparison 2: Radiation therapy with anti-VEGF versus anti-VEGF alone, Outcome 1: Three or more lines visual acuity lost at 12 months

Analysis 2.2. Comparison 2: Radiation therapy with anti-VEGF versus anti-VEGF alone, Outcome 2: Three or more lines visual acuity lost at 24 months

Analysis 2.3. Comparison 2: Radiation therapy with anti-VEGF versus anti-VEGF alone, Outcome 3: Change in BCVA at 12 months

Analysis 2.4. Comparison 2: Radiation therapy with anti-VEGF versus anti-VEGF alone, Outcome 4: Change in BCVA at 24 months

ADDITIONAL TABLES

APPENDICES

WHAT'S NEW

HISTORY

CONTRIBUTIONS OF AUTHORS

DECLARATIONS OF INTEREST

SOURCES OF SUPPORT

DIFFERENCES BETWEEN PROTOCOL AND REVIEW

INDEX TERMS 
[Intervention Review]

\title{
Radiotherapy for neovascular age-related macular degeneration
}

Jennifer R Evans ${ }^{1}$, Chinedu Igwe ${ }^{2}$, Timothy L Jackson ${ }^{3}$, Victor Chong 4

${ }^{1}$ Cochrane Eyes and Vision, ICEH, London School of Hygiene \& Tropical Medicine, London, UK. ${ }^{2}$ Sutton Hospital, Surrey, UK. ${ }^{3}$ Department of Ophthalmology, King's College London, London, UK. ${ }^{4}$ Oxford Eye Hospital, Oxford, UK

Contact address: Victor Chong, victor@eretina.org.

Editorial group: Cochrane Eyes and Vision Group.

Publication status and date: New search for studies and content updated (conclusions changed), published in Issue 8, 2020.

Citation: Evans JR, Igwe C, Jackson TL, Chong V. Radiotherapy for neovascular age-related macular degeneration. Cochrane Database of Systematic Reviews 2020, Issue 8. Art. No.: CD004004. DOI: 10.1002/14651858.CD004004.pub4.

Copyright $@ 2020$ The Cochrane Collaboration. Published by John Wiley \& Sons, Ltd.

\begin{abstract}
A B S T R A C T

\section{Background}

Radiotherapy has been proposed as a treatment for new vessel growth in people with neovascular age-related macular degeneration
\end{abstract} (AMD).

\section{Objectives}

To examine the effects of radiotherapy on neovascular AMD.

\section{Search methods}

We searched CENTRAL, MEDLINE, Embase, LILACS and three trials registers and checked references of included studies. We last searched the databases on 4 May 2020.

\section{Selection criteria}

We included all randomised controlled trials in which radiotherapy was compared to another treatment, sham treatment, low dosage irradiation or no treatment in people with choroidal neovascularisation (CNV) secondary to AMD.

\section{Data collection and analysis}

We used standard procedures expected by Cochrane. We graded the certainty of the evidence using GRADE. We considered the following outcomes at 12 months: best-corrected visual acuity (BCVA) (loss of 3 or more lines, change in visual acuity), contrast sensitivity, new vessel growth, quality of life and adverse effects at any time point.

\section{Main results}

We included 18 studies ( $n=2430$ people, 2432 eyes) of radiation therapy with dosages ranging from 7.5 to 24 Gy. These studies mainly took place in Europe and North America but two studies were from Japan and one multicentre study included sites in South America. Three of these studies investigated brachytherapy (plaque and epimacular), the rest were studies of external beam radiotherapy (EBM) including one trial of stereotactic radiotherapy. Four studies compared radiotherapy combined with anti-vascular endothelial growth factor (antiVEGF) with anti-VEGF alone. Eleven studies gave no radiotherapy treatment to the control group; five studies used sham irradiation; and one study used very low-dose irradiation (1 Gy). One study used a mixture of sham irradiation and no treatment. Fifteen studies were judged to be at high risk of bias in one or more domains.

\section{Radiotherapy versus no radiotherapy}

There may be little or no difference in loss of 3 lines of vision at 12 months in eyes treated with radiotherapy compared with no radiotherapy (risk ratio $(\mathrm{RR}) 0.82,95 \%$ confidence interval $(\mathrm{Cl}) 0.64$ to $1.04,811$ eyes, 8 studies, $\mathrm{I}^{2}=66 \%$, low-certainty evidence). Low-certainty 
evidence suggests a small benefit in change in visual acuity (mean difference (MD) $-0.10 \log \mathrm{MAR}, 95 \% \mathrm{Cl}-0.17$ to -0.03 ; eyes $=883$; studies $=10$ ) and average contrast sensitivity at 12 months (MD $0.15 \log$ units, $95 \% \mathrm{Cl} 0.05$ to 0.25; eyes $=267$; studies $=2$ ). Growth of new vessels (largely change in CNV size) was variably reported and It was not possible to produce a summary estimate of this outcome. The studies were small with imprecise estimates and there was no consistent pattern to the study results (very low-certainty evidence). Quality of life was only reported in one study of 199 people; there was no clear difference between treatment and control groups (lowcertainty evidence). Low-certainty evidence was available on adverse effects from eight of 14 studies. Seven studies reported on radiation retinopathy and/or neuropathy. Five of these studies reported no radiation-associated adverse effects. One study of 88 eyes reported one case of possible radiation retinopathy. One study of 74 eyes graded retinal abnormalities in some detail and found that $72 \%$ of participants who had radiation compared with $71 \%$ of participants in the control group had retinal abnormalities resembling radiation retinopathy or choroidopathy. Four studies reported cataract surgery or progression: events were generally few with no consistent evidence of any increased occurrence in the radiation group. One study noted transient disturbance of the precorneal tear film but there was no evidence from the other two studies that reported dry eye of any increased risk with radiation therapy. None of the participants received anti-VEGF injections.

\section{Radiotherapy combined with anti-VEGF versus anti-VEGF alone}

People receiving radiotherapy/anti-VEGF were probably more likely to lose 3 or more lines of BCVA at 12 months compared with anti-VEGF alone (RR 2.11, 95\% Cl 1.40 to 3.17, 1050 eyes, 3 studies, moderate-certainty). Most of the data for this outcome come from two studies of epimacular brachytherapy (114 events) compared with 20 events from the one trial of EBM. Data on change in BCVA were heterogenous (I2 $=82 \%$ ). Individual study results ranged from a small difference of $-0.03 \log$ MAR in favour of radiotherapy/anti-VEGF to a difference of 0.13 logMAR in favour of anti-VEGF alone (low-certainty evidence). The effect differed depending on how the radiotherapy was delivered (test for interaction $\mathrm{P}=0.0007$ ). Epimacular brachytherapy was associated with worse visual outcomes (MD $0.10 \log \mathrm{MAR}, 95 \% \mathrm{Cl} 0.05$ to 0.15 , 820 eyes, 2 studies) compared with EBM (MD - 0.03 logMAR, $95 \% \mathrm{Cl}-0.09$ to $0.03,252$ eyes, 2 studies). None of the included studies reported contrast sensitivity or quality of life. Growth of new vessels (largely change in CNV size) was variably reported in three studies (803 eyes). It was not possible to produce a summary estimate and there was no consistent pattern to the study results (very low-certainty evidence). For adverse outcomes, variable results were reported in the four studies. In three studies reports of adverse events were low and no radiationassociated adverse events were reported. In one study of epimacular brachytherapy there was a higher proportion of ocular adverse events (54\%) compared to the anti-VEGF alone (18\%). The majority of these adverse events were cataract. Overall $5 \%$ of the treatment group had radiation device-related adverse events ( 17 cases); 10 of these cases were radiation retinopathy. There were differences in average number of injections given between the four studies (1072 eyes). In three of the four studies, the anti-VEGF alone group on average received more injections (moderate-certainty evidence).

\section{Authors' conclusions}

The evidence is uncertain regarding the use of radiotherapy for neovascular AMD. Most studies took place before the routine use of anti-VEGF, and before the development of modern radiotherapy techniques such as stereotactic radiotherapy. Visual outcomes with epimacular brachytherapy are likely to be worse, with an increased risk of adverse events, probably related to vitrectomy. The role of stereotactic radiotherapy combined with anti-VEGF is currently uncertain. Further research on radiotherapy for neovascular AMD may not be justified until current ongoing studies have reported their results.

\section{PLAIN LANGUAGE SUMMARY}

\section{How effective is radiotherapy for treating wet age-related macular degeneration (AMD) (a degenerative eye condition)?}

\section{Why this question is important}

AMD is a common condition of the eyes that may develop in people aged over 50. It affects the central area (macula) of the back of the eye (retina). First, yellow spots (drusen) develop under the retina. These can been seen by health professionals during examinations of the eyes. As AMD progresses, new blood vessels can grow in the macula. These vessels may bleed or cause scarring; this is called 'neovascular' or 'wet' AMD. Wet AMD can cause people to lose the central part of their vision.

There is no cure for wet AMD. However, there are treatments designed to stop vision from worsening. One such treatment is radiotherapy (using radiation to kill harmful cells). To find out how effective radiotherapy is for treating wet AMD and whether it causes unwanted effects, we reviewed the evidence from research studies.

\section{How we identified and assessed the evidence}

First, we searched for all relevant studies in the medical literature. We then compared the results, and summarized the evidence from all the studies. Finally, we assessed how certain the evidence was. We considered factors such as the way studies were conducted, study sizes, and consistency of findings across studies. Based on our assessments, we categorized the evidence as being of very low-, low-, moderateor high-certainty.

\section{What we found}

We identified 18 relevant studies on a total of 2340 people with wet AMD. These studies mainly took place in Europe and North America, though two studies were from Japan and one study included sites in South America. Fifteen studies investigated external beam 
radiotherapy and three studies investigated internal radiotherapy (brachytherapy), where radioactive materials are placed on the surface of the eye.

Studies compared:

\# radiotherapy alone with no radiotherapy or a sham treatment (14 studies,1223 people); or

\# radiotherapy plus eye injections (of a medicine called anti-vascular endothelial growth factor (VEGF)) with eye injections only (four studies,1117 people); or

The studies showed that:

When radiotherapy was compared with no radiotherapy or a sham treatment, at 12-month follow-up

\# There may be little difference in how likely people's vision is to worsen by 3 lines or more on a vision chart (low-certainty).

\# There may be a small difference in average visual sharpness (in the order of 1 line of a vision chart) favouring radiotherapy (low-certainty).

\# People's ability to distinguish between bright and dim parts of an image may be slightly better with radiotherapy (low-certainty).

\# The evidence on growth of new blood vessels in the back of the eye was inconsistent (very low-certainty).

\# There may be little difference in quality of life (low-certainty).

\# Studies that recorded unwanted effects generally reported no radiation-associated damage to the retina or optical nerve. Other unwanted effects, such as cataracts, were uncommon. There was no consistent evidence that unwanted effects were more likely in the radiation group (low-certainty).

When radiotherapy combined with anti-VEGF was compared with anti-VEGF alone, 12 months follow-up

\# People treated with radiotherapy plus anti-VEGF are probably twice as likely to lose 3 lines or more on a vision chart than people treated with anti-VEGF alone (moderate-certainty).

\# Studies reported inconsistent results on average vision sharpness (low-certainty) and new vessel growth (very low-certainty evidence). Average vision sharpness may be worse with brachytherapy.

\# No studies investigated the impact on people's ability to distinguish between bright and dim parts of an image, or quality of life.

\# Three out of four studies reported few unwanted effects and no radiation-associated damage to the retina or optical nerve. In one study, half of the people treated with brachytherapy reported unwanted effects (particularly cataracts) and there were some instances of damage to the retina caused by the brachytherapy (low-certainty).

\# In three out of four studies, people treated with radiotherapy received fewer anti-VEGF injections (moderate-certainty).

\section{Conclusion}

It is uncertain whether radiotherapy on its own or with eye injections of anti-VEGF is effective for treating wet AMD.

\section{How up-to-date is this review?}

Cochrane researchers searched for studies that had been published up to 4 May 2020. 


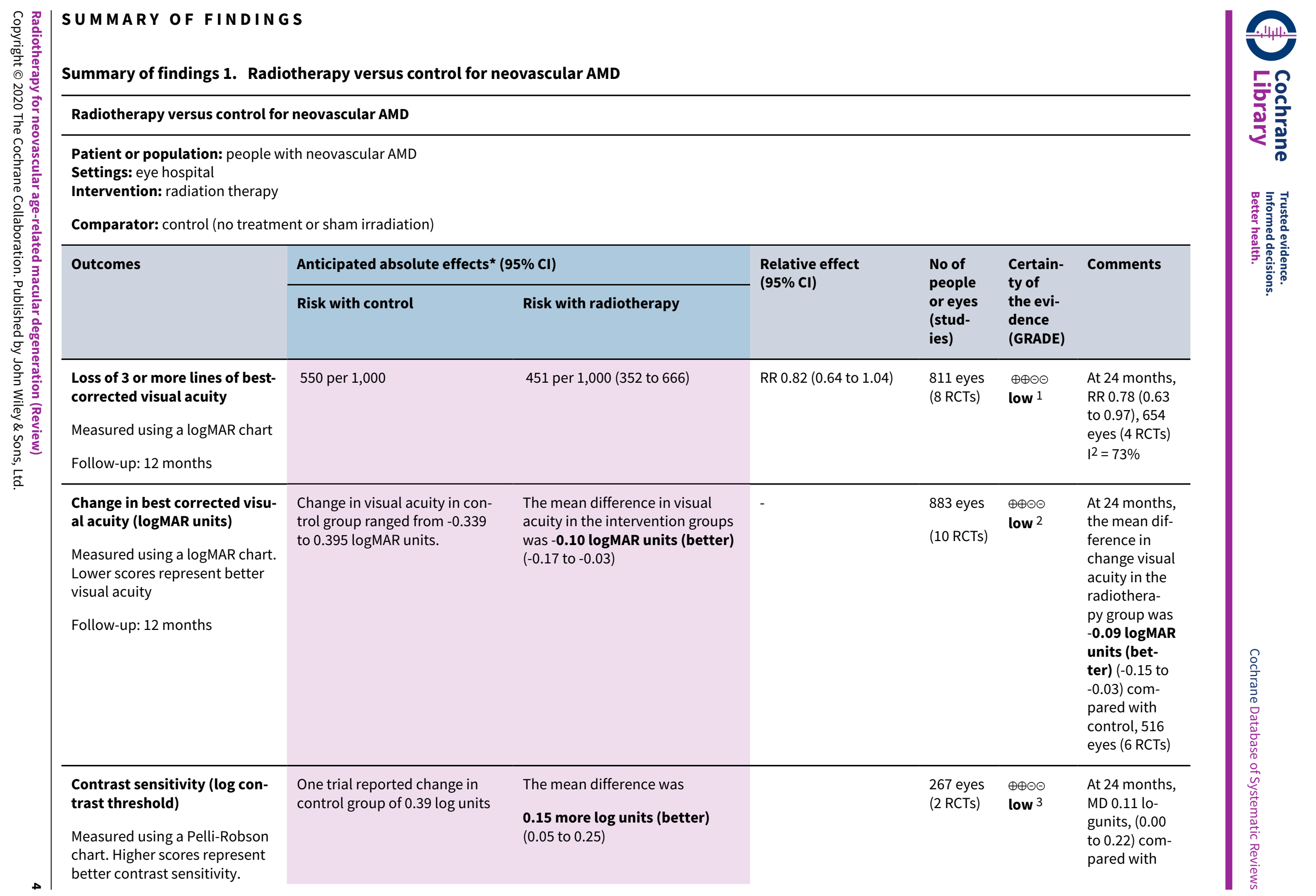




\section{New vessel growth}

Measured using fluorescein angiography or fundus photographs

Follow-up: 12 months

\section{Quality of life}

Follow-up: 12 months

Any adverse outcome

Follow-up: any time point
It was not possible to produce a summary estimate due to variable reporting of this outcome. The studies were small with imprecise estimates and there was no consistent pattern to the study results.

\section{(9 RCTs) $\oplus \odot \ominus \ominus$}

very low of 74 eyes graded retinal abnormalities in some detail and found that $72 \%$ of participants who had radiation compared with $71 \%$ of participants in the control group had retinal abnormalities resembling radiation retinopathy or choroidopathy. Four studies reported cataract surgery or progression: events were generally low and no consistent evidence of any increased occurrence in the radiation group. One study noted transient disturbance of the precorneal tear film but no evidence from the other 2 studies that reported dry eye of any increased risk with radiation therapy.

\section{Number of anti-VEGF injec- Not relevant to this comparison \\ tions}

${ }^{\star}$ The risk with control was estimated from the pooled risk in the control groups of the included studies. The risk with radiotherapy (and its $95 \%$ confidence interval) is based on the risk in the control group and therelative effect of the intervention (and its $95 \% \mathrm{Cl}$ ).

AMD: age-related macular degeneration Anti-VEGF: anti-vascular endothelial growth factor Cl: Confidence interval; RR: Risk ratio;

\section{GRADE Working Group grades of evidence}

High-certainty: We are very confident that the true effect lies close to that of the estimate of the effect

Moderate-certainty: We are moderately confident in the effect estimate: The true effect is likely to be close to the estimate of the effect, but there is a possibility that it is substantially different

Low-certainty: Our confidence in the effect estimate is limited: The true effect may be substantially different from the estimate of the effect

Very low-certainty: We have very little confidence in the effect estimate: The true effect is likely to be substantially different from the estimate of effect

1Downgraded one level for risk of bias ( 6 of the 8 studies were high risk of bias in one or more domain) and downgraded one level for inconsistency (individual study effect estimates ranged from 0.42 to $1.22,12=66 \%$ ). We did not downgrade an additional level for imprecision, even though the confidence intervals include 1 (no difference), because we had already downgraded for inconsistency which will have contributed to the imprecision of the pooled estimate.

Six out of 14 studies did not report on adverse effects. Seven studies reported on radiation retinopathy and/or neuropathy. Five of these studies reported no radiation-associated adverse effects. One study of 88 eyes reported one case of possible radiation retinopathy. One study

Mean change in scores on four dimensions of Daily Living Tasks Dependent on Vision were similar in radiotherapy and control groups. Mean differences ranged from -2.80 (-8.89 to 3.29) to

$(1 \mathrm{RCT})$

\section{1 eyes}

(8 RCTs) $\oplus \oplus \ominus \ominus$

low 5

\section{low 6}


2 Downgraded one level for risk of bias ( 8 of the 10 studies were high risk of bias in one or more domain); and downgraded one level for publication bias as there was an asymmetric funnel plot indicating possible publication bias.

3 Downgraded one level for risk of bias (both studies were high risk of bias in one or more domains); and downgraded one level for imprecision (the upper confidence interval was close to 0 , no difference).

${ }^{4}$ Downgraded one level for risk of bias (8 out of the 9 studies were high risk of bias in one or more domain); downgraded one level for imprecision (the individual studies were small with imprecise estimates); and downgraded one level for inconsistency (there was no consistent pattern to the individual study results)

5 Downgraded one level for risk of bias study (study was not masked); and downgraded one level for imprecision (confidence intervals include 0 ).

${ }^{6}$ Downgraded one level for risk of bias ( 8 out of the 9 studies were high risk of bias in one or more domain); downgraded one level for imprecision (the individual studies were small with imprecise estimates).

\section{Summary of findings 2. Radiotherapy combined with anti-VEGF versus anti-VEGF alone for neovascular AMD}

\section{Radiotherapy combined with anti-VEGF versus anti-VEGF alone for neovascular AMD}

Patient or population: people with neovascular AMD

Settings: eye hospital

Intervention: radiation therapy (external beam or brachytherapy) combined with anti-VEGF (ranibizumab or bevacizumab)

Comparator: anti-VEGF alone (ranibizumab or bevacizumab)

\begin{tabular}{|c|c|c|c|c|c|c|}
\hline \multirow[t]{2}{*}{ Outcomes } & \multicolumn{2}{|c|}{ Anticipated absolute effects* $(95 \% \mathrm{Cl})$} & \multirow{2}{*}{$\begin{array}{l}\text { Relative effect } \\
(95 \% \mathrm{Cl})\end{array}$} & \multirow{2}{*}{$\begin{array}{l}\text { No of } \\
\text { people } \\
\text { or eyes } \\
\text { (stud- } \\
\text { ies) }\end{array}$} & \multirow{2}{*}{$\begin{array}{l}\text { Certain- } \\
\text { ty of } \\
\text { the evi- } \\
\text { dence } \\
\text { (GRADE) }\end{array}$} & \multirow[t]{2}{*}{ Comments } \\
\hline & Risk with anti-VEGF & $\begin{array}{l}\text { Risk with radiotherapy com- } \\
\text { bined with anti-VEGF }\end{array}$ & & & & \\
\hline $\begin{array}{l}\text { Loss of } 3 \text { or more lines of } \\
\text { best-corrected visual acuity } \\
\text { Measured using a logMAR } \\
\text { chart } \\
\text { Follow-up: } 12 \text { months }\end{array}$ & 70 per 1,000 & 148 per 1,000 (98 to 222 ) & $\begin{array}{l}\text { RR } 2.11 \\
\text { (1.40 to } 3.17)\end{array}$ & $\begin{array}{l}1050 \\
\text { eyes } \\
\text { (3 RCTs) }\end{array}$ & $\begin{array}{l}\oplus \oplus \oplus \odot \\
\text { moder- } \\
\text { ate }^{1}\end{array}$ & $\begin{array}{l}\text { At } 24 \\
\text { months, } \\
\text { RR } 2.39 \\
(1.68,3.39) \text {, } \\
820 \text { eyes } \\
\text { ( } 2 \text { RCTs) }\end{array}$ \\
\hline $\begin{array}{l}\text { Change in best corrected vi- } \\
\text { sual acuity (logMAR units) } \\
\text { Measured using a logMAR } \\
\text { chart. Lower scores repre- } \\
\text { sent better visual acuity } \\
\text { Follow-up: } 12 \text { months }\end{array}$ & \multicolumn{3}{|c|}{$\begin{array}{l}\text { We did not pool study results because of substantial heterogeneity. Individual study results } \\
\text { ranged from a small mean difference of }-0.03 \text { logMAR in favour of radiotherapy combined with an- } \\
\text { ti-VEGF to a mean difference of } 0.13 \text { logMAR in favour of anti-VEGF alone }\left(\mathrm{I}^{2}=82 \%\right) \text {. There was ev- } \\
\text { idence of a difference in effect depending on how the radiotherapy was delivered(test for interac- } \\
\text { tion } \mathrm{P}=0.0007) \text {. Epimacular brachytherapy was associated with worse visual outcomes (MD } 0.10 \\
\text { logMAR, } 95 \% \mathrm{Cl} 0.05 \text { to } 0.15,2 \text { studies, } 820 \text { eyes) compared with external beam radiotherapy (MD } \\
-0.03 \operatorname{logMAR,} 95 \% \mathrm{Cl}-0.09 \text { to } 0.03,252 \text { eyes). }\end{array}$} & $\begin{array}{l}1072 \\
\text { eyes } \\
\text { (4 RCTs) }\end{array}$ & $\begin{array}{l}\oplus \oplus \ominus \ominus \\
\text { low } 2\end{array}$ & $\begin{array}{l}\text { At } 24 \\
\text { months, the } \\
\text { mean dif- } \\
\text { ference in } \\
\text { change vi- } \\
\text { sual acu- } \\
\text { ity in the } \\
\text { radiother- } \\
\text { apy with } \\
\text { anti-VEGF } \\
\text { group }\end{array}$ \\
\hline
\end{tabular}




\begin{tabular}{|c|c|c|c|c|}
\hline & & & & $\begin{array}{l}\text { was } \mathbf{0 . 1 7} \\
\text { logMAR } \\
\text { (worse) } \\
\text { (Cl } 0.11 \text { to } \\
0.23 \text { ) com- } \\
\text { pared with } \\
\text { anti-VEGF } \\
\text { alone, } \\
819 \text { eyes, } \\
2 \text { RCTs of } \\
\text { epimacular } \\
\text { brachyther- } \\
\text { apy }\end{array}$ \\
\hline $\begin{array}{l}\text { Contrast sensitivity (log } \\
\text { contrast threshold) }\end{array}$ & \multirow[t]{3}{*}{ None of the included studies reported this outcome. } & \multirow[t]{3}{*}{ - } & \multirow[t]{3}{*}{ - } & \\
\hline $\begin{array}{l}\text { Measured using a Pelli-Rob- } \\
\text { son chart. Higher scores rep- } \\
\text { resent better contrast sensi- } \\
\text { tivity. }\end{array}$ & & & & \\
\hline Follow-up: 12 months & & & & \\
\hline $\begin{array}{l}\text { New vessel growth } \\
\text { Measured using fluorescein } \\
\text { angiography or fundus pho- } \\
\text { tographs }\end{array}$ & \multirow[t]{2}{*}{$\begin{array}{l}\text { It was not possible to produce a summary estimate due to variable reporting of this outcome. } \\
\text { There was no consistent pattern to the individual study results. }\end{array}$} & $\begin{array}{l}803 \text { eyes } \\
\text { (3 RCTs) }\end{array}$ & \multirow[t]{2}{*}{$\begin{array}{l}\oplus \oplus \ominus \ominus \\
\text { very } \\
\text { low }{ }^{3}\end{array}$} & \\
\hline Follow-up: 12 months & & & & \\
\hline Quality of life & \multirow[t]{2}{*}{ None of the included studies reported this outcome. } & - & \multirow[t]{2}{*}{-} & \\
\hline Follow-up: 12 months & & & & \\
\hline $\begin{array}{l}\text { Any adverse outcome } \\
\text { Follow-up: any time point }\end{array}$ & $\begin{array}{l}\text { Variable results were reported in the } 4 \text { studies. In } 3 \text { studies reports of adverse events were low and } \\
\text { no radiation-associated adverse events reported. In one study of epimacular brachytherapy the } \\
\text { radiotherapy and anti-VEGF treatment group had a higher proportion of ocular adverse events } \\
(54 \%) \text { compared to the anti-VEGF alone (18\%). The majority of these adverse events were cataract. } \\
\text { Overall } 5 \% \text { of the treatment group had radiation device-related adverse events (17 cases); } 10 \text { of } \\
\text { these cases were radiation retinopathy. }\end{array}$ & $\begin{array}{l}1072 \\
\text { eyes } \\
\text { (4 RCTs) }\end{array}$ & $\begin{array}{l}\oplus \oplus \ominus \ominus \\
\text { low } 6\end{array}$ & \\
\hline $\begin{array}{l}\text { Number of anti-VEGF injec- } \\
\text { tions }\end{array}$ & $\begin{array}{l}\text { There were some differences in average number of injections. In } 3 \text { of the } 4 \text { studies, the anti-VEGF } \\
\text { alone group on average received more injections }\end{array}$ & $\begin{array}{l}1072 \\
\text { eyes } \\
\text { (4 RCTs) }\end{array}$ & $\begin{array}{l}\oplus \oplus \oplus \odot \\
\text { moder- } \\
\text { ate }^{\mathbf{1}}\end{array}$ & \\
\hline
\end{tabular}

Measured using a Pelli-Robtivity. 
*The risk with control was estimated from the pooled risk in the control groups of the included studies. The risk with radiotherapy (and its $95 \%$ confidence interval) is based on the risk in the control group and therelative effect of the intervention (and its $95 \% \mathrm{Cl}$ ).

AMD: age-related macular degeneration Anti-VEGF: anti-vascular endothelial growth factor CI: Confidence interval; RR: Risk ratio;

\section{GRADE Working Group grades of evidence}

High-certainty: We are very confident that the true effect lies close to that of the estimate of the effect

Moderate-certainty: We are moderately confident in the effect estimate: The true effect is likely to be close to the estimate of the effect, but there is a possibility that it is substantially different

Low-certainty: Our confidence in the effect estimate is limited: The true effect may be substantially different from the estimate of the effect

Very low-certainty: We have very little confidence in the effect estimate: The true effect is likely to be substantially different from the estimate of effect

1Downgraded one level for risk of bias ( 2 of the studies were at risk of performance and detection bias).

2Downgraded one level for risk of bias ( 3 of the 4 studies were high risk of bias in one or more domain); and downgraded one level for inconsistency ( $12=81 \%)$.

3Downgraded one level for risk of bias ( 2 of the studies were at risk of performance and detection bias); downgraded one level for imprecision ( 2 of the individual studies estimates were imprecise); and downgraded one level for inconsistency (there was no consistent pattern to the individual study results).

${ }^{4}$ Downgraded one level for risk of bias ( 3 out of the 4 studies were high risk of bias in one or more domain); downgraded one level for inconsistency (different results in the different studies) 


\section{B A C K G R O U N D}

\section{Description of the condition}

The macula, the central area of the retina, is used for detailed vision such as reading, recognising faces and driving. Age-related macular degeneration (AMD) is the leading cause of blindness in higher income countries (Flaxman 2017). It is difficult to get a clear definition of AMD. The term 'age-related' is used partly due to its unknown pathogenesis. It is believed that both genetic and environmental factors play a significant role in the development of the disease (Evans 2012). From a clinical perspective, AMD primarily affects the macular region. The term 'degeneration' is used to distinguish AMD from other genetic macular dystrophies which run in families and those where there is a clear environmental cause such as an infection or trauma.

There are several signs appearing in the retina that are associated with increasing age and increased risk of developing AMD. These signs, known as age-related maculopathy (ARM), include the presence of drusen (yellow spots beneath the retina), pigmentary disturbance and small focal areas of atrophy. In general, ARM is not associated with significant visual loss. Some people with ARM will go on to develop AMD.

There are two types of AMD: geographic atrophy (large area of atrophy centred in the macula) and choroidal neovascularisation (CNV) also known as wet AMD. This review is concerned with treatment for neovascular AMD.

In neovascular AMD, CNV develops beneath the retina. In the initial phase the CNV might cause visual distortion due to leakage of fluid into the surrounding retina. At this stage the retinal function is only mildly affected and the CNV is potentially reversible. However, the CNV may leak serum lipid and protein leading to exudation and significant swelling of the retina. The CNV may bleed and the haemorrhages may be toxic. Both exudation and haemorrhages induce a scarring response. These are associated with extensive damage to the architecture of the retina-retinal pigment epithelium-choroid complex, leading to significant visual loss.

Choroidal neovascularisation is defined as classic or occult according to its appearance on fluorescein angiography, where fluorescent dye is injected intravenously and imaged as it passes through the blood vessels of the eye. Classic membranes are clearly delineated and can be seen in the early frames of the angiogram. Occult membranes present as either late leakage, which cannot be seen in the early frames, or fibrovascular pigment epithelial detachment. Most lesions have both classic and occult components.

\section{Description of the intervention}

Radiotherapy is commonly used in oncology and its use is increasing in the treatment of non-neoplastic diseases. It is believed that it can preferentially damage dividing and fast growing cells more than normal supporting cells. In rats, photoreceptor cell death is not seen at doses less than $10 \mathrm{~Gy}$ and the retinal pigment epithelial cell loss does not occur under $20 \mathrm{~Gy}$ in singlefraction. There is also evidence to suggest that fractionation of irradiation greatly reduces the toxicity but preserves the DNAdamaging effects in rapidly dividing cells.
There are two ways of delivering the radiation dose, either by external beam radiotherapy (i.e. from outside the eye) or by brachytherapy whereby the dose is delivered intra-ocularly or transscleral. The original external beam radiation therapy techniques delivered high-energy radiation through the eye and surrounding tissue. More recent modifications of this technique include stereotactic radiotherapy whereby lower doses are applied in a targeted fashion. In epimacular brachytherapy, after vitrectomy the radiation source is applied to the fovea for a short period of time.

\section{How the intervention might work}

Clinical experience suggests that cumulative doses of up to 25 Gy seldom cause damage to the retina or optic nerve. Radiation therapy is anti-angiogenic. Radiation targets cells that are dividing. As the endothelial cells in CNV are dividing the hypothesis is that radiotherapy can stop the growth of new blood vessels without significant damage to the retina.

\section{Why it is important to do this review}

There are several RCTs of radiotherapy for neovascular AMD using different dosage and fractionation schemes. The aim of this review was to assess systematically the results of these studies with a view to providing an overall estimate of treatment effect.

\section{O B JECT IVES}

To examine the effects of radiotherapy on neovascular AMD.

\section{METHODS}

\section{Criteria for considering studies for this review}

\section{Types of studies}

We included randomised controlled trials (RCTs).

\section{Types of participants}

We included trials in which participants were people with CNV secondary to AMD as defined by the study investigators.

\section{Types of interventions}

We included studies in which radiotherapy, no matter how it was delivered, was compared to another treatment, low dosage irradiation, sham treatment or no treatment.

\section{Types of outcome measures}

The outcomes have been amended for the current update: see Differences between protocol and review.

\section{Primary outcomes}

The primary outcome for this review was visual acuity. We considered two measures of visual acuity: 3 or more lines bestcorrected visual acuity (BCVA) lost on a logMAR chart (equivalent to doubling of visual angle or worse) and change in mean BCVA as a continuous score.

\section{Secondary outcomes}

The secondary outcomes for this review were:

- mean change in contrast sensitivity; 
- proportion of people with new vessel growth;

- mean (median) quality of life measured using any validated measurement scale which aims to measure the impact of visual function loss on quality of life of participants;

- any adverse outcomes as reported in trials.

In a protocol amendment we added the following outcome:

- number of anti-VEGF injections during the first 12 and 24 months.

\section{Follow up}

We measured outcomes at 12 ( 6 to 18 ) and 24 (18 to 30 ) months after radiation treatment.

\section{Search methods for identification of studies}

\section{Electronic searches}

The Cochrane Eyes and Vision Information Specialist conducted systematic searches in the following databases for randomised controlled trials and controlled clinical trials. There were no restrictions to language or year of publication. The date of the search was 4 May 2020.

- Cochrane Central Register of Controlled Trials (CENTRAL; 2020, Issue 5) (which contains the Cochrane Eyes and Vision Trials Register) in the Cochrane Library (searched 4 May 2020) (Appendix 1).

- MEDLINE Ovid (1946 to 4 May 2020) (Appendix 2).

- Embase Ovid (1980 to 4 May 2020) (Appendix 3).

- LILACS (Latin American and Caribbean Health Science Information database (1982 to 4 May 2020) (Appendix 4).

- International Standard Randomised Controlled Trial Number (ISRCTN) registry (www.isrctn.com/editAdvancedSearch; searched 4 May 2020) (Appendix 5).

- US National Institutes of Health Ongoing Trials Register ClinicalTrials.gov (www.clinicaltrials.gov; searched 4 May 2020) (Appendix 6).

- World Health Organization (WHO) International Clinical Trials Registry Platform (ICTRP) (www.who.int/ictrp; searched 22 May 2019. Update search not run as the database is not available due to Covid 19 resource restrictions) (Appendix 7).

\section{Searching other resources}

We contacted the investigators of the trials included in this review for information about further trials. We searched the reference lists of relevant studies for further trial reports. We did not perform manual searches of conference proceedings or journals.

\section{Data collection and analysis}

\section{Selection of studies}

Two review authors independently scanned the titles and abstracts resulting from the searches. We obtained full-text copies of all potentially or definitely relevant articles. Two review authors assessed the full-text copies according to the 'Criteria for considering studies for this review'. We resolved disagreements by discussion.

\section{Data extraction and management}

Two review authors independently extracted data using a form developed by Cochrane Eyes and Vision. We resolved discrepancies by discussion. In the original review (Sivagnanavel 2004), one author entered data into RevMan 4.2 using the double data-entry facility to check for errors. For the updates in Review Manager 5 (RevMan 5) (Review Manager 2014), data were entered onto a spreadsheet and cut and pasted into RevMan.

\section{Assessment of risk of bias in included studies}

We used Cochrane's tool for assessing risk of bias.

\section{Selection bias}

Sequence generation:

- Low risk of bias: Computer generated list, random table, other method of generating random list

- Unclear risk of bias: Not reported how list was generated. Trial may be described as "randomised" but with no further details.

- High risk of bias: Alternate allocation, date of birth, records (these RCTs should be excluded)

\section{Allocation concealment}

- Low risk of bias: Central centre (web/telephone access), sealed opaque envelopes

- Unclear risk of bias: Not reported how allocation administered. Trial may be described as "randomised" but with no further details.

- High risk of bias: Investigator involved in treatment allocation or treatment allocation clearly not masked

\section{Performance bias}

\section{Masking of participants and personnel}

- Low risk of bias: Sham treatment in control group and/or clearly stated that participants and personnel (apart from person applying intervention) not aware of which treatment received

- Unclear risk of bias: Described as "double blind" with no information on who was masked.

- High risk of bias: No information on masking and interventions different

\section{Detection bias}

- Low risk of bias: clearly stated that outcome assessors were masked and/or sham irradiation in control group

- Unclear risk of bias: Described as "double blind" with no information on who was masked.

- High risk of bias: No information on masking and interventions different

\section{Attrition bias}

- Low risk of bias: Missing data less than $20 \%$ (i.e. more than $80 \%$ follow-up) and equal follow-up in both groups and no obvious reason why loss to follow-up should be related to outcome

- Unclear risk of bias: Follow-up not reported or missing data $>20 \%$ (i.e. follow-up < $80 \%$ ) but follow-up equal in both groups

- Follow-up different in each group and/or related to outcome 


\section{Selective outcome reporting}

- Low risk of bias: outcomes on protocol or trial registry entry reported

- Unclear risk of bias: no access to protocol or trial registry entry

- High risk of bias: outcomes on protocol or trial registry entry not reported

\section{Measures of treatment effect}

We used the mean difference (MD) with 95\% confidence intervals (CI) for continuous outcomes (e.g. visual acuity logMAR score) and risk ratio (RR) with $95 \% \mathrm{Cl}$ for dichotomous outcomes (e.g. loss of 3 or more lines of BCVA).

\section{Unit of analysis issues}

Most studies randomised participants and then studied one eye per person. One trial (Jaakkola 2005) reported data from 88 eyes in 86 participants. As the numbers of people with both eyes erroneously included in the analysis was small in this study, and it was not possible to extract data for people, this error was ignored and data on eyes used in the analysis. There were no cross-over or cluster RCTs, indeed they would not be expected for this intervention. Two of the studies were three arm studies with two intervention groups of with different doses of radiotherapy. For the purposes of the analysis, we combined the intervention groups using the RevMan calculator.

\section{Dealing with missing data}

Our analyses assume that missing data are missing at random.

In previous versions of this review we did sensitivity analyses to look at the effect of missing data (Evans 2010). Under various reasonable assumptions regarding missing data, the percentage change in the pooled estimates was small. We have not repeated these analyses for the current update.

\section{Assessment of heterogeneity}

We assessed heterogeneity by looking at the forest plots to see whether the confidence intervals for the estimates of effect overlapped and by looking at the $\mathrm{X}^{2}$ and $\mathrm{I}^{2}$ value.

\section{Assessment of reporting biases}

We investigated publication bias by doing a scatter plot of the effect estimates from the individual studies against their standard error. We only did this on analyses that included 10 or more study results. An asymmetric graph may indicate that smaller studies that are not statistically significant have not been published although it also may indicate that the effects of treatment are different in small studies.

We assessed selective outcome reporting using the Cochrane risk of bias tool (Assessment of risk of bias in included studies).

\section{Data synthesis}

We used a random-effects model to combine results. When data were sparse and we judged a random-effects model would not provide a robust estimate of effect (for example, if there were three or fewer trials), we used a fixed-effect model.

\section{Subgroup analysis and investigation of heterogeneity}

Not all of the trials reported data for all outcomes. This meant that our options for exploring the sources of heterogeneity were limited. In our protocol we specified three factors of interest for subgroup analyses (method of delivery, dosage and type of CNV). In a previous version of this review we identified one additional aspect of study design as being of interest for subgroup analysis. This was whether or not sham irradiation was carried out in the control group.

Using these factors we performed stratified analyses, the purpose of which was to determine whether the outcome varied significantly with type of explanatory variable. We divided the trials into two groups for each factor:

- external beam versus brachytherapy;

- high dose (more than $14 \mathrm{~Gy}$ ) versus low dose (less than or equal to $14 \mathrm{~Gy}$ );

- $50 \%$ or more of participants with classic CNV versus less than $50 \%$ with classic CNV; and

- trials with no sham irradiation versus those with sham irradiation.

\section{Sensitivity analysis}

We did not conduct any sensitivity analyses.

\section{Summary of findings and assessment of the certainty of the evidence}

We prepared a summary of findings table presenting relative and absolute risks. One author (JE) graded the overall quality of the evidence for each outcome using the GRADE classification (GRADEpro) and the other authors checked this grading. We included the following outcomes at 12 months: loss of 3 or more lines BCVA, change in BCVA, contrast sensitivity, new vessel growth, quality of life, any adverse outcome (any time point), and number of anti-VEGF injections.

\section{RES U L T S}

\section{Description of studies}

\section{Results of the search}

The searches conducted in July 2004 identified 149 reports. A further two potentially relevant reports were identified by subsequent electronic searching carried out for another project. We obtained full copies of 28 reports which referred to 23 potentially relevant studies. We excluded 12 of these trials largely because the treatment groups were not randomly allocated. A total of 11 trials were considered suitable for inclusion in the review (Anders 1998; Bergink 1998; Char 1999; Ciulla 2002; Eter 2002; Kacperek 2001; Kobayashi 2000; Marcus 2001; RAD 1999; SFRADS 2002; Valmaggia 2002).

An update search done in March 2010 identified 487 reports of trials. After initial assessment by the Trials Search Co-ordinator, 477 references were excluded as they were deemed not relevant to the scope of the review and the review authors subsequently assessed ten reports. Of these ten reports, three were relevant trials (AMDLRTSG 2003; AMDRT 2004; Jaakkola 2005), six were ineligible trials and one was a report on quality of life outcomes in SFRADS 2002. 
Update searches run in May 2020 identified a further 1120 records (Figure 1). The Cochrane Information Specialist removed 217 duplicates and screened the remaining 903 reports, of which 804 were not relevant to the scope of the review. We reviewed the remaining 99 reports and discarded 80 records as not relevant. We obtained 19 full-text reports for potential inclusion in the review. We included 11 reports of four new studies - CABERNET 2013, INTREPID 2013, MERLOT 2016 and Osmanovic 2017 - and included a further three reports of the RAD 1999 study, which was already included in the previous version of this review. A newly published report from the MERLOT 2016 study giving results at 24 months was added to this review just prior to publication of this update. 
Figure 1. Study flow diagram.

14 studies included in previous version of the review (searches as of Mar 2010)
1120 records identified through electronic database searching (March 2010 to May 2020)
*1 newly published report of a trial with updated results added to the search results

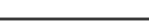
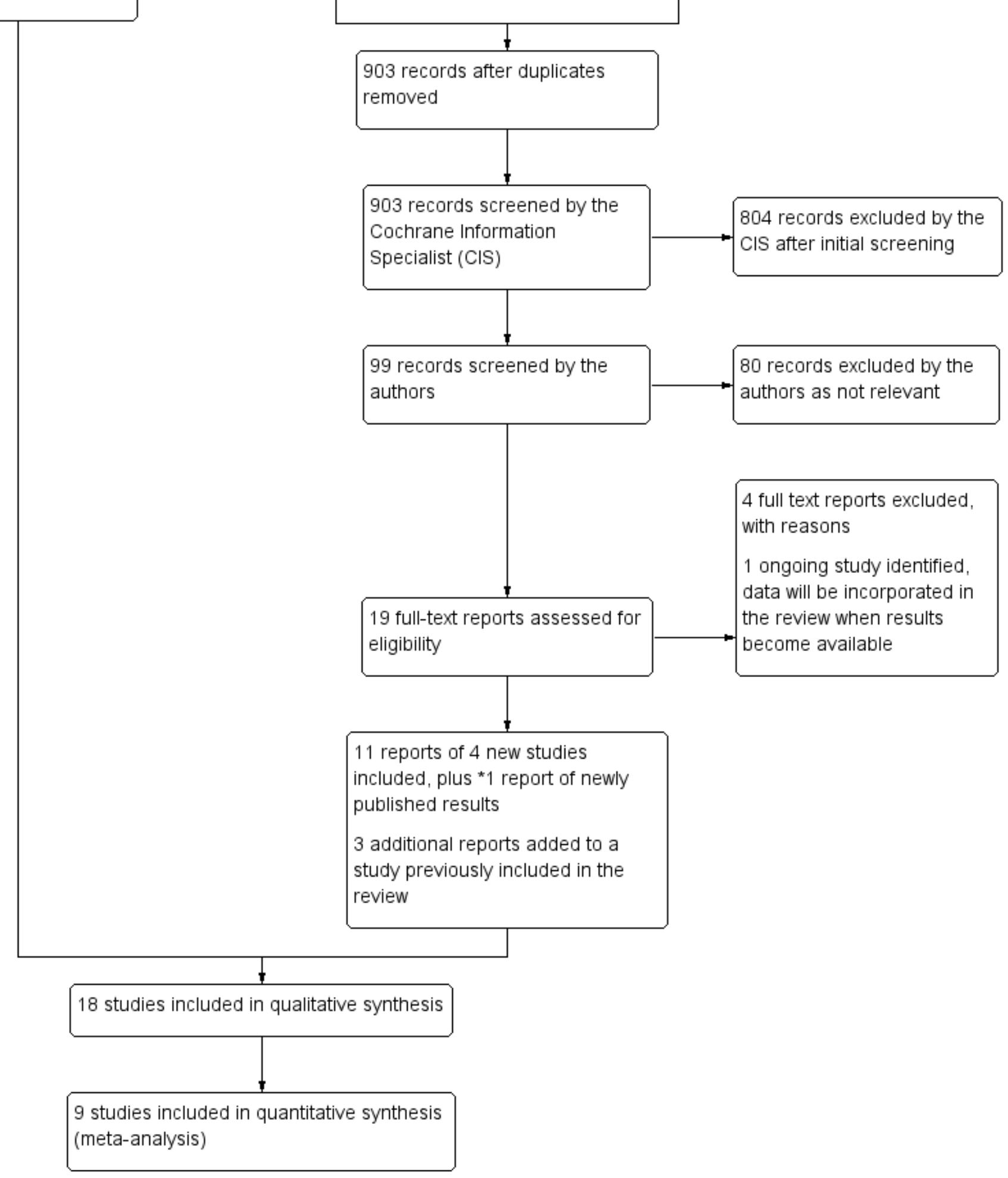
We excluded four studies. See Characteristics of excluded studies for details. We identified one ongoing study and will include it in the review when data becomes available (STAR (NCT02243878)).

\section{Summary}

The current edition of the review has 18 included studies (Characteristics of included studies), 22 excluded studies (Characteristics of excluded studies) and one ongoing study (Characteristics of ongoing studies).

\section{Included studies}

See Table 1 and Table 2.

\section{Types of studies}

All studies were parallel group randomised controlled trials; people were randomly allocated to treatment and one eye per person enrolled in the trial. In three trials it was not clear how many eyes were studied (Anders 1998; Ciulla 2002; Kacperek 2001). In Jaakkola 2005 two (out of 82) participants had both eyes enrolled.

\section{Types of participants}

The 18 trials randomised a total of 2430 people (2432 eyes). The studies took place in Germany (Anders 1998; Eter 2002; RAD 1999), the Netherlands (Bergink 1998), Finland (Jaakkola 2005), USA (AMDRT 2004; Char 1999; Ciulla 2002; Marcus 2001; Osmanovic 2017), Japan (AMDLRTSG 2003; Kobayashi 2000), UK (Kacperek 2001;MERLOT 2016; SFRADS 2002), and Switzerland (Valmaggia 2002). Three studies were multi-centre: CABERNET 2013 took place in US, Europe, Israel, South America, INTREPID 2013 took place in Europe and MERLOT 2016 was conducted in the UK.

The average age of participants in the studies ranged from 71 to 77 years (median average age 76 years). In most studies the majority of participants were women; the percentage female ranged from $30 \%$ to $69 \%$ (median $60 \%$ ).

Most studies recruited participants with subfoveal CNV associated with AMD. INTREPID 2013 did not specify that the CNV had to be subfoveal. Most studies, with the exception of AMDLRTSG 2003, Anders 1998, INTREPID 2013 and Kacperek 2001, classified the CNV lesion as classic, occult or mixed (Table 2). The percentage of participants with classic CNV ranged between 12\% (Marcus 2001;MERLOT 2016) and 57\% (Valmaggia 2002). The percentage of participants with occult CNV ranged between 2\% (SFRADS 2002) and 75\% (MERLOT 2016).

Two studies did not specify visual acuity criteria for entry to the trial (Eter 2002; Valmaggia 2002). Most studies specified worst visual acuity in the study eye, in the region of $6 / 60$ and $6 / 120$ (AMDLRTSG 2003; AMDRT 2004; Anders 1998; Bergink 1998; Ciulla
2002; Jaakkola 2005; Kacperek 2001; Marcus 2001; RAD 1999; SFRADS 2002); two studies did not specify a worst acuity (Char 1999; Kobayashi 2000). More recent trials (CABERNET 2013; INTREPID 2013; MERLOT 2016; Osmanovic 2017) specified more moderate thresholds of visual impairment e.g. 6/12.

\section{Types of intervention}

Table 3 shows the detail of the radiation therapy and control in the different studies. Fifteen studies used external beam radiation therapy. The dosages ranged from 24 Gy (Bergink 1998; INTREPID 2013; Osmanovic 2017) to 7.5 Gy (Char 1999). Three studies used brachytherapy with a dose of 24 Gy (CABERNET 2013; MERLOT 2016) and 12.6 Gy delivered over 11 minutes (Jaakkola 2005).

Eleven of the studies gave no radiotherapy treatment to the control group (AMDLRTSG 2003; Anders 1998; Bergink 1998; CABERNET 2013; Char 1999; Eter 2002; Jaakkola 2005; Kacperek 2001; Kobayashi 2000; MERLOT 2016; SFRADS 2002); five studies used sham irradiation (Ciulla 2002; INTREPID 2013; Marcus 2001; Osmanovic 2017 ; RAD 1999) and one study used very lowdose irradiation (1 Gy) (Valmaggia 2002). In AMDRT 2004 some participants in the control group received sham irradiation and others received no treatment.

In the four more recent trials, radiation therapy was combined with anti-VEGF treatment - ranibizumab (CABERNET 2013; INTREPID 2013; MERLOT 2016) and either ranibizumab or bevacizumab (Osmanovic 2017).

\section{Types of outcome measures}

In most studies the primary outcome was visual acuity. This was usually measured using the ETDRS chart or equivalent logMAR chart. The exception to this was Bergink 1998 where Snellen acuity was measured. Most studies considered some aspect of the clinical progression of CNV such as area of CNV (AMDLRTSG 2003; AMDRT 2004; Kobayashi 2000; Osmanovic 2017; Valmaggia 2002) and appearance of the fundus on fluorescein angiography (Jaakkola 2005; Marcus 2001; RAD 1999). Near vision (SFRADS 2002) and reading ability (Valmaggia 2002) were also considered. Five studies specifically considered safety (AMDRT 2004; Kobayashi 2000; MERLOT 2016; Osmanovic 2017; SFRADS 2002). In INTREPID 2013 and MERLOT 2016 the primary outcome was the number of pro re nata (PRN) ranibizumab injections administered over 52 weeks.

\section{Excluded studies}

See 'Characteristics of excluded studies' table.

\section{Risk of bias in included studies}

Figure 2 and Figure 3 summarise the assessment of the risk of bias in included studies. 
Figure 2. Methodological quality graph: review authors' judgements about each methodological quality item presented as percentages across all included studies.

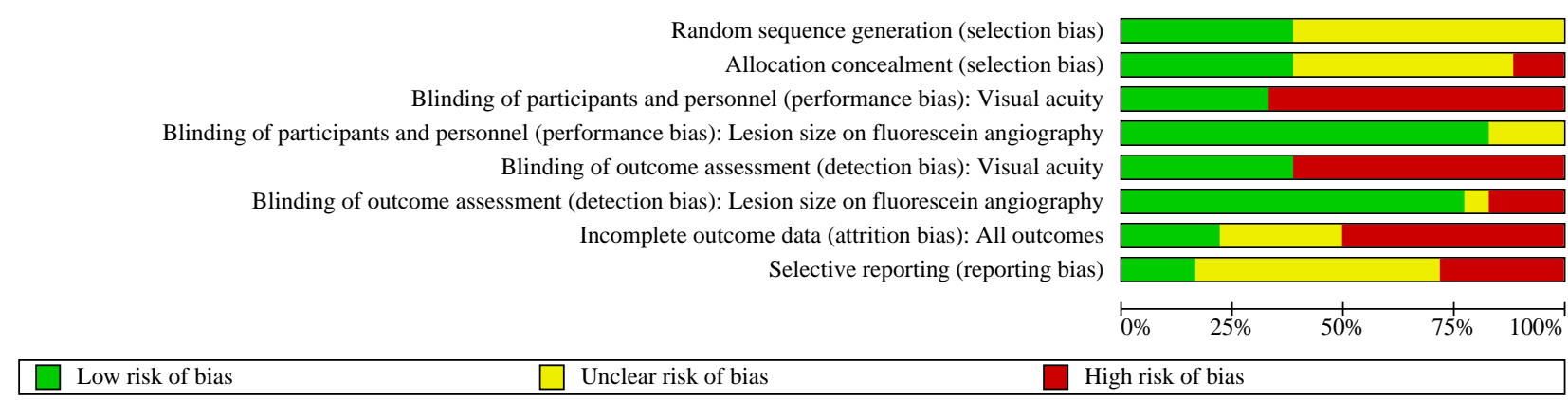


Figure 3. Risk of bias summary: review authors' judgements about each risk of bias item for each included study.

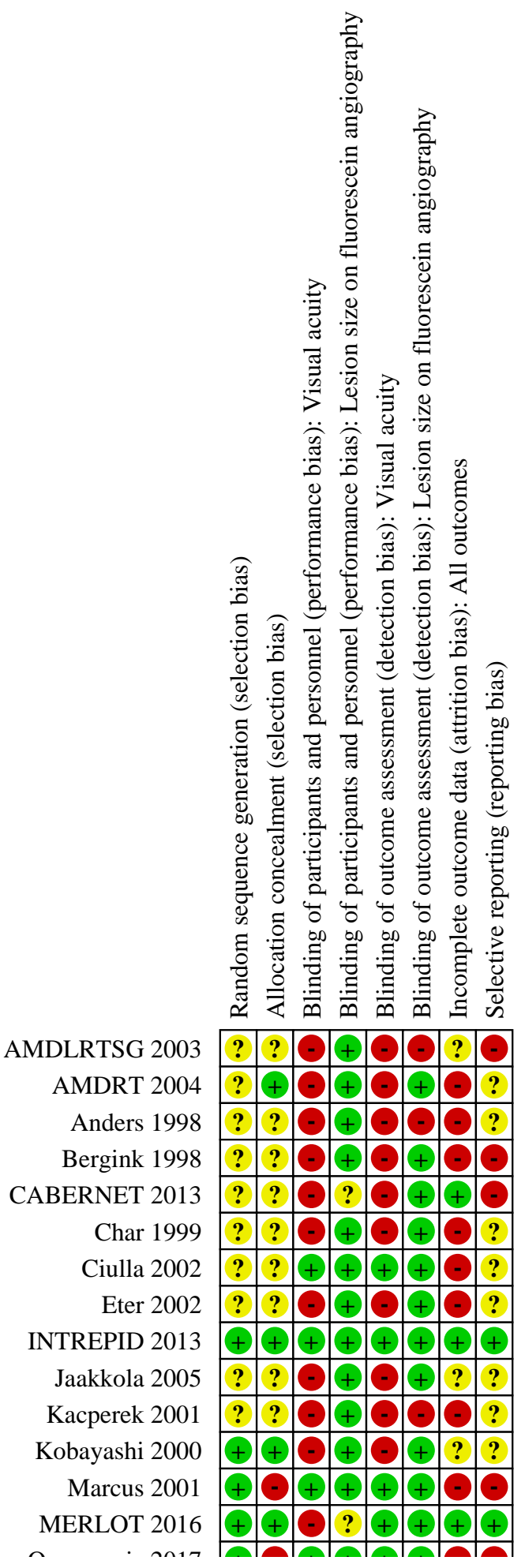

Radiotherapy for neovascular age-related macular degeneration (Review) 
Figure 3. (Continued)

\begin{tabular}{|c|c|c|c|c|c|c|c|}
\hline MERLOT 2016 & $+\oplus$ & - & $?$ & + & + & + & + \\
\hline Osmanovic 2017 & $+C$ & + & + & + & + & & \\
\hline RAD 1999 & $+\oplus$ & + & + & + & + & + & $?$ \\
\hline SFRADS 2002 & +4 & - & $?$ & 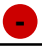 & $?$ & $?$ & + \\
\hline Valmaggia 2002 & ? & + & + & + & + & $?$ & ? \\
\hline
\end{tabular}

\section{Allocation}

For five studies, trial reports indicated that randomisation had been executed properly, that is, an unpredictable sequence of treatment allocation was concealed properly from people recruiting participants into the trial (INTREPID 2013; Kobayashi 2000; MERLOT 2016; RAD 1999; SFRADS 2002).

In two studies the method of generating the allocation schedule was not clearly described but it was clear that the schedule was concealed (AMDRT 2004; Valmaggia 2002).

In one study the allocation was almost certainly unpredictable but it was printed out so clearly was not concealed (Marcus 2001). In another study the allocation was almost certainly unpredictable (coin toss) but was administered by an unmasked study co-ordinator and balanced in a way that was probably not random (Osmanovic 2017).

The other nine studies did not report the randomisation in sufficient detail (AMDLRTSG 2003; Anders 1998; Bergink 1998; CABERNET 2013; Char 1999; Ciulla 2002; Eter 2002; Jaakkola 2005; Kacperek 2001).

\section{Blinding}

We judged six studies to be at low risk of performance and detection bias for both visual acuity and lesion size (Ciulla 2002; INTREPID 2013; Marcus 2001; Osmanovic 2017; RAD 1999; Valmaggia 2002). All these studies gave convincing accounts of masking through sham radiotherapy and clear statements that participants, study personnel and outcome assessors were masked.

There were 12 studies that did not perform sham irradiation (AMDLRTSG 2003; AMDRT 2004; Anders 1998; Bergink 1998; CABERNET 2013; Char 1999; Eter 2002; Jaakkola 2005; Kacperek 2001; Kobayashi 2000; MERLOT 2016;SFRADS 2002). We judged all these studies at high risk of performance bias for visual acuity. We also judged them to be at high risk of detection bias for visual acuity with the exception of MERLOT 2016 where masked outcome assessors were used for visual acuity measurement.

We judged most studies to be at low risk of performance bias for lesion size on fluorescein angiography. We judged that masking, or lack of it, was unlikely to affect performance bias in studies where other treatments were not available. There were two studies where participants and personnel were unmasked and where the availability of anti-VEGF treatment meant that we were unsure as to the possibility of performance bias (CABERNET 2013; MERLOT 2016).

We felt that masking, or lack of masking, may well affect detection bias for lesion size on fluorescein angiography. Three studies did not report masking of assessment of lesion size and so were judged to be high risk of bias (AMDLRTSG 2003; Anders 1998; Kacperek 2001). The remaining studies were judged low risk of bias as the reports mentioned specific efforts to mask this outcome.

SFRADS 2002 did not report lesion size.

\section{Incomplete outcome data}

Only four studies were judged to be at low risk of attrition bias i.e. they reported high rates of follow-up that were reasonably equal between treatment groups (CABERNET 2013; INTREPID 2013; MERLOT 2016; RAD 1999). For five studies follow-up was not reported in enough detail to make a judgement (AMDLRTSG 2003; Jaakkola 2005; Kobayashi 2000; SFRADS 2002; Valmaggia 2002). The remaining studies were judged to be at high risk of attrition bias with lower proportions lost to follow-up and/or unequal follow-up between groups.

\section{Selective reporting}

In five studies not all the trials registry or protocol outcomes were reported (AMDLRTSG 2003; Bergink 1998; CABERNET 2013; Marcus 2001; Osmanovic 2017). In most of the other studies, in the absence of trials registry entries and protocols, it was unclear. In only two studies (INTREPID 2013; SFRADS 2002) there was a trials registry entry that also corresponded with the published reports.

\section{Other potential sources of bias}

No other potential sources of bias were noted.

\section{Effects of interventions}

See: Summary of findings 1 Radiotherapy versus control for neovascular AMD; Summary of findings 2 Radiotherapy combined with anti-VEGF versus anti-VEGF alone for neovascular AMD

See Summary of findings 1.

\section{Radiotherapy versus control for neovascular AMD}

Fourteen studies considered this comparison: 13 studies used external beam radiation therapy with doses ranging from 24 Gy (Bergink 1998) to 7.5 Gy (Char 1999) and one study used plaque brachytherapy with a dose of 12.6 Gy delivered over 11 minutes (Jaakkola 2005). Nine of the studies gave no radiotherapy treatment to the control group (AMDLRTSG 2003; Anders 1998; Bergink 1998; Char 1999; Eter 2002; Jaakkola 2005; Kacperek 2001; Kobayashi 2000; SFRADS 2002), three studies used sham irradiation (Ciulla 2002; Marcus 2001 ; RAD 1999), one study did a mixture of sham irradiation and observation (AMDRT 2004), and one study used very low-dose irradiation (1 Gy) (Valmaggia 2002). 


\subsection{Loss of 3 or more lines of best-corrected visual acuity}

Eight studies (811 eyes) reported data on this outcome at 12 months (Analysis 1.1). The results were heterogenous. Individual study estimates ranged from 0.42 (0.26 to 0.69 ) in favour of radiotherapy (Valmaggia 2002) to 1.22 (0.91 to 1.62) in favour of no radiotherapy (Marcus 2001). The 12 value suggested that a substantial proportion of this variation was not due to chance $(12=66 \%)$. The overall pooled value was $0.82(95 \% \mathrm{Cl} 0.64$ to 1.04$)$. We judged this to be lowcertainty evidence. We downgraded one level for risk of bias (6 of the 8 studies were high risk of bias in one or more domains) and downgraded one level for inconsistency (individual study effect estimates ranged from 0.42 to $1.22,1^{2}=66 \%$ ). We did not downgrade an additional level for imprecision, even though the confidence intervals include 1 (no difference), because we had already downgraded for inconsistency which will have contributed to the imprecision of the pooled estimate.

We performed subgroup analyses by dose of radiation, type of CNV and sham irradiation in the control group (Table 4). Although there were some differences between subgroups, none of the differences were statistically significant (test for interaction).
Five studies reported this outcome at 24 months (Analysis 1.2).there was heterogeneity with study results ranging from 0.58 ( 0.43 to 0.80 ) in favour of radiotherapy (Kobayashi 2000) to 1.03 (0.79 to 1.36) (Jaakkola 2005) $(12=73 \%)$. The pooled risk ratio for studies of radiotherapy compared with no radiotherapy was 0.78 ( $95 \% \mathrm{Cl} 0.63$ to 0.97 ).

\subsection{Change in best-corrected visual acuity}

Ten studies (883 eyes) reported mean change in best-corrected visual acuity or final best-corrected visual acuity at 12 months (Analysis 1.3). Study results ranged from - 0.33 logMAR units in favour of radiotherapy (Ciulla 2002) to 0.07 logMAR units in favour of no radiotherapy (Marcus 2001) $(12=49 \%)$. People receiving radiation therapy on average had a small (approximately 1 line) better visual acuity at 12 months (mean difference (MD) $-0.10,95 \%$ $\mathrm{Cl}-0.17$ to -0.03 ). These analyses may be at risk of selective outcome bias because continuous data may be ana lysed two ways - as final visual acuity or change in visual acuity from baseline. It is possible that the choice of which outcome to present was influenced by the results. We also noted an asymmetric funnel plot (Figure 4) possibly indicative of publication bias. We judged this to be low-certainty evidence, downgrading for risk of bias and publication bias.

Figure 4.

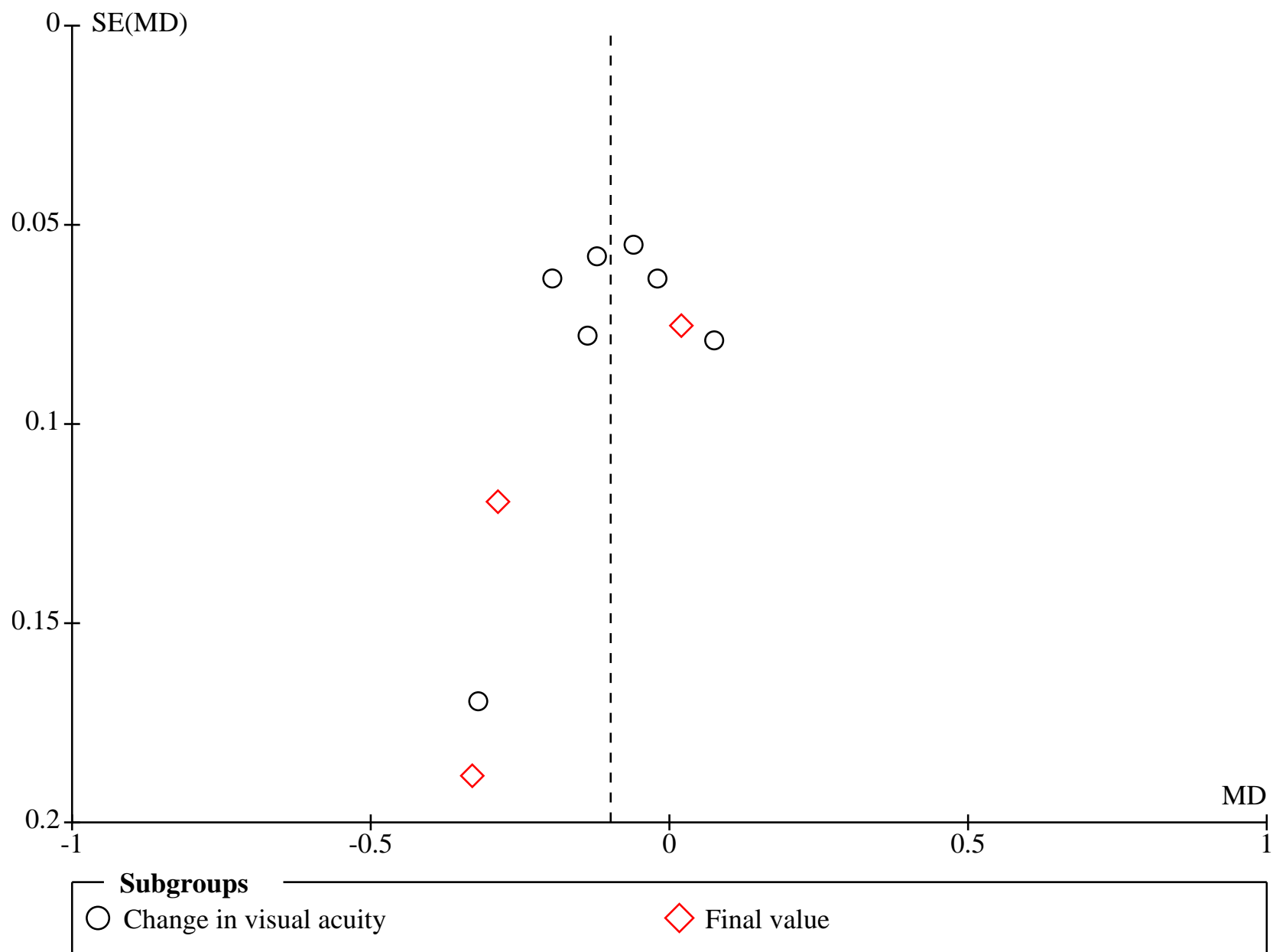


We performed subgroup analyses by dose, type of CNV and sham irradiation in the control group (Table 5). Although there were some differences between subgroups, none of the differences were statistically significant (test for interaction).

\subsection{Contrast sensitivity}

Two studies reported contrast sensitivity measured on a PelliRobson chart (Jaakkola 2005; SFRADS 2002). There was a small difference in favour of radiation therapy at 12 months (MD 0.15 logunits, $95 \% \mathrm{Cl} 0.05$ to 0.25 ; eyes $=267$ ) (Analysis 1.5) and 24 months (MD 0.11 logunits, $95 \% \mathrm{Cl} 0.00$ to 0.22 ; eyes $=257$ ). We judged this to be low-certainty evidence downgrading one level for risk of bias (as neither of these two studies were masked) and one level for imprecision (confidence intervals close to 0 ).

Marcus 2001 reported the \% contrast sensitivity threshold (PelliRobson chart). At 12 months there were some differences in the distribution in the treatment and observation groups but it was not possible to exclude the possibility that these were chance findings $(P=0.18)$.

\begin{tabular}{lll}
\hline Threshold \% & Radiation & Control \\
& $(\mathbf{n}=\mathbf{3 7})$ & $\mathbf{( n = 3 3 )}$ \\
& $\mathbf{n}(\%)$ & $\mathbf{n}(\%)$ \\
\hline$\leq 10$ & $8(22)$ & $15(45)$ \\
\hline 11 to 49 & $10(27)$ & $5(15)$ \\
\hline$\geq 50$ & $19(51)$ & $13(39)$ \\
\hline
\end{tabular}

\subsection{New vessel growth}

CNV was reported in different ways which makes it difficult to produce a summary estimate.

\section{Size of CNV at 12 months (continuous)}




\begin{tabular}{|c|c|c|c|c|c|c|c|c|}
\hline \multirow[t]{2}{*}{ Study } & \multicolumn{3}{|c|}{ Radiation therapy } & \multicolumn{3}{|c|}{ Control } & \multirow{2}{*}{$\begin{array}{l}\text { Mean } \\
\text { differ- } \\
\text { ence } \\
(95 \% \mathrm{Cl})\end{array}$} & \multirow[t]{2}{*}{ Comments } \\
\hline & Mean & SD & $\mathbf{n}$ & Mean & SD & $\mathbf{n}$ & & \\
\hline $\begin{array}{l}\text { AMDLRTSG } \\
2003\end{array}$ & 0.082 & 0.738 & 32 & 0.886 & 0.562 & 22 & $\begin{array}{l}-0.80 \\
(-1.15 \text { to } \\
-0.46)\end{array}$ & $\begin{array}{l}\text { Disc diameters measured by fluorescein angiog- } \\
\text { raphy. } \\
\text { Follow-up: } 12 \text { months }\end{array}$ \\
\hline Eter 2002 & 56 & - & 27 & 28 & - & 15 & $\begin{array}{l}28.00 \\
(-78.67 \\
\text { to } \\
134.67) \\
\text { (estimat- } \\
\text { ed using } \\
\text { reported } \\
\text { P value } \\
\text { of } 0.61 \text { ) }\end{array}$ & $\begin{array}{l}\text { Average } \% \text { increase in membrane size measured } \\
\text { by fluorescein angiography. } \\
\text { Follow-up: } 6 \text { months }\end{array}$ \\
\hline $\begin{array}{l}\text { Kobayashi } \\
2000\end{array}$ & 8.305 & 9.967 & 45 & 8.172 & 7.674 & 39 & $\begin{array}{l}0.13 \\
(-3.65 \text { to } \\
3.91)\end{array}$ & $\begin{array}{l}\text { CNV area } \mathrm{mm}^{2} \text { measured using the Heidelberg } \\
\text { Retina Tomograph } \\
\text { Follow-up: } 12 \text { months }\end{array}$ \\
\hline Marcus 2001 & 1.83 & - & 37 & 1.21 & - & 33 & $\begin{array}{l}0.62 \\
(-0.17 \text { to } \\
1.41) \text { (es- } \\
\text { timated } \\
\text { using re- } \\
\text { ported } \mathrm{P} \\
\text { value of } \\
0.13)\end{array}$ & $\begin{array}{l}\text { Increase in CNV (categories), measured using } \\
\text { fluorescein angiograms and colour fundus pho- } \\
\text { tographs. } \\
\text { Follow-up: } 12 \text { months }\end{array}$ \\
\hline
\end{tabular}




\begin{tabular}{|c|c|c|c|c|}
\hline Study & $\begin{array}{l}\text { Radiation } \\
\text { therapy } \\
\mathrm{n} / \mathrm{N}\end{array}$ & $\begin{array}{l}\text { Control } \\
\mathrm{n} / \mathrm{N}\end{array}$ & $\begin{array}{l}\text { Risk ratio }(95 \% \\
\mathrm{CI})\end{array}$ & Comments \\
\hline $\begin{array}{l}\text { Bergink } \\
1998\end{array}$ & $\begin{array}{l}7 / 34 \\
(20 \%)\end{array}$ & $\begin{array}{l}7 / 29 \\
(25 \%)\end{array}$ & $\begin{array}{l}0.81(0.25 \text { to } \\
2.68)\end{array}$ & $\begin{array}{l}\text { Number of people in whom the size of the CNV doubled over } 12 \text { months } \\
\text { measured using fluorescein angiography } \\
\text { Follow-up: } 12 \text { months }\end{array}$ \\
\hline $\begin{array}{l}\text { Jaakkola } \\
2005\end{array}$ & $\begin{array}{l}33 / 43 \\
(77 \%)\end{array}$ & $\begin{array}{l}29 / 41 \\
(71 \%)\end{array}$ & $\begin{array}{l}1.37(0.51 \text { to } \\
3.62)\end{array}$ & $\begin{array}{l}\text { CNV "less active" measured by fluorescein angiography } \\
\text { Follow-up: } 12 \text { months }\end{array}$ \\
\hline
\end{tabular}

Results from other studies were as follows:

- Char 1999 reported no differences in CNV area and membrane edge but we were not able to extract data.

- Ciulla 2002 reported that the greatest linear dimension of CNV was not associated with treatment but data not reported.

- Valmaggia 2002 CNV size increased in all groups. The authors reported no significant differences between groups but data could not be extracted.

We judged this to be very low-certainty evidence. We downgraded one level for risk of bias (eight out of the nine studies reporting this outcome were high risk of bias in one or more domain); downgraded one level for imprecision (the individual studies were small with imprecise estimates); and downgraded one level for inconsistency (there was no consistent pattern to the individual study results).

\subsection{Quality of life}

Quality of life outcomes were reported in SFRADS 2002. Visual functioning was assessed by the Daily Living Tasks Dependent on Vision (DLTV) questionnaire (Hart 1999). There were no important differences between treatment and control groups on any dimension of the DLTV 12 or 24 months after treatment.

\begin{tabular}{|c|c|c|c|c|c|c|}
\hline \multirow{2}{*}{$\begin{array}{l}\text { DLTV } \\
\text { di- } \\
\text { men- } \\
\text { sion }\end{array}$} & \multicolumn{2}{|c|}{$\begin{array}{l}\text { Change at } 12 \text { months } \\
\text { mean (standard error) }\end{array}$} & \multirow[t]{2}{*}{$\begin{array}{l}\text { Mean difference } \\
(95 \% \mathrm{CI})\end{array}$} & \multicolumn{2}{|c|}{$\begin{array}{l}\text { Change at } 24 \text { months } \\
\text { mean (standard error) }\end{array}$} & \multirow[t]{2}{*}{$\begin{array}{l}\text { Mean difference } \\
(95 \% \mathrm{CI})\end{array}$} \\
\hline & $\begin{array}{l}\text { Radiation thera- } \\
\text { py } \\
n=87\end{array}$ & $\begin{array}{l}\text { Control } \\
n=86\end{array}$ & & $\begin{array}{l}\text { Radiation thera- } \\
\text { py } \\
n=87\end{array}$ & $\begin{array}{l}\text { Control } \\
n=88\end{array}$ & \\
\hline 1 & $-10.6(2.2)$ & $-9.5(2.6)$ & $-1.10(-7.77$ to 5.57$)$ & $-13.5(2.3)$ & $-15.5(3.3)$ & $2.00(-5.90$ to 9.90$)$ \\
\hline 2 & $-10.6(2.2)$ & $-7.8(2.2)$ & $-2.80(-8.89$ to 3.29$)$ & $-10.6(2.5)$ & $-11.9(2.6)$ & $1.30(-5.77$ to 8.37$)$ \\
\hline 3 & $-8.4(2.4)$ & $-6.5(2.3)$ & $-1.90(-8.41$ to 4.61$)$ & $-8.2(2.4)$ & $-10.7(1.7)$ & $2.50(-3.26$ to 8.26$)$ \\
\hline 4 & $-2.0(3.1)$ & $-3.2(3.2)$ & $1.20(-7.53$ to 9.93$)$ & $-3.2(3.0)$ & $-3.2(2.4)$ & $0.00(-7.53$ to 7.53$)$ \\
\hline
\end{tabular}

We judged this to be low-certainty evidence. We downgraded one level for risk of bias study (study was not masked) and downgraded one level for imprecision (confidence intervals include 0 ).

\subsection{Adverse outcomes}

Reports of adverse outcomes are described in Table 6.

Six studies did not report on adverse effects (AMDLRTSG 2003; Char 1999; Ciulla 2002; Eter 2002; Jaakkola 2005; Kacperek 2001).

Eight studies (991 eyes) reported on adverse effects.

\section{Radiation-associated retinopathy or neuropathy}

Seven studies reported on radiation retinopathy, neuropathy or both. Five of these studies reported no radiation-associated adverse effects. One study of 88 eyes reported one case of possible radiation retinopathy. One study of 74 eyes graded retinal abnormalities in some detail and found that $72 \%$ of participants who had radiation compared with $71 \%$ of participants in the control group had retinal abnormalities resembling radiation retinopathy or choroidopathy.

- AMDRT 2004 (88 eyes): 1 case of possible radiation retinopathy 
- Bergink 1998 (74 eyes): 72\% in radiation group, 71\% in control group retinal abnormalities resembling radiation retinopathy or choroidopathy

- Kobayashi 2000 (101 eyes): reported no radiation-associated adverse effects

- Marcus 2001 (83 eyes): reported no radiation-associated adverse effects

- RAD 1999 (205 eyes): reported no radiation-associated adverse effects

- SFRADS 2002 (203 eyes): reported no radiation-associated adverse effects

- Valmaggia 2002 (161 eyes): reported no radiation-associated adverse effects

\section{Cataract}

Four studies reported cataract surgery or progression: events were generally low and no consistent evidence of any increased occurrence in the radiation group.

- AMDRT 2004 (88 eyes): cataract surgery on two participants, 1 in each group

- Kobayashi 2000 (101 eyes): cataract observed in 1 participant in radiation group

- Marcus 2001 (83 eyes): cataract progression similar in radiation and control groups

- RAD 1999 (295 eyes): cataract developed in 7 (10.3\%) radiation group, $12(16 \%)$ control group) $(P=0.218)$.

\section{Dry eye}

One study noted transient disturbance of the precorneal tear film but no evidence from the other 2 studies that reported dry eye of any increased risk with radiation therapy.

- AMDRT 2004 (88 eyes): 2 cases of ocular dryness in radiation group, 4 in control group

- RAD 1999 (205 eyes): dry eye symptoms in were recorded in $30(40 \%)$ radiation group and $38(45.2 \%)$ in control group ( $\mathrm{P}=$ $0.525)$.

- SFRADS 2002 (203 eyes): transient disturbance of the precorneal tear film noted in treated participants

\section{Other}

- AMDRT 2004 (88 eyes): 5 deaths, 1 in radiation group and 4 in control group

- Anders 1998 (76 eyes): 3 subretinal haemorrhage in radiation group, 3 in control group

- Kobayashi 2000 (101 eyes): 2 people in radiation group complained of "transient conjunctival injection that resolved within 2 weeks"

- Marcus 2001 (83 eyes): 1 case of retinal detachment and 1 case of vitreous haemorrhage in the radiation group

- RAD 1999 (205 eyes): 4 deaths unrelated to radiation treatment, 3 in radiation group, 1 in control group

We judged this to be low-certainty evidence. We downgraded one level for risk of bias (eight out of the nine studies were high risk of bias in one or more domain) and downgraded one level for imprecision (the individual studies were small with imprecise estimates).

\subsection{Number of anti-VEGF injections}

This outcome was introduced in the current update and is only relevant to the next comparison where anti-VEGF was combined with radiotherapy.

\section{Radiotherapy combined with anti-VEGF versus anti-VEGF alone for neovascular AMD}

Four studies considered this comparison: two studies were of external beam radiotherapy (INTREPID 2013; Osmanovic 2017) and two studies of epimacular brachytherapy (CABERNET 2013; MERLOT 2016). INTREPID 2013 used IRay Radiotherapy System (Oraya Therapeutics, Newark, CA) to deliver ionising radiation targeted at the neovascular lesions. Two of the studies were threearm studies with two intervention groups of $24 \mathrm{~Gy}$ and $16 \mathrm{~Gy}$ (INTREPID 2013; Osmanovic 2017). For the purposes of the analysis, we combined the intervention groups using the RevMan calculator. The other studies used $24 \mathrm{~Gy}$ dose. Three studies used ranibizumab (0.5 mg, PRN) in radiation and control groups; Osmanovic 2017 used either ranibizumab or bevacizumab. INTREPID 2013 and Osmanovic 2017 were sham-controlled.

\subsection{Loss of 3 or more lines of best-corrected visual acuity}

People receiving radiotherapy combined with anti-VEGF are probably more likely to lose 3 or more lines of BCVA over 12 months compared with people having anti-VEGF alone (RR 2.11, 95\% Cl 1.40 to 3.17 ; eyes $=1050$; studies $=3 ; 1^{2}=0 \%$ ) (Analysis 2.1). Two of these studies were of epimacular brachytherapy (CABERNET 2013; MERLOT 2016) and these had a higher risk (RR $2.3695 \% \mathrm{Cl} 1.49$ to 3.74) than the one study of stereotactic radiotherapy (INTREPID 2013) (RR $1.24,95 \% \mathrm{Cl} 0.50$ to 3.11) although the formal test for subgroup differences was not statistically significant $(P=0.22)$. We judged this moderate-certainty evidence, downgrading for risk of bias (two of the studies were at risk of performance and detection bias).

Two studies reported data at 24 months (820 eyes) (CABERNET 2013; MERLOT 2016). There was an increased risk of loss of 3 or more lines in people treated with radiotherapy plus anti-VEGF compared with people treated with anti-VEGF alone (RR 2.39, 1.68 to 3.39) (Analysis 2.2).

\subsection{Change in best-corrected visual acuity}

Four studies reported this outcome at 12 months. Three of the studies reported logMAR letters. We converted this to logMAR score by multiplying the mean and standard deviation by 0.02 and changing the direction of the mean value by multiplying by -1 (as a larger logMAR score represents poorer vision). For two studies that had three arms we combined the $16 \mathrm{~Gy}$ and $24 \mathrm{~Gy}$ groups using the RevMan calculator. For Osmanovic 2017 standard deviations were not reported. We attempted to estimate the standard deviation using information in the paper ( $P$ values) but this produced values that appeared too small and gave this small study much too much weight in the analysis (of the order of $25 \%$ ). We decided to impute the standard deviation by using values from the other included studies. The included studies ranged from standard deviations of approximately 0.2 to 0.3 so we chose a standard deviation of 0.25 .

There was considerable heterogeneity (Analysis 2.4). Results ranged from a small mean difference of -0.03 logMAR in favour of radiotherapy combined with anti-VEGF (INTREPID 2013; Osmanovic 2017) to a mean difference of 0.13 logMAR (CABERNET 2013) and 
0.08 logMAR (MERLOT 2016) in favour of anti-VEGF alone. With an 12 of $82 \%$ we took the decision not to pool these data. Subgroup analysis suggested a different effect in studies of external beam radiotherapy (MD $-0.03 \log \mathrm{MAR}, 95 \% \mathrm{Cl}-0.09$ to 0.03 ; participants $=$ 252; studies $=2 ; 1^{2}=0 \%$ ) and studies of epimacular brachytherapy (MD $0.10 \log M A R, 95 \% \mathrm{Cl} 0.05$ to 0.15 ; participants $=820$; studies $=$ $2 ; 1^{2}=50 \%$, test for interaction $\mathrm{P}=0.0007$ ).

We judged this to be low-certainty evidence, downgrading for risk of bias (three of the four studies were high risk of bias in one or more domains) and inconsistency.

Two studies reported data at 24 months (819 eyes) (CABERNET 2013; MERLOT 2016). The mean difference in change visual acuity in the radiotherapy with anti-VEGF group was 0.17 logMAR (worse) (CI 0.11 to 0.23 ) compared with anti-VEGF alone (Analysis 2.2). Both studies were of epimacular brachytherapy.

\subsection{Contrast sensitivity}

None of the included studies reported this outcome.

\subsection{New vessel growth}

There were inconsistent results on size of the CNV at 12 months with one study finding increased lesion size with radiotherapy group whereas the other two studies found small differences (one in favour of radiotherapy, one not). One study did not report results disaggregated by treatment group. We judged this to be very lowcertainty evidence, downgrading one level for risk of bias (two of the studies were at risk of performance and detection bias), one level for imprecision (two of the individual studies estimates were imprecise) and one level for inconsistency (there was no consistent pattern to the individual study results).

Size of CNV at 12 months (continuous) 


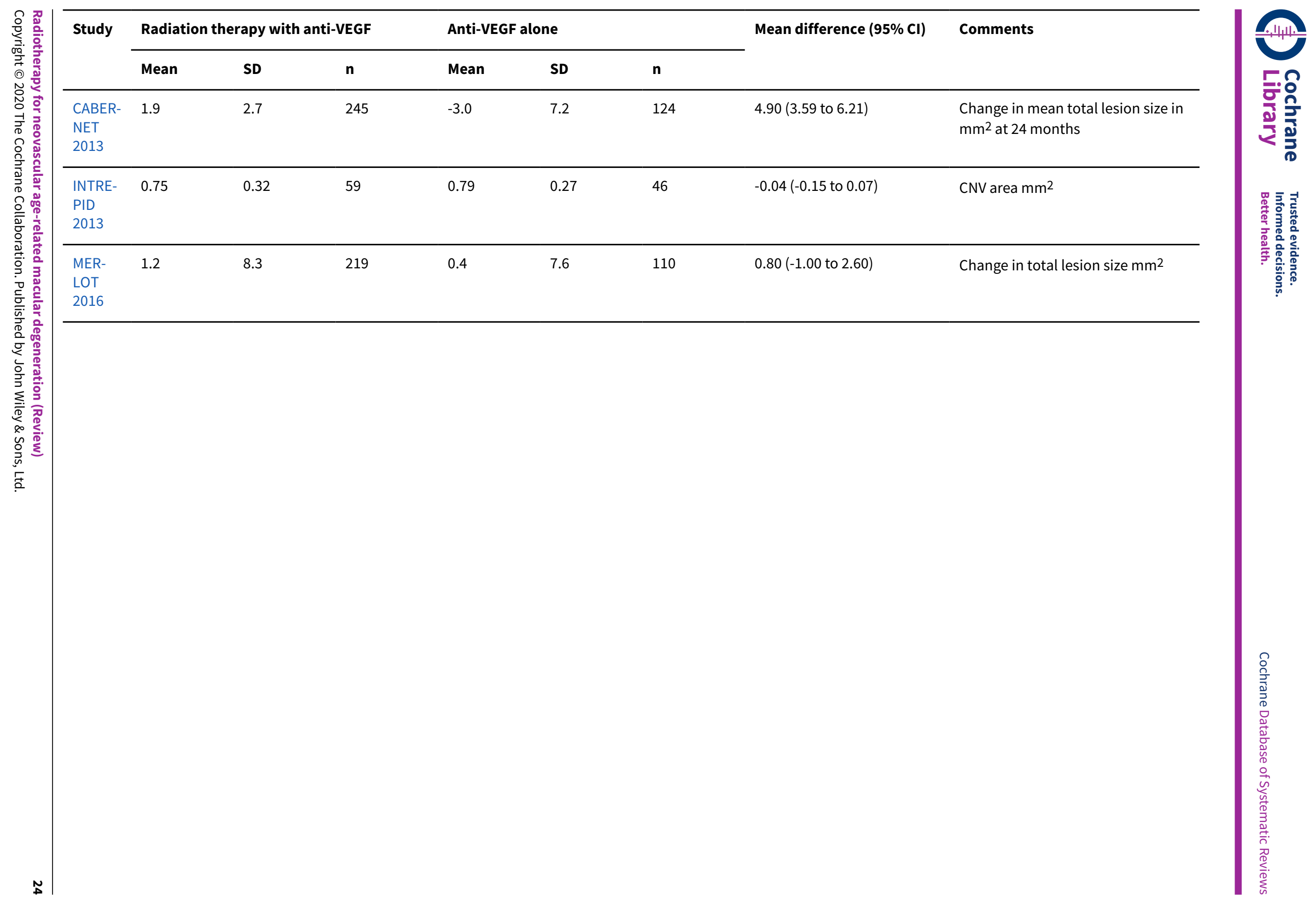




\section{SD: Standard deviation}

Osmanovic 2017 noted that the lesion area measured on FA decreased from 1.61 (SD 1.10) $\mathrm{mm}^{2}$ at baseline to 0.73 (SD 0.85) $\mathrm{mm}^{2}$ at one year for the overall study population. No differences were noted between the two intervention groups (16 and $24 \mathrm{~Gy}$ ) and the sham irradiation group (data not reported for groups individually).

\subsection{Quality of life}

None of the included studies reported this outcome.

\subsection{Adverse effects}

In CABERNET 2013 the radiotherapy and anti-VEGF treatment group had a higher proportion of ocular adverse events (54\%) compared to the anti-VEGF alone (18\%). The majority of these adverse events were cataract. Overall $5 \%$ of the treatment group had radiation device-related adverse events (17 cases); 10 of these cases were radiation retinopathy.

INTREPID 2013 reported that adverse effects were similar across study arms and none were attributed to radiation.
In MERLOT 2016 the radiotherapy plus anti-VEGF group (n $=244$ ) there were four cases of reduced visual acuity, one vitreous haemorrhage, three retinal haemorrhage, three retinal detachment, one vision blurred, one endophthalmitis, one vitreous floaters, two postoperative uveitis. In the anti-VEGF alone group (n $=119$ ) there was one case of reduced visual acuity and one case of retinal haemorrhage.

Osmanovic 2017 reported no radiation associated adverse effects and no vascular adverse events. Four out of 13 phakic eyes had cataract progression (one from the control and three from the radiation group).

\subsection{Number of anti-VEGF injections}

This outcome was introduced in the current update and is only relevant to the four studies that combined anti-VEGF with radiotherapy (CABERNET 2013; INTREPID 2013; MERLOT 2016; Osmanovic 2017).

There were some differences in average number of injections given between the four studies. In three of the four studies, the anti-VEGF alone group on average received more injections.

\begin{tabular}{|c|c|c|c|c|}
\hline & Radiotherapy & ith anti-VEGF & Anti-VEGF alon & \\
\hline Study & $\begin{array}{l}\text { Number of } \\
\text { loading injec- } \\
\text { tions planned }\end{array}$ & Total mean number of injections (SD) & $\begin{array}{l}\text { Number of } \\
\text { loading injec- } \\
\text { tions planned }\end{array}$ & $\begin{array}{l}\text { Total mean number of injec- } \\
\text { tions (SD) }\end{array}$ \\
\hline $\begin{array}{l}\text { CABER- } \\
\text { NET } 2013\end{array}$ & $\begin{array}{l}2 \text { (baseline, } \\
\text { month } 1 \text { ) }\end{array}$ & $\begin{array}{l}12 \text { months: (3.7) } \\
24 \text { months: (h6.2) }\end{array}$ & $\begin{array}{l}3 \text { (baseline, } \\
\text { month 1, } \\
\text { month 2) }\end{array}$ & $\begin{array}{l}12 \text { months: }(6.2) \\
24 \text { months: (10.4) }\end{array}$ \\
\hline $\begin{array}{l}\text { INTREPID } \\
2013\end{array}$ & 1 (baseline) & $\begin{array}{l}12 \text { months: } \\
\text { 16-Gy: } 2.64 \text { (2.46) (median, 2; range, } 0 \text { to } 10) \\
24-G y: 2.43(2.40) \text { (median, 2; range, } 0 \text { to } 10)\end{array}$ & 1 (baseline) & $\begin{array}{l}12 \text { months: } \\
3.74(2.57) \text { (median, } 3.5 \text {; range, } 0 \\
\text { to } 10 \text { ) }\end{array}$ \\
\hline $\begin{array}{l}\text { MERLOT } \\
2016\end{array}$ & $0^{*}$ & $\begin{array}{l}4.8(3.2) \\
4.5(3.8)\end{array}$ & $0^{*}$ & $\begin{array}{l}4.1(2.4) \\
4.2(2.7)\end{array}$ \\
\hline $\begin{array}{l}\text { Osman- } \\
\text { ovic } 2017\end{array}$ & 3 & $\begin{array}{l}16-G y: 3.52 \text { (range } 4 \text { to } 8 \text { ) } \\
24-G y: 3.83 \text { (range } 3 \text { to } 5 \text { ) }\end{array}$ & 3 & 6.13 (range 3 to 8 ) \\
\hline
\end{tabular}

\section{SD: Standard deviation}

*Quote: "Inclusion criteria included completion of a loading phase of 3 anti-VEGF induction injections, followed by ongoing monthly PRN therapy, with a minimum of 4 ranibizumab treatments in the previous 12 months or 2 ranibizumab treatments in the previous 6 months."

\section{DISCUSSION}

\section{Summary of main results}

We included 18 studies ( $n=2430$ people, 2432 eyes) of radiation therapy with dosages ranging from 7.5 to 24 Gy.These studies mainly took place in Europe and North America but two studies were from Japan and one multicentre study included sites in South America. Three of these studies investigated brachytherapy (plaque and epimacular), the rest were studies of external beam radiotherapy including one trial of stereotactic radiotherapy. Four studies compared radiotherapy combined with anti-vascular 
endothelial growth factor (anti-VEGF) with anti-VEGF alone. Eleven of the studies gave no radiotherapy treatment to the control group; five studies used sham irradiation; and one study used very lowdose irradiation (1 Gy) and one study used a mixture of sham irradiation and no treatment. Fifteen studies were judged to be at high risk of bias in one or more domains.

For the comparison radiotherapy versus no radiotherapy, our results suggest little or no difference in loss of 3 lines of vision at 12 months (low-certainty evidence). We observed a small benefit in average visual acuity at 12 months for radiotherapy; there was some evidence of possible publication bias (low-certainty evidence). Low-certainty evidence suggested a small benefit in average contrast sensitivity at 12 months but the effect was small and we judged the certainty of the evidence to be low. Growth of new vessels (largely change in CNV size) was variably reported and It was not possible to produce a summary estimate of this outcome. The studies were small with imprecise estimates and there was no consistent pattern to the study results (very lowcertainty evidence). Quality of life was only reported in one study of 199 people; there was no clear differences between treatment and control groups (low-certainty evidence). Six out of 14 studies did not report on adverse effects. Seven studies reported on radiation retinopathy or neuropathy or both. Five of these studies reported no radiation-associated adverse effects. One study of 88 eyes reported one case of possible radiation retinopathy. One study of 74 eyes graded retinal abnormalities in some detail and found that $72 \%$ of participants who had radiation, compared with $71 \%$ of participants in the control group, had retinal abnormalities resembling radiation retinopathy or choroidopathy. Four studies reported cataract surgery or progression: events were generally low and no consistent evidence of any increased occurrence in the radiation group. One study noted transient disturbance of the precorneal tear film but no evidence from the other two studies that reported dry eye of any increased risk with radiation therapy. None of the participants received anti-VEGF injections.

When radiotherapy was combined with anti-VEGF and compared to anti-VEGF alone, people receiving radiotherapy plus anti-VEGF were had worse visual outcomes which was probably largely attributable to the epimacular brachytherapy technique which involves pars plana vitrectomy. Anti-VEGF regimens with fewer injections may be associated with less visual gain (Kim 2016, Li 2020) and this may be another explanation for worse visual outcomes in the radiotherapy group in unmasked studies. None of the included studies reported contrast sensitivity or quality of life. Growth of new vessels (largely change in CNV size) was variably reported in three studies (803 eyes); It was not possible to produce a summary estimate. There was no consistent pattern to the study results (very low-certainty evidence). For adverse outcomes, variable results were reported in the 4 studies. In 3 studies reports of adverse events were low and no radiation-associated adverse events reported. In one study the radiotherapy and anti-VEGF treatment group had a higher proportion of ocular adverse events (54\%) compared to the anti-VEGF alone (18\%). The majority of these adverse events were cataract. Overall $5 \%$ of the treatment group had radiation device-related adverse events (17 cases); 10 of these cases were radiation retinopathy.

There is one large ongoing study (STAR (NCT02243878)) involving over 400 participants in 10 UK centres. Stereotactic radiotherapy combined with ranibizumab is being compared to sham radiotherapy plus ranibizumab alone with estimated study completion in 2024.

\section{Overall completeness and applicability of evidence}

Although there are 18 trials published, the overall completeness of the evidence is less than might be expected from the number of trials. This is because of the different dosages used, different outcome measures and different follow-up times reported. Most studies included in this review took place before the use of antiVEGF became widespread, and before the development of modern radiotherapy techniques, such as stereotactic radiotherapy. We observed worse visual outcomes with epimacular brachytherapy, and there is an increased risk of adverse events with that technique. The role of modern radiotherapy, in combination with anti-VEGF, is currently uncertain. It may offer the potential to reduce the need for anti-VEGF retreatment, and there are ongoing studies addressing this question.

\section{Quality of the evidence}

The evidence was largely judged to be of low-certainty, depending on the outcome. We downgraded for risk of bias because of limitations in the studies, particularly in regard to selection, performance and detection bias. We also downgraded for imprecision because the confidence intervals included no effect or clinically unimportant differences. We could assess publication bias for only one outcome - change in visual acuity at 12 months - and this showed an asymmetric plot indicative of publication bias.

The applicability of this evidence is also limited by differences in inclusion criteria and study design among studies. For example, in CABERNET 2013, an unmasked study, patients received a loading phase of three injections in the anti-VEGF-alone arm and two injections in the combined radiotherapy arm. The lack of masking may have led to a further tendency to prescribe fewer injections in the combination arm, which may have led to less visual gain. Lack of masking may have influenced the attitude towards prescription of anti-VEGF injections also in Osmanovic 2017. Another limitation is in the inclusion of patients with newly diagnosed versus chronic active CNV, such as in Osmanovic 2017 and INTREPID 2013. Finally, the mean number of injections was small in some studies. This caused skewed estimates, with mean values being similar to their standard deviations.

\section{Potential biases in the review process}

There have been many changes to both AMD treatment and Cochrane methods since the protocol for this review was first published in 2002. As such, many of the decisions have been made post-hoc. In the case of Cochrane methods, the introduction of new methods is unlikely to have introduced bias, indeed, it is likely to have improved the overall robustness of the review. When it comes to incorporating new evidence, the key decision was how to incorporate trials where radiotherapy was combined with antiVEGF. Given that the baseline risk for many outcomes included in this review is so different with anti-VEGF, and given the overall context in which the studies took place, we took the decision to add in a separate comparison to this review. An alternative approach may have been to consider these as a subgroup. However, given that the effects were so different, and that we included an additional outcome of number of injections, we felt that it was clearer to consider these as a separate comparison. We feel that either approach would have produced similar results. Similarly, 
we had discussion about the heterogeneity in radiotherapy interventions in the more recent studies. We considered external beam radiotherapy and epimacular brachytherapy as subgroups; as the results were quite different we have presented the results of this subgroup analysis in the abstract.

\section{Agreements and disagreements with other studies or reviews}

Other reviews, in general, acknowledge the disappointing results with external beam radiotherapy and focus on the potential role of more targeted radiotherapy techniques - either stereotactic and brachytherapy (plaque or epimacular) - in combination with antiVEGF therapy (Englander 2013; Kishan 2013; Mendez 2013; Silva 2011). These other reviews are narrative, rather than systematic, and discuss a broader section of the literature, including nonrandomised studies.

\section{AUTHORS' CONCLUSIONS}

\section{Implications for practice}

The results of this review are uncertain regarding the use of radiotherapy in people with neovascular AMD; the majority of the studies took place before the use of anti-VEGF became widespread and before the development of modern radiotherapy techniques such as stereotactic radiotherapy. Visual outcomes with epimacular brachytherapy are likely to be worse and there is an increased risk of adverse events with that technique. The role of modern radiotherapy, in combination with anti-VEGF, is currently uncertain; ongoing studies are assessing its role in reducing the need for antiVEGF retreatment.

\section{Implications for research}

Given the results of this review, further research on radiotherapy for neovascular AMD may not be justified until current ongoing studies, in particular the STAR trial, have reported. Future trials should have a sufficient sample size to detect moderate effects and should report data on visual acuity outcomes so as to enable their inclusion in systematic overviews. Consistent reporting of data on factors such as lesion size and composition would also facilitate synthesis. Adequate masking of the treatment groups should be considered a priority. Current ongoing studies are addressing the issue as to whether radiotherapy combined with anti-VEGF may reduce the need to anti-VEGF retreatment.

\section{ACKNOWLEDGEMENTS}

The Cochrane Eyes and Vision (CEV) editorial team prepared and executed the electronic searches. We are grateful to Rebecca Wong, Catey Bunce and Roberta Scherer for peer review. We thank Zoe Ockrim and Vasuki Sivagnanavel for their contributions to previous versions of this review. We thanks Anupa Shah, Managing Editor for CEV for her assistance throughout the review process. We would also like to thank Takehiro Yamashita and Ryo Asaoka for translating a Japanese article for the 2010 update. 


\section{R E F E R E N C E S}

\section{References to studies included in this review \\ AMDLRTSG 2003 \{published data only\}}

Treatment of Age-related Macular Degeneration with Low-dose Radiation Therapy Study Group. The results of randomized controlled trial of low-dose radiation for wet-type age-related macular degeneration on a 1-year term basis. Nippon Ganka Gakkai Zasshi 2003;107(6):326-30.

\section{AMDRT 2004 \{published data only\}}

Marcus DM, Peskin E, Maguire M, Weissgold D, Alexander J, Fine S, et al The AMDRT Research Group. The age-related macular degeneration radiotherapy trials (AMDRT): one year results from a pilot study. American Journal of Ophthalmology 2004;138(5):818-28.

\section{Anders 1998 \{published data only\}}

Anders N, Stahl H, Dorn A, Walkow T, Hosten N, Wust P, et al. Radiotherapy of exudative senile macular degeneration. $A$ prospective controlled study [Strahlentherapie der exsudativen altersabhangigen Makuladegeneration. Eine prospektive kontrollierte Studie]. Ophthalmologe 1998;95(11):760-4.

\section{Bergink 1998 \{published data only\}}

* Bergink GJ, Hoyng CB, Van der Maazen RW, Vingerling JR, van Daal WA, Deutman AF. A randomised controlled trial of efficacy of radiation therapy in the control of subfoveal neovascularisation in age-related macular degeneration: radiation verses observation. Graefe's Archive for Clinical and Experimental Ophthalmology 1998;236(5):321-5.

Hoyng CB, Tromp Al, Meulendijks CFM, Leys A, van der Maazen RWM, Deutman AF, et al. Side effects after radiotherapy of age-related macular degeneration with the Nijmegen technique. Graefe's Archive for Clinical and Experimental Ophthalmology 2002;240(5):337-41.

\section{CABERNET 2013 \{published data only\}}

Dugel PU, Bebchuk JD, Nau J, Reichel E, Singer M, Barak A, et al. Epimacular brachytherapy for neovascular age-related macular degeneration: a randomized, controlled trial (CABERNET). Ophthalmology 2013;120(2):317-27.

Jackson TL, Dugel PU, Bebchuk JD, Smith KR, Petrarca R, Slakter JS, et al. Epimacular brachytherapy for neovascular age-related macular degeneration (CABERNET): Fluorescein angiography and optical coherence tomography.

Ophthalmology 2013;120(2):1597-603.

\section{Char 1999 \{published data only\}}

Char DH, Irvine AI, Posner MD, Quivey J, Phillips TL, Kroll S. Randomised trial of radiation for age-related macular degeneration. American Journal of Ophthalmology 1999;127(5):574-8.

\section{Ciulla 2002 \{published data only\}}

Ciulla TA, Danis RP, Klein SB, Malinovsky VE, Soni PS, Pratt LM, et al. Proton therapy for exudative age-related macular degeneration: a randomized, sham-controlled clinical trial. American Journal of Ophthalmology 2002;134(6):905-6.
Eter 2002 \{published data only\}

Eter N, Schuller H, Spitznas M. Radiotherapy for age-related macular degeneration: is there a benefit for classic CNV? International Ophthalmology 2002;24(1):13-9.

INTREPID 2013 \{published data only\}

Freiberg FJ, Michels S, Muldrew A, Slakter J, O'Shaughnessy D, Czeszynski A et al. Microvascular abnormalities secondary to radiation therapy in neovascular age-related macular degeneration: findings from the INTREPID clinical trial. British Journal of Ophthalmology 2019;103(4):459-74.

Jackson TL, Chakravarthy U, Kaiser PK, Slakter JS, Jan E, Bandello F, et al. Stereotactic radiotherapy for neovascular age-related macular degeneration: 52-week safety and efficacy results of the INTREPID study. Ophthalmology 2013;120(9):1893-900.

Jackson TL, Chakravarthy U, Slakter JS, Muldrew A, Shusterman EM, O'Shaughnessy D, et al. Stereotactic radiotherapy for neovascular age-related macular degeneration: year 2 results of the INTREPID study. Ophthalmology 2015;122(1):138-45.

Jackson TL, Dugel PU, Bebchuk JD, Smith KR, Petrarca R, Slakter JS, et al The CABERNET Study Group. Epimacular brachytherapy for neovascular age-related macular degeneration (CABERNET) fluorescein angiography and optical coherence tomography. Ophthalmology 2013;120(9):1597-1603.

Jackson TL, Shusterman EM, Arnoldussen M, Chell E, Wang K, Moshfeghi DM, et al. Stereotactic radiotherapy for wet agerelated macular degeneration (INTREPID): influence of baseline characteristics on clinical response. Retina 2015;35(2):194-204.

\section{Jaakkola 2005 \{published data only\}}

Jaakkola A, Heikkonen J, Tommila P, Laatikainen L, Immonen I. Strontium plaque brachytherapy for exudative age-related macular degeneration: three-year results of a randomized study. Ophthalmology 2005;112(4):567-73.

\section{Kacperek 2001 \{published data only\}}

Kacperek A, Briggs M, Sheen M, Damato BE, Errington RD, Harding S. Macular degeneration treatment at Clatterbridge Centre for oncology: treatment and preliminary results. Physica Medica 2001;17(Suppl 3):7-9.

\section{Kobayashi 2000 \{published data only\}}

Kobayashi H, Kobayashi K. Age-related macular degeneration: long-term results of radiotherapy for subfoveal neovascular membranes. American Journal of Ophthalmology 2000;130(5):617-35.

\section{Marcus 2001 \{published data only\}}

Marcus DM, Camp MW, Sheils WC, McIntosh SB, Leibach DB, Johnson $\mathrm{MH}$, et al. Sham radiation in clinical trials assessing radiotherapy for exudative age-related macular degeneration. Retina 1999;19(6):525-30. 
Marcus DM, Sheils C, Johnson MH, Mclntosh SB, Leibach DB, Maguire A, et al. External beam irradiation of subfoveal choroidal neovascularisation complicating age-related macular degeneration. Archives of Ophthalmology 2001;1(19):171-80.

\section{MERLOT 2016 \{published data only\}}

* Jackson TL, Desai R, Simpson A, Neffendorf JE, Petrarca R, Smith K, et al The Macular Epiretinal Brachytherapy versus Ranibizumab (Lucentis) Only Treatment (MERLOT) Study Group. Epimacular brachytherapy for previously treated neovascular age-related macular degeneration (MERLOT): a phase 3 randomized controlled trial. Ophthalmology 2016;123(6):1287-96.

Jackson TL, Soare C, Petrarca C, Simpson A, Neffendorf JE, Petrarca R, et al. Evaluation of month-24 efficacy and safety of epimacular brachytherapy for previously treated neovascular age-related macular degeneration: the MERLOT randomized clinical trial. JAMA Ophthalmology 2020;138(8):1-8.

\section{Osmanovic 2017 \{published data only\}}

Lu J, Daftari I, Mishra K, Moshiri A, Park SS. Changes in subretinal hyperreflective material in phase I/II study of proton beam irradiation combined with anti-VEGF therapy for exudative age-related macular degeneration. Investigative Ophthalmology and Visual Science 2017;58(8):ARVO E-abstract 4831.

NCT01213082. Prospective trial of proton beam combined with anti-VEGF therapy for exudative age-related macular degeneration (AMD) (PBAMD2). clinicaltrials.gov/ct2/show/ NCT01213082 (first received 1 October 2010).

* Osmanovic S, Moisseiev E, Mishra KK, Daftari I, Moshiri A, Morse L, et al. Phase I/II randomized study of proton beam with anti-vascular endothelial growth factor for exudative agerelated macular degeneration: one-year results. Ophthalmology Retina 2017;1(3):217-26.

Wong S, Daftari I, Mishra K, Migacz J V, Gorczynska I, Moshiri A et al. Fluorescein and OCT angiographic evaluation of choroidal neovascular membrane following proton beam and intravitreal anti-VEGF therapy for exudative AMD: 2-year follow up. Investigative Ophthalmology and Visual Science 2017;58(8):ARVO E-abstract 370.

\section{RAD 1999 \{published data only\}}

Bellmann C, Unnebrink K, Rubin GS, Miller D, Holz FG. Visual acuity and contrast sensitivity in patients with neovascular age-related macular degeneration. Results from the Radiation Therapy for Age-Related Macular Degeneration (RAD-) Study. Graefe's Archive for Clinical and Experimental Ophthalmology 2003;241(12):968-74.

Holz FG, Unnebrink K, Staudt S, Voelcker HE, Wannenmacher M, Bellmann C, et al. Two-years results of a prospective, randomized, double-blind multicenter trial on radiation therapy for neovascular ARMD. American Academy of Ophthalmology 2000:115.

Holz FG, Voelcker HE, Engenhart-Cabillic R, Bellmann C, Unnebrink K, Debus J, et al. A prospective randomized, controlled, double-blind multicenter trial on radiation therapy for subfoveal CNV secondary to ARMD. American Academy of Ophthalmology 1999:247-8.

* The Radiation Therapy for Age-Related Macular Degeneration (RAD) Group. A prospective, randomised, double-masked trial on radiation therapy for neovascular age-related macular degeneration. Ophthalmology 1999;106(12):2239-47.

Vacha P, Debus J, Wiegel T, Schuchardt U, Schaefer U, Engenhart-Cabillic R. A prospective randomized, double-blind multicenter-trial on radiation therapy for neovascular agerelated macular degeneration. European Journal of Cancer 2001;37:275 (A1015).

\section{SFRADS 2002 \{published data only\}}

Hart PM, Chakravarthy U, Mackenzie G, Chisholm IH, Bird AC, Stevenson MR, et al. Visual outcomes in the subfoveal radiotherapy study: a randomized controlled trial of teletherapy for age-related macular degeneration. Archives of Ophthalmology 2002;120(8):1029-38.

Stevenson MR, Hart PM, Chakravarthy U, MacKenzie G, Bird AC, Owens SL, et al. Visual functioning and quality of life in the SubFoveal Radiotherapy Study (SFRADS): SFRADS report 2. British Journal of Ophthalmology 2005;89(8):1045-51.

\section{Valmaggia 2002 \{published data only\}}

Valmaggia C, Ries G, Ballinari P. A 5-year follow-up study for distance visual acuity after low dose radiation on subfoveal choroidal neovascularization in age-related macular degeneration. Documenta Ophthalmologica 2001;103(3):201-9.

* Valmaggia C, Ries G, Ballinari P. Radiotherapy for subfoveal choroidal neovascularization in age-related macular degeneration: a randomized clinical trial. American Journal of Ophthalmology 2002;133(4):521-9.

\section{References to studies excluded from this review}

Avila 2009 \{published data only\}

Avila MP, Farah ME, Santos A, Duprat JP, Woodward BW, Nau J. Twelve-month short-term safety and visual-acuity results from a multicentre prospective study of epiretinal strontium-90 brachytherapy with bevacizumab for the treatment of subfoveal choroidal neovascularisation secondary to age-related macular degeneration. British Journal of Ophthalmology 2009;93(3):305-9.

\section{Barak 2005 \{published data only\}}

Barak A, Hauser D, Yipp P, Morse L, Leigh B, Kubo D, et al. A phase I trial of stereotactic external beam radiation for subfoveal choroidal neovascular membranes in agerelated macular degeneration. British Journal of Radiology 2005;78(933):827-31.

\section{Bergink 1995 \{published data only\}}

Bergink GJ, Deutman AF, Van Den Broek JECM, Van Daal WAJ, Van Der Maazen RMW. Radiation therapy for age-related subfoveal choroidal neovascular membranes. Documenta Ophthalmologica 1995;90(1):67-74. 
Brown 1997 \{published data only\}

Brown GC, Freire JE, Vander J, Brady LW, Shields CL, Shields JA, et al. Strontium-90 brachytherapy for exudative, age related macular degeneration: a pilot study. International Journal of Radiation Oncology, Biology, Physics 1997;39(2, Suppl 1):332 (A2184).

\section{Churei 2004 \{published data only\}}

* Churei H, Ohkubo K, Nakajo M, Hokotate H, Baba Y, Ideue J, et al. External-beam radiation therapy for age-related macular degeneration: Two years' follow-up results at a total dose of 20 Gy in 10 fractions. Radiation Medicine 2004;22(6):398-404.

\section{Eter 2001 \{published data only\}}

Eter N, Schuller H. External beam radiotherapy for age-related macular degeneration causes transient objective changes in tear-film function. Graefe's Archive for Clinical and Experimental Ophthalmology 2001;239(12):923-6.

\section{Friedrichsen 1996 \{published data only\}}

Friedrichsen EJ, Slater JD, Hagele JE, Chan CK, Yonemoto LT, Garcia C A, et al. Proton beam irradiation of subfoveal choroidal neovascularization: a pilot study of single-dose $800 \mathrm{cGy}$ and 1400 cGy. American Academy of Ophthalmology 1996:135.

\section{Heier 2008 \{published data only\}}

Heier JS, Farah M, Duprat JP, Avila M, Fujii GY, Rossi J, et al. A study to evaluate the safety and feasibility of radiotherapy and bevacizumab (Avastin) for the treatment of subfoveal choroidal neovascularization (CNV) secondary to age-related macular degeneration (AMD). The Macular Society 2008:186.

\section{Honjo 1997 \{published data only\}}

Honjo M, Mandai M, Hiroshiba N, Miyamoto H, Takahashi M, Ogura Y, et al. Evaluation of the early-phase response of neovascular membrane in age-related macular degeneration to low-dose radiation. Japanese Journal of Clinical Ophthalmology 1997;51(9):1563-9.

\section{Jackson 2012 \{published data only\}}

Jackson TL, Kirkpatrick L, Tang G, Prasad S. Cost analysis comparing adjuvant epimacular brachytherapy with anti-VEGF monotherapy for the management of neovascular age-related macular degeneration. Eye 2012;26(4):557-63.

\section{Mandai 1998 \{published data only\}}

Mandai M, Takahashi M, Miyamoto H, Hiroshiba N, Kimura H, Ogura Y, et al. Long term effects of radiation treatment for agerelated macular degeneration. Japanese Journal of Clinical Ophthalmology 1998;52:567-71.

\section{Mandai 2000 \{published data only\}}

Mandai M, Takahashi M, Miyamoto H, Hiroshiba N, Kimura H, Ogura $\mathrm{Y}$, et al. Long-term outcome after radiation therapy for subfoveal choroidal neovascularization associated with age-related macular degeneration. Japanese Journal of Ophthalmology 2000;44(5):530-7.

\section{Marcus 2004 \{published data only\}}

Marcus DM, Sheils WC, Young JO, McIntosh SB, Johnson MH, Alexander J, et al. Radiotherapy for recurrent choroidal neovascularisation complicating age related macular degeneration. British Journal of Ophthalmology 2004;88(1):114-9.

\section{Matsuhashi 1996 \{published data only\}}

Matsuhashi H, Takahashi D, Noda Y, Mariya Y, Tarusawa N, Yoshimoto $\mathrm{H}$, et al. Low-dose radiation, therapy for choroidal neovascularization in age-related macular degeneration. Nippon Ganka Gakkai Zasshi 1996;100(10):803-9.

Matsuhashi 2000 \{published data only\}

Matsuhashi H, Noda Y, Takahashi D, Mariya Y. Radiation therapy for small choroidal neovascularization in age-related macular degeneration. Japanese Journal of Ophthalmology 2000;44(6):653-60.

\section{NCT01833325 \{unpublished data only\}}

NCT01833325. Proton radiation therapy for macular degeneration. clinicaltrials.gov/ct2/show/NCT01833325 (first received 16 April 2013).

\section{Postgens 1997 \{published data only\}}

Postgens H, Bodanowitz S, Kroll P. Low-dose radiation therapy for age-related macular degeneration. Graefe's Archive for Clinical and Experimental Ophthalmology 1997;235(10):656-61.

\section{Reichel 2007 \{published data only\}}

Reichel E, Farah M, Duprat JP, Avila M, Fujii GY, Rossi, et al. A study to evaluate the safety and feasibility of radiotherapy and bevacizumab (Avastin) for the treatment of subfoveal choroidal neovascularization (CNV) secondary to age-related macular degeneration. Investigative Ophthalmology and Visual Science 2007;48(13):ARVO E-Abstract 3657.

\section{Saric 2001 \{published data only\}}

Saric B, Sikic J, Katusic D, Vukojevic N. Brachytherapy - optional treatment for choroidal neovascularization secondary to agerelated macular degeneration. Collegium Antropologicum 2001;25 Suppl:89-96.

\section{Taniguchi 1996 \{published data only\}}

Taniguchi T, Mandai M, Honjo M, Matsuda N, Miyamoto H, Takahashi M, et al. Radiation treatment for age-related macular degeneration. Japanese Journal of Clinical Ophthalmology 1996;50:1821-6.

\section{Tholen 2000 \{published data only\}}

* Tholen AM, Meister A, Bernasconi PP, Messmer EP. Radiotherapy for choroidal neovascularization (CNV) in agerelated macular degeneration (AMD) [Radiotherapie von choroidalen Neovaskularisationen (CNV) bei altersabhangiger Makuladegeneration (AMD)]. Klinische Monatsblatter fur Augenheilkunde 2000;216(2):112-5.

Tholen AM, Meister A, Bernasconi PP, Messmer EP. Radiotherapy for choroidal neovascularization in age-related macular degeneration. A pilot study using low- versus high-dose photon beam radiation [Radiotherapie von subretinalen Neovaskularisationsmembranen bei altersabhangiger Makuladegeneration (AMD). Niedrig- versus hochdosierte Photonenbestrahlung]. Ophthalmologe 1998;95(10):691-8. 
Zambarakji 2006 \{published data only\}

Zambarakji HJ, Lane AM, Ezra E, Gauthier D, Goitein M, Adams JA, et al. Proton beam irradiation for neovascular age-related macular degeneration. Ophthalmology 2006;113(11):2012-9.

\section{References to ongoing studies}

STAR (NCT02243878) \{published data only\}ISRCTN12884465 NCT02243878. Stereotactic radiotherapy for wet AMD (STAR). clinicaltrials.gov/ct2/show/NCT02243878 (first received 18 September 2014).

\section{Additional references}

\section{Englander 2013}

Englander M, Kaiser PK. Combination therapy for the treatment of neovascular age-related macular degeneration. Current Opinion in Ophthalmology 2013;24(3):233-8.

\section{Evans 2012}

Evans JR, Wong TY. Age-related macular degeneration. In: Johnson GJ, Minassian DC, Weale RA, West SK, Gower EW, Kuper $\mathrm{H}$, Lindfield R, editors(s). The Epidemiology of Eye Disease. 3rd edition. London: Imperial College Press, 2012.

\section{Flaxman 2017}

Flaxman SR, Bourne RR, Resnikoff S, Ackland P, Braithwaite T, Cicinelli MV, et al. Global causes of blindness and distance vision impairment 1990-2020: a systematic review and meta-analysis. Lancet Global Health 2017;5(12):e1221-34.

\section{Glanville 2006}

Glanville JM, Lefebvre C, Miles JN, Camosso-Stefinovic J. How to identify randomized controlled trials in MEDLINE: ten years on. Journal of the Medical Library Association 2006;94(2):130-6.

\section{GRADEpro [Computer program]}

GRADE Working Group, McMaster University GRADEpro GDT. Version accessed prior to 7 May 2020. Hamilton (ON): GRADE Working Group, McMaster University. Available at gradepro.org.

\section{Hart 1999}

Hart PM, Chakravarthy U, Stevenson MR, Jamison JQ. A vision specific functional index for use in patients with age related macular degeneration. British Journal of Ophthalmology 1999;83(10):1115-20.

\section{Kim 2016}

Kim LN, Mehta H, Barthelmes D, Nguyen V, Gillies MC. Metaanalysis of real-world outcomes of intravitreal ranibizumab

\section{CHARACTERISTICS OF STUDIES}

Characteristics of included studies [ordered by study ID] for the treatment of neovascular age-related macular degeneration. Retina 2016;36(8):1418-31..

\section{Kirkham 2010}

Kirkham JJ, Dwan KM, Altman DG, Gamble C, Dodd S, Smyth R, et al. The impact of outcome reporting bias in randomised controlled trials on a cohort of systematic reviews. BMJ 2010;340:c365.

\section{Kishan 2013}

Kishan AU, Modjtahedi BS, Morse LS, Lee P. Radiation therapy for neovascular age-related macular degeneration. International Journal of Radiation Oncology, Biology, Physics 2013;85(3):583-97.

\section{Li 2020}

Li E, Donati S, Lindsley KB, Krzustolik MG, Virgili G. Treatment regimens for administration of anti-vascular endothelial growth factor agents for neovascular agerelated macular degeneration. Cochrane Database of Systematic Reviews 2020, Issue 5. Art. No: CD012208. [DOI: 10.1002/14651858.CD012208.pub2]

\section{Mendez 2013}

Mendez CA, Ehlers JP. Radiation therapy: age-related macular degeneration. Developments in Ophthalmology 2013;52:75-84.

\section{Review Manager 2014 [Computer program]}

Nordic Cochrane Centre, The Cochrane Collaboration Review Manager 5 (RevMan 5). Version 5.3. Copenhagen: Nordic Cochrane Centre, The Cochrane Collaboration, 2014.

\section{Silva 2011}

Silva RA, Moshfeghi AA, Kaiser PK, Singh RP, Moshfeghi DM. Radiation treatment for age-related macular degeneration. Seminars in Ophthalmology 2011;26(3):121-30.

\section{References to other published versions of this review \\ Evans 2010}

Evans J R, Sivagnanavel V, Chong V. Radiotherapy for neovascular age-related macular degeneration. Cochrane Database of Systematic Reviews 2010, Issue 5. Art. No: CD004004. [DOI: 10.1002/14651858.CD004004.pub3]

\section{Sivagnanavel 2004}

Sivagnanavel V, Evans JR, Ockrim Z, Chong V. Radiotherapy for neovascular age-related macular degeneration. Cochrane Database of Systematic Reviews 2004, Issue 4. Art. No: CD004004. [DOI: 10.1002/14651858.CD004004.pub2]

* Indicates the major publication for the study 
AMDLRTSG 2003

\section{Study characteristics}

\begin{tabular}{|c|c|}
\hline Methods & $\begin{array}{l}\text { Parallel group RCT } \\
\text { One eye per person, unclear how selected }\end{array}$ \\
\hline Participants & $\begin{array}{l}\text { Country: Japan } \\
\text { Number of participants (eyes) enrolled: NR } \\
\text { Number of participants (eyes) excluded after randomisation: NR } \\
\text { Number of participants (eyes) ana lysed at } 12 \text { months: } 69 \text { (69) } \\
\text { Average age: } 72 \text { years (range NR) } \\
\text { Sex: } 30 \% \text { women } \\
\text { Inclusion criteria: } \\
\text { - At least } 60 \text { years of age } \\
\text { - Worsening of symptoms or clinical features within } 12 \text { months } \\
\text { - A best corrected visual acuity is } 20 / 200 \text { or more } \\
\text { - CNV with AMD was assessed by FA or IA } \\
\text { - A maximum CNV size was one optic-disk diameter } \\
\text { - CNV located at the fovea or the edge of CNV within } 200 \text { micro meters from the fovea } \\
\text { - Signature on the Informed Consent Form with ability to fully understand the informed consent } 7 \\
\text { Exclusion criteria: } \\
\text { - Under } 60 \text { years of age } \\
\text { - Difficult to asses the size of CNV } \\
\text { - Cataract with less-visible fundus } \\
\text { - History of diabetes } \\
\text { - History of hypertension } \\
\text { - Optic neuropathy }\end{array}$ \\
\hline
\end{tabular}

- External beam radiation therapy (10 fractions of $2 \mathrm{~Gy}$ )

- Duration: NR

Comparator: $(n=31)$

- Observation

Secondary: NR

Reported:

- Visual acuity (logMAR)

- Size of CNV (by FA or IA).

Follow-up: 12 months

$\begin{array}{ll}\text { Notes } & \text { Date conducted: NR } \\ & \text { Sources of funding: NR }\end{array}$


AMDLRTSG 2003 (Continued)

Declaration of interest: NR

Trial id: NR

Information from translation

\section{Risk of bias}

\begin{tabular}{|c|c|c|}
\hline Bias & Authors' judgement & Support for judgement \\
\hline $\begin{array}{l}\text { Random sequence genera- } \\
\text { tion (selection bias) }\end{array}$ & Unclear risk & Judgement comment: not reported \\
\hline $\begin{array}{l}\text { Allocation concealment } \\
\text { (selection bias) }\end{array}$ & Unclear risk & Judgement comment: not reported \\
\hline $\begin{array}{l}\text { Blinding of participants } \\
\text { and personnel (perfor- } \\
\text { mance bias) } \\
\text { Visual acuity }\end{array}$ & High risk & $\begin{array}{l}\text { Judgement comment: masking was not mentioned in the report. We judged } \\
\text { that participants and personnel were probably not masked which may have af- } \\
\text { fected the visual acuity outcome. }\end{array}$ \\
\hline $\begin{array}{l}\text { Blinding of participants } \\
\text { and personnel (perfor- } \\
\text { mance bias) } \\
\text { Lesion size on fluorescein } \\
\text { angiography }\end{array}$ & Low risk & $\begin{array}{l}\text { Judgement comment: masking was not mentioned in the report. We judged } \\
\text { that participants and personnel were probably not masked but felt that lack of } \\
\text { masking was unlikely to lead to performance bias for this outcome. }\end{array}$ \\
\hline $\begin{array}{l}\text { Blinding of outcome as- } \\
\text { sessment (detection bias) } \\
\text { Visual acuity }\end{array}$ & High risk & $\begin{array}{l}\text { Judgement comment: masking was not mentioned in the report. It is possible } \\
\text { that an individual's performance on the visual acuity test could be influenced } \\
\text { by their perceptions as to which treatment they received. }\end{array}$ \\
\hline $\begin{array}{l}\text { Blinding of outcome as- } \\
\text { sessment (detection bias) } \\
\text { Lesion size on fluorescein } \\
\text { angiography }\end{array}$ & High risk & Judgement comment: masking was not mentioned in the report. \\
\hline $\begin{array}{l}\text { Incomplete outcome data } \\
\text { (attrition bias) } \\
\text { All outcomes }\end{array}$ & Unclear risk & Not reported \\
\hline $\begin{array}{l}\text { Selective reporting (re- } \\
\text { porting bias) }\end{array}$ & High risk & $\begin{array}{l}\text { Study was planned as 2-year study enrolling } 100 \text { participants but only } 69 \text { par- } \\
\text { ticipants reported after one year. }\end{array}$ \\
\hline
\end{tabular}

\section{AMDRT 2004}

\section{Study characteristics}

\begin{tabular}{ll}
\hline Methods & Parallel group RCT \\
& One eye per person \\
& Multicentre study: 10 sites \\
\hline Participants & Country: US \\
Number of participants (eyes) randomised: 88 (88) \\
Number of participants (eyes) excluded after randomisation: NR
\end{tabular}


Average age: 77 years (63 to 92)

Sex: $58 \%$ women

Inclusion criteria:

- Age 50 or older

- New or recurrent CNV secondary to AMD

- Occult CNV or minimally classic or predominately classic subfoveal CNV

- CNV not amenable to laser treatment or participant refuses

- $<50 \%$ fibrosis

- No ocular histoplasmosis

- No ocular conditions precluding good photography

- No other ocular condition likely to affect visual acuity in 2 years

- Myopia $<=8$ diopters

- Acuity $>=20 / 320$

Exclusion criteria:

- Diabetes

- Prior ocular/periocular radiation

- CNV secondary to non-AMD causes

- Prior or current chemotherapy

- History of macula affecting drugs

- External beam radiation therapy (5 fractions of $4 \mathrm{~Gy}$ )

Comparator: $(n=47)$

- Observation $(n=25)$

- Sham radiotherapy $(n=22)$

Primary:
- Loss of 3 or more lines of visual acuity
- 5 to 8 working days
Secondary:
- Lesion size graded on fluorescein angiography.
- Side effects.
Follow-up: 12 months

Notes

Full trial name: Age-related macular degeneration radiotherapy trial (AMDRT).

Date conducted: January 2000 to December 2001

Sources of funding: Supported by grant R21 EY12341 from the National Eye Institute, National Institutes of Health, Department of Health and Human Services and institutional funds from each of the participating centres.

Declaration of interest: NR

Trial id: NR

Planned sample size 100 participants; stopped early because of a low rate of recruitment. 
AMDRT 2004 (Continued)

Risk of bias

\begin{tabular}{lll}
\hline Bias & Authors' judgement & Support for judgement \\
\hline $\begin{array}{ll}\text { Random sequence genera- } \\
\text { tion (selection bias) }\end{array}$ & Unclear risk & $\begin{array}{l}\text { Quote "Randomised treatment assignment schedules, stratified by lesion type } \\
\text { (new or recurrent) and status of blood ( }<50 \% \text { or }>=50 \% \text { of the lesion) were gen- } \\
\text { erated for each clinical site" Page } 819, \text { methods, enrolment and randomisation } \\
\text { procedures, 2nd paragraph. }\end{array}$
\end{tabular}

Judgement comment: not clear how the allocation schedule was generated.

Allocation concealment Low risk

(selection bias)

Quote "After required examinations and photography were completed, an eligibility checklist was faxed to the Coordinating Center. The enrolling ophthalmologist and clinic coordinator verbally confirmed eligibility of the patient by telephone with a Coordinating Center staff member. For centres performing sham radiotherapy, sealed, black-lined security envelopes containing a randomized assignment were provided to the ophthalmology clinical staff. At enrollment, the clinic co-ordinator confirmed with the Co-ordinating center the assignment of the patient to the next sequentially numbered envelope for the appropriate strata. The sealed envelope was sent to the Radiation Oncology Department and opened by the radiation oncologist and radiation physicist immediately before treatment. For centers not performing sham radiotherapy, the coordinator called the Co-ordinating center to obtain the treatment assignment" Page 819, methods, enrolment and randomisation procedures, $1^{\text {st }}$ and $2^{\text {nd }}$ paragraphs.

Blinding of participants High risk and personnel (performance bias)

Visual acuity
Quote: "At the outset, each center had the option to choose sham radiotherapy or observation only as the control treatment for active radiotherapy. Three centers chose sham radiotherapy." Page 819 , methods, $1^{\text {st }}$ paragraph.

Judgement comment: participants and personnel were not masked in 7 out of 10 centres (25/47 participants) which may have affected the visual acuity outcome.

Blinding of participants Low risk
and personnel (perfor-
mance bias)
Lesion size on fluorescein
angiography

Blinding of outcome assessment (detection bias) Visual acuity
High risk

tor

Quote: "At the outset, each center had the option to choose sham radiotherapy or observation only as the control treatment for active radiotherapy. Three centers chose sham radiotherapy." Page 819 , methods, $1^{\text {st }}$ paragraph.

Judgement comment: participants and personnel were not masked in 7 out of 10 centres (25/47 participants). We felt that lack of masking was unlikely to lead to performance bias for this outcome.
Quote: "At the outset, each center had the option to choose sham radiotherapy or observation only as the control treatment for active radiotherapy. Three centers chose sham radiotherapy." Page 819 , methods, $1^{\text {st }}$ paragraph. "During follow-up, examiners were masked to the patient's treatment assignment" Page $820,1^{\text {st }}$ paragraph.

Judgement comment: it was obvious which group received radiotherapy. Only 3 out of 10 centres chose to perform sham radiotherapy. Only some of the control group (22/47) received sham radiotherapy. Visual acuity assessment was masked to treatment group, however, it is possible that an individual's performance on the visual acuity test could be influenced by their perceptions as to which treatment they received.

Quote: "Certified photographers performed all fundus photography and fluorescein angiography following SST protocols. Initial visit photography was
Blinding of outcome as- Low risk sessment (detection bias) 
AMDRT 2004 (Continued) Lesion size on fluorescein angiography

required within 42 days of enrollment. Expert readers at the FPRC, masked to treatment assignment, reviewed all baseline photographs and angiograms for eligibility." Page 820 , photography and fluorescein angiography, $1^{\text {st }}$ and $2^{\text {nd }}$ paragraphs.

Although the report does not explicitly state that photograph graders were masked to treatment assignment when considering follow-up photographs and angiograms it is highly likely that they were and it is unlikely that a participant's knowledge of treatment group would influence the appearance of photographs or fluorescein angiograms.

Incomplete outcome data High risk (attrition bias)

All outcomes
$31 / 41(76 \%)$ in treatment group seen at 12 months; $31 / 47$ (66\%) of the control group seen at 12 months. 12 randomised participants were subsequently considered ineligible; all these participants included in the analysis. 5 participants did not get the treatment they were assigned but were analysed in the original group to which they were assigned.

Quote: "Among all missed visits, the most common reason for not completing the visit was patient refusal; other reasons were illness and transportation problems"

The follow-up in the control group was rather low which is why this is marked "no".

Selective reporting (re- Unclear risk No access to study protocol or trial registry entry.

porting bias)

Anders 1998

\section{Study characteristics}

\begin{tabular}{ll}
\hline Methods & Parallel group RCT \\
& Unclear whether one or both eyes enrolled \\
\hline
\end{tabular}

Participants

\section{Country: Germany}

Number of participants (eyes) randomised: 76 (?)

Number of participants (eyes) excluded after randomisation:NR

Number of participants (eyes) analysed: 76 (6 months) and 37 (12 months)

Average age: 77 years (range NR)

Sex: $67 \%$ women

Inclusion criteria:

- fluorescein angiography detectable classic subfoveal choroidal neovascular membranes;

- no foveal bleeding

- history of severe visual impairment does not exceed 6 months

- visual acuity is not better than 0.5 and no worse than 0.05

- age over 50 years

- no previous laser photocoagulation of macular

- no previous irradiation of the region

- no other eye diseases that could deteriorate the visual acuity

- opportunity to participate in further follow-up up to 5 years 
Anders 1998 (Continued)

Exclusion criteria: NR

Interventions
- External beam radiation therapy ( 6 fractions of $2 \mathrm{~Gy}$ )
- Duration: 8 days
Comparator: $(\mathrm{n}=37)$
- Observation

Primary: NR
Secondary: NR
Reported:
- Near visual acuity
- Distance visual acuity
- Metamorphopsia by Amslernetz
- Complications including subretinal haemorrhage and lens opacity
Follow- 3 , 6 and 12 months

$\begin{array}{ll}\text { Notes } & \text { Date conducted:NR } \\ & \text { Sources of funding: NR } \\ & \text { Declaration of interest: NR } \\ & \text { Trial id: NR }\end{array}$

\section{Risk of bias}

\begin{tabular}{|c|c|c|}
\hline Bias & Authors' judgement & Support for judgement \\
\hline $\begin{array}{l}\text { Random sequence genera- } \\
\text { tion (selection bias) }\end{array}$ & Unclear risk & Judgement comment: not reported. \\
\hline $\begin{array}{l}\text { Allocation concealment } \\
\text { (selection bias) }\end{array}$ & Unclear risk & Judgement comment: not reported. \\
\hline $\begin{array}{l}\text { Blinding of participants } \\
\text { and personnel (perfor- } \\
\text { mance bias) } \\
\text { Visual acuity }\end{array}$ & High risk & $\begin{array}{l}\text { Judgement comment: masking was not mentioned in the report. We judged } \\
\text { that participants and personnel were probably not masked which may have af- } \\
\text { fected visual acuity outcome. }\end{array}$ \\
\hline $\begin{array}{l}\text { Blinding of participants } \\
\text { and personnel (perfor- } \\
\text { mance bias) } \\
\text { Lesion size on fluorescein } \\
\text { angiography }\end{array}$ & Low risk & $\begin{array}{l}\text { Judgement comment: masking was not mentioned in the report. We judged } \\
\text { that participants and personnel were probably not masked but felt that lack of } \\
\text { masking was unlikely to lead to performance bias for this outcome. }\end{array}$ \\
\hline
\end{tabular}

\begin{tabular}{|c|c|c|}
\hline $\begin{array}{l}\text { Blinding of outcome as- } \\
\text { sessment (detection bias) } \\
\text { Visual acuity }\end{array}$ & High risk & Not reported and groups different \\
\hline
\end{tabular}

Blinding of outcome as-
sessment (detection bias) $\quad$ High risk $\quad$ Not reported and groups different


Anders 1998 (Continued) Lesion size on fluorescein angiography

\section{Incomplete outcome data High risk} (attrition bias)

All outcomes
$19 / 39(49 \%)$ radiation group and 18/37 (49\%) control group seen at 12 months. No information as to the reason for loss to follow-up given.

Selective reporting (re- Unclear risk porting bias)

No access to study protocol or trial registry entry.

Bergink 1998

\section{Study characteristics}

\begin{tabular}{|c|c|}
\hline Methods & $\begin{array}{l}\text { Parallel group RCT } \\
\text { One eye per person, unclear how eye was selected - described as "affected eye" }\end{array}$ \\
\hline Participants & $\begin{array}{l}\text { Country: The Netherlands } \\
\text { Number of participants (eyes) randomised: } 74 \text { (74) } \\
\text { Number of participants (eyes) excluded after randomisation: } 3 \text { (3) } \\
\text { Number of participants (eyes) analysed: } 68 \text { (68) (at } 3 \text { months) } 63 \text { (63) (at } 12 \text { months) } \\
\text { Average age: } 75 \text { years (range NR) } \\
\text { Sex: } 56 \% \text { women. } \\
\text { Inclusion criteria: } \\
\text { - Recent drop in central vision (within } 2 \text { months) } \\
\text { - Best-corrected Snellen visual acuity }>0.1 \\
\text { - Angiographically proven classic, occult or mixed type subfoveal CNV } \\
\text { - Clinical signs of ARM, e.g., drusen or pigment epithelial changes } \\
\text { - Age } \geq 55 \text { years } \\
\text { - Informed consent } \\
\text { - No previous laser photocoagulation in the macular area } \\
\text { - No radiation treatment for ear, nose, throat or brain disease } \\
\text { - No diabetes mellitus } \\
\text { Exclusion criteria: NR }\end{array}$ \\
\hline
\end{tabular}

Interventions
- External beam radiation therapy (4 fractions of 6Gy) $(n=36)^{\star}$
- Duration: 3 weeks
Comparator: $(n=32)^{\star}$
- Observation

${ }^{\star}$ Number randomised not reported. This is the number in each group at 3 months.

Outcomes

Primary: NR but sample size calculation based on loss of 1 or more lines of Snellen acuity ending up with visual acuity $<0.1$.

Secondary: NR 
Bergink 1998 (Continued)

Reported:

- Visual acuity (loss of 3 or more lines and loss of 6 or more lines)

- Size of the CNV

Follow-up: 3, 6 and 12 months

$\begin{array}{ll}\text { Notes } & \text { Date conducted: NR } \\ & \text { Sources of funding:NR } \\ & \text { Declaration of interest: NR } \\ & \text { Trial id: NR }\end{array}$

\section{Risk of bias}

Bias Authors' judgement Support for judgement

Random sequence genera- Unclear risk tion (selection bias)
Quote: "...patients were assigned randomly to either radiation treatment or observation." Page 322

Judgement comment: not clear how the allocation schedule was generated.

Allocation concealment Unclear risk Judgement comment: not reported.

(selection bias)

$\begin{array}{ll}\begin{array}{l}\text { Blinding of participants } \\ \text { and personnel (perfor- }\end{array} & \text { High risk } \\ \begin{array}{l}\text { mance bias) } \\ \text { Visual acuity }\end{array} & \begin{array}{l}\text { Quote: "The patients in the control group did not receive a sham radiation } \\ \text { treatment" Page } 322 .\end{array} \\ & \begin{array}{l}\text { Judgement comment: participants and personnel were not masked which } \\ \text { may have affected the visual acuity outcome. }\end{array}\end{array}$

\begin{tabular}{|c|c|c|}
\hline $\begin{array}{l}\text { Blinding of participants } \\
\text { and personnel (perfor- } \\
\text { mance bias) } \\
\text { Lesion size on fluorescein } \\
\text { angiography }\end{array}$ & Low risk & $\begin{array}{l}\text { Quote: "The patients in the control group did not receive a sham radiation } \\
\text { treatment" Page } 322 \text {. } \\
\text { Judgement comment: participants and personnel were not masked but we } \\
\text { felt that lack of masking was unlikely to lead to performance bias for this out- } \\
\text { come. }\end{array}$ \\
\hline
\end{tabular}

\begin{tabular}{|c|c|c|}
\hline $\begin{array}{l}\text { Blinding of outcome as- } \\
\text { sessment (detection bias) } \\
\text { Visual acuity }\end{array}$ & High risk & $\begin{array}{l}\text { Quote: "The patients in the control group did not receive a sham radiation } \\
\text { treatment" Page } 322 .\end{array}$ \\
\hline
\end{tabular}

Visual acuity

Blinding of outcome as- $\quad$ Low risk
sessment (detection bias)
Lesion size on fluorescein
angiography

Quote: "The readers were blinded for treatment status." Page 322
Incomplete outcome data High risk Quote "Initially, 74 patients were included in the study. Of these, one died and (attrition bias) two stopped before the first control, one because of fear of malignancies due
All outcomes to the treatment. In addition, one was excluded because of previously unnot- ed diabetes mellitus and two patients showed insufficient evidence for CNV on the angiogram later on. As a result, 68 patients, 36 in the treatment group and 32 in the observation group completed at least 3 months/ follow-up. Twelve months follow-up was obtained in 63 patients." Page 322.

No information on the numbers originally randomised to treatment and control. 
Bergink 1998 (Continued)

Selective reporting (reporting bias)

High risk Outcome on which sample size was based not reported

\section{CABERNET 2013}

\section{Study characteristics}

Methods Parallel group RCT

One eye included in study; if both eyes were eligible, then the eye with the worse VA was treated.

\section{Participants}

Country: US, Europe, Israel, South America

Number of participants (eyes) randomised: 494 (494)

Number of participants (eyes) excluded after randomisation: 0

Number of participants (eyes) analysed: 457 (457)

Average age: 77 years (range 50 to 96)

Sex: $68 \%$ women

Inclusion criteria:

- age 50 or older

- predominantly classic, minimally classic, or occult with no classic lesions, as determined by the Investigator, secondary to AMD, with a total lesion size (including blood, scarring, and neovascularization) of $\leq 12$ total disc areas $\left(21.24 \mathrm{~mm}^{2}\right)$, and a GLD $\leq 5.4 \mathrm{~mm}$

- primary (newly diagnosed and untreated) or recurrent lesions (previously diagnosed and regressed but currently presenting with a new, active component)

- ETDRS best corrected visual acuity of 69 to 24 letters (20/40 to 20/320 Snellen Equivalent) in the study eye

- if both eyes eligible, one with worse acuity selected; if only one eye eligible, vision in the non-study eye was $20 / 400$ or better

- subretinal haemorrhage (if any) not more than $50 \%$ of total lesion size, and not involving the subfoveal space

- minimally classic and occult with no classic lesions must have evidence of presumed recent disease progression defined as:(i) The presence of subretinal haemorrhage and/or fluid and/or lipid or (ii) loss of one or more lines of vision (ETDRS or equivalent) during previous six months or FA documented lesion growth by $\geq 10 \%$ during past 6 months

- women post-menopausal \#1 year or surgically sterilized or negative serum pregnancy test required within 14 days prior to randomisation

Exclusion criteria:

In the study eye:

- prior or concurrent treatment for neovascular AMD or glaucoma

- prior or concomitant disease

- CNV lesion contained more than $25 \%$ scarring and/or atrophy

- inadequate pupillary dilation or significant media opacities

- vitreous haemorrhage

- history of rhegmatogenous retinal detachment or macular hole

- any intraocular surgery of the study eye within 12 weeks prior to the screening visit, with the exception of cataract surgery 
- Other systemic conditions/treatments and/or any other condition preventing from completing the study (details in online appendices to published paper)

Intervention: $(\mathrm{n}=331)$
- Epimacular brachytherapy (standardised point dose of $24 \mathrm{~Gy})$
- 2 intravitreal injections of $0.5 \mathrm{mg}$ ranibizumab, one at the end of surgery and one 30 days later
Comparator: $(\mathrm{n}=163)$
- Ranibizumab $(0.5 \mathrm{mg}) 3$ injections, over 3 months followed by quarterly injections
Epimacular brachytherapy was delivered by an intraocular strontium $90 / \mathrm{yttrium} 90$ (Sr $\left.90 / \mathrm{Y}^{90}\right)$ applica-
tor device designed to deliver local, targeted radiation to the neovascular tissue associated with wet
AMD.
Participants were followed up monthly and received an additional injection if one or more of the re-
treatment criteria were met. Retreatment was mandated if any of the following applied: loss of 10 let-
ters of VA, verified by repeat testing within 7 days; 50 - $\mu$ increase in OCT central retinal thickness; new
subretinal haemorrhage;or new neovascularization visible using FA.

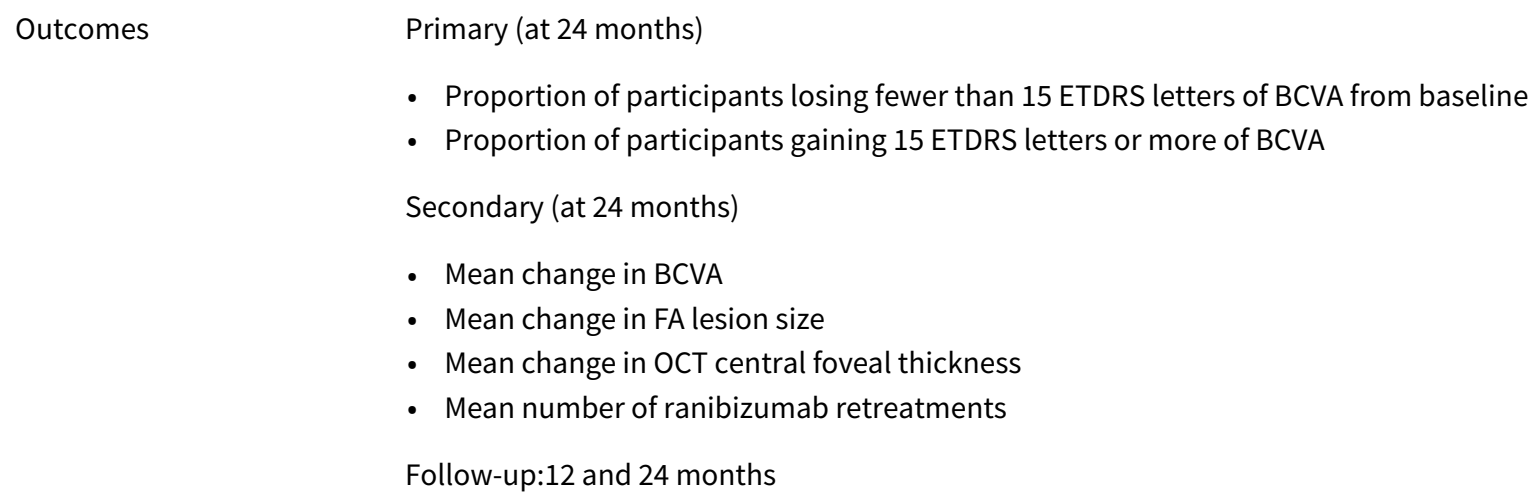

Trial registration ID number: NCT00454389

\section{Risk of bias}

\section{Bias \\ Authors' judgement Support for judgement}

Random sequence genera- Unclear risk tion (selection bias)
Quote: "Randomization was stratified by study center, type of lesion (predominantly classic, minimally classic, or occult), and baseline VA (53 letters or 53 letters) using a 2:1 randomization scheme in favor of EMBT" Page 319

Judgement comment: unclear how the schedule was generated.

Allocation concealment $\quad$ Unclear risk Judgement comment: not reported
(selection bias)




\section{CABERNET 2013 (Continued)}

Blinding of participants and personnel (performance bias)

Visual acuity
High risk

Quote: "Because this study involved a surgical intervention and sham surgery with a nonradioactive probe was not believed to be ethically appropriate, masking to study treatment was not possible for the treating surgeon and the patient; however, the VA examiner and the reading centers that reviewed all optical coherence tomography (OCT) and FA images were masked." Page 319

Judgement comment: participants and personnel were not masked which may have affected the visual acuity outcome.

\section{Blinding of participants Unclear risk} and personnel (perfor-

mance bias)

Lesion size on fluorescein

angiography
Quote: "Because this study involved a surgical intervention and sham surgery with a nonradioactive probe was not believed to be ethically appropriate, masking to study treatment was not possible for the treating surgeon and the patient; however, the VA examiner and the reading centers that reviewed all optical coherence tomography (OCT) and FA images were masked." Page 319

Judgement comment: participants and personnel were not masked. We felt that it was unclear what effect this would have on lesion progression.
Quote: "Because this study involved a surgical intervention and sham surgery with a nonradioactive probe was not believed to be ethically appropriate, masking to study treatment was not possible for the treating surgeon and the patient; however, the VA examiner and the reading centers that reviewed all optical coherence tomography (OCT) and FA images were masked." Page 319

Although visual acuity assessment was masked to treatment group, physicians and participants were not. It is possible that an individual's performance on the visual acuity test could be influenced by their perceptions as to which treatment they received.

\section{Blinding of outcome as- Low risk} sessment (detection bias) Lesion size on fluorescein angiography
Quote: "Because this study involved a surgical intervention and sham surgery with a nonradioactive probe was not believed to be ethically appropriate, masking to study treatment was not possible for the treating surgeon and the patient; however, the VA examiner and the reading centers that reviewed all optical coherence tomography (OCT) and FA images were masked." Page 319

$\begin{array}{ll}\begin{array}{l}\text { Incomplete outcome data } \\ \text { (attrition bias) }\end{array} & \text { Low risk } \\ \text { All outcomes } & \begin{array}{l}\text { 302/331 (91\%) in the intervention arm were analysed and 155/163 (95\%) of } \\ \text { comparator arm. }\end{array}\end{array}$

Selective reporting (re- High risk porting bias)

Outcomes pre-specified at 12 months (on trials registry entry) but reported at 24 months.

Char 1999

\section{Study characteristics}

Methods
Parallel group RCT
One eye per person. "In patients with bilateral disease, all had marked disparity in visual acuity between
the two eyes. The eye with better vision, having worse than 20/40 best-corrected visual acuity, was en-
tered in the trial, except for five patients in whom the treated eye was worse than 20/40 and the fellow eye
had better acuity."

Participants

Country: USA.

Number of participants (eyes) randomised: 27 (27)

Number of participants (eyes) excluded after randomisation: NR 
Char 1999 (Continued)

Number of participants (eyes) analysed: 27 (27)

Average age: 76 years (range 64 to 89 )

Sex: $52 \%$ women

Inclusion criteria:

- Subfoveal CNV secondary to AMD with visual acuity less than 20/40.

Exclusion criteria: NR

\begin{tabular}{ll}
\hline Interventions & Intervention: $(n=14)$ \\
- External beam radiation therapy (1 fraction of $7.5 \mathrm{~Gy})$ \\
Comparator: $(n=13)$ \\
- Observation
\end{tabular}

Outcomes

Primary: NR

Secondary: NR

Reported:

- Visual acuity (ETDRS chart)

- Changes in subretinal neovascular area and membrane edge

Follow-up: Every 3 months, average follow-up 17 months (range 0 to 32 months)

Notes

Date conducted: NR

Sources of funding: "This study was supported in part by a grant from That Man May See, San Francisco, California, an unrestricted grant from Research to Prevent Blindness Inc, New York, New York, and an unrestricted grant from the Tumori Foundation, San Francisco, California."

Declaration of interest: NR

Trial id: NR

\section{Risk of bias}

\section{Bias}

\section{Authors' judgement Support for judgement}

Random sequence genera- Unclear risk tion (selection bias)

Quote: "Patients were randomly assigned to either no treatment or to treatment with...." Page 575, methods.

Judgement comment: unclear how the allocation sequence was generated.

Allocation concealment Unclear risk Judgement comment: not reported.

(selection bias)
Blinding of participants High risk and personnel (performance bias)

Visual acuity
Quote: "... visual acuity examination with refraction by a trained ophthalmic technician, who was masked to the patients' status in the trial" Page 575, methods.

Judgement comment: participants and personnel were not masked which may have affected the visual acuity outcome.

Blinding of participants Low risk
and personnel (perfor-
mance bias)
Lesion size on fluorescein
angiography

Quote: "Initial and serial fluorescein angiograms were read in a masked manner by two observers...." Page 575, methods. 
Char 1999 (Continued)

Judgement comment: participants and personnel were not masked. We felt that lack of masking was unlikely to lead to performance bias for this outcome.

\begin{tabular}{lll}
\hline $\begin{array}{l}\text { Blinding of outcome as- } \\
\text { sessment (detection bias) }\end{array}$ & High risk & $\begin{array}{l}\text { Quote: "... visual acuity examination with refraction by a trained ophthalmic } \\
\text { technician, who was masked to the patients' status in the trial" Page 575, } \\
\text { Visual acuity }\end{array}$ \\
methods.
\end{tabular}

Judgement comment: However, patients were not masked which may influence visual acuity assessment.

\begin{tabular}{|c|c|c|}
\hline $\begin{array}{l}\text { Blinding of outcome as- } \\
\text { sessment (detection bias) } \\
\text { Lesion size on fluorescein } \\
\text { angiography }\end{array}$ & Low risk & $\begin{array}{l}\text { Quote: "Initial and serial fluorescein angiograms were read in a masked man- } \\
\text { ner by two observers...." Page 575, methods. } \\
\text { Judgement comment: Lack of masking of participants is unlikely to influence } \\
\text { this outcome. }\end{array}$ \\
\hline $\begin{array}{l}\text { Incomplete outcome data } \\
\text { (attrition bias) } \\
\text { All outcomes }\end{array}$ & High risk & $\begin{array}{l}\text { Judgement comment: } 27 \text { participants were entered in the trial with a mean } \\
\text { follow-up of } 15 \text { months (range of } 7 \text { to } 32 \text { months). In the radiation group mean } \\
\text { follow-up was } 17 \text { months. In the group assigned to observation the mean fol- } \\
\text { low-up was } 16 \text { months. In the methods it states that participants "were fol- } \\
\text { lowed on a 3-month basis" however it was not clear from the report why differ- } \\
\text { ent participants had different lengths of follow-up. }\end{array}$ \\
\hline
\end{tabular}
Selective reporting (re-
Unclear risk Judgement comment: no access to study protocol or trial registry entry. porting bias)

Ciulla 2002

\section{Study characteristics}

$\begin{array}{ll}\text { Methods } & \text { Parallel group RCT } \\ \text { Probably one eye per person as refer to "affected eye", unclear how selected }\end{array}$

Participants

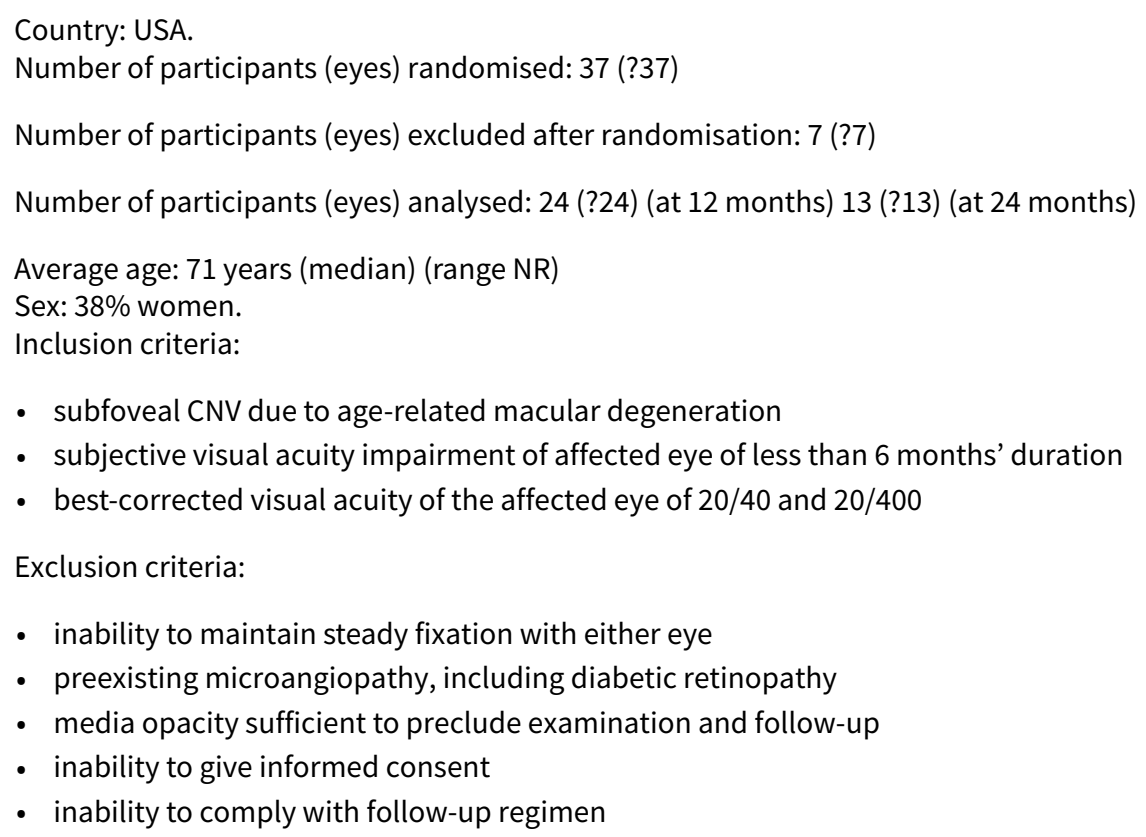


Ciulla 2002 (Continued)

Interventions
- External beam radiation therapy (2 fractions of $8 \mathrm{~Gy}$ )
- Duration: 2 days
Comparator: $\left(n=10^{\star}\right)$

- Sham External beam radiation therapy (not described

*37 participants recruited but "No data were recovered from seven subjects owing to four baseline discrepancies, one off-protocol treatment due to equipment failure, and two discontinuations before the first treatment". NR which groups these 7 lost to follow-up belonged to.

Primary: NR
Secondary: NR
Reported (but data available only for visual acuity):
- Visual acuity (logMAR, ETDRS chart)
- CNV size and leakage
- Subretinal haemorrhage
Follow-up: $3,6,12,18$ and 24 months

Notes Date conducted: June 1998 to January 2000

Sources of funding: "Supported by the Indiana Lions Club, by an unrestricted grant from Research to Prevent Blindness, Inc, New York, New York, and by an Intercampus Research Grant from Research and University Graduate School, Indiana University and the Pearl Vision Foundation. Doctor Ciulla is a recipient of a Career Development Award from Research to Prevent Blindness, Inc."

Conflict of interest: NR

Trial id: NR

Other information: "Recruitment was halted at 37 subjects for ethical reasons regarding randomization to sham treatment when Food and Drug Administration approval of Visudyne (Novartis Ophthalmics, Duluth, Georgia, USA) was anticipated."

\section{Risk of bias}

\begin{tabular}{|c|c|c|}
\hline Bias & Authors' judgement & Support for judgement \\
\hline $\begin{array}{l}\text { Random sequence genera- } \\
\text { tion (selection bias) }\end{array}$ & Unclear risk & Judgement comment: not reported. \\
\hline $\begin{array}{l}\text { Allocation concealment } \\
\text { (selection bias) }\end{array}$ & Unclear risk & Judgement comment: not reported. \\
\hline $\begin{array}{l}\text { Blinding of participants } \\
\text { and personnel (perfor- } \\
\text { mance bias) } \\
\text { Visual acuity }\end{array}$ & Low risk & $\begin{array}{l}\text { Quote: "A randomized, sham-controlled clinical trial" Description of study in } \\
\text { title, abstract and methods page } 905 . \\
\text { Quote "Masked assessment of angiography and analysis of visual acuity be- } \\
\text { tween groups were performed" Page } 905 . \\
\text { Judgement comment: although this statement is not very clear as to whether } \\
\text { the measurement of visual acuity was masked as the control group had sham } \\
\text { irradiation we have assumed that measurement of visual acuity was masked. }\end{array}$ \\
\hline
\end{tabular}


Ciulla 2002 (Continued)

Blinding of participants and personnel (performance bias)

Lesion size on fluorescein angiography
Low risk Quote: "Masked assessment of angiography and analysis of visual acuity between groups were performed" Page 905.

Judgement comment: although this statement is not very clear as to whether the measurement of visual acuity was masked as the control group had sham irradiation we have assumed that as the trial was sham-controlled participants and personnel were masked.
Blinding of outcome as- Low risk sessment (detection bias)

Visual acuity
Quote: "Masked assessment of angiography and analysis of visual acuity between groups were performed" Page 905.

Judgement comment: although this statement is not very clear as to whether the measurement of visual acuity was masked as the control group had sham irradiation we have assumed that measurement of visual acuity was masked.

\section{Blinding of outcome as- Low risk} sessment (detection bias) Lesion size on fluorescein angiography
Quote: "Masked assessment of angiography and analysis of visual acuity between groups were performed" Page 905.

Judgement comment: although this statement is not very clear as to whether the measurement of visual acuity was masked as the control group had sham irradiation we have assumed that measurement of visual acuity was masked.

\section{Incomplete outcome data High risk} (attrition bias)

All outcomes
Quote: "Of the 37 subjects enrolled in this investigation [...] no data were recovered from seven subjects owing to four baseline discrepancies, one off-protocol treatment due to equipment failure, and two discontinuations before the first treatment." Page 906.

Judgement comment: no information was given as to which treatment group these exclusions belonged to and only data for 30 participants analysed. At 12 months, $16 / 20$ and $7 / 10$ participants in treatment and control group respectively seen (page 906, table 1 ). No reason was given for this loss to follow-up.

Selective reporting (re- Unclear risk Judgement comment: no access to study protocol or trial registry entry.

porting bias)

\section{Study characteristics}

\begin{tabular}{ll}
\hline Methods & Parallel group RCT \\
& One eye per person, unclear how eye selected
\end{tabular}

\section{Participants}

Country: Germany.

Number of participants (eyes) randomised: 45 (45)

Number of participants (eyes) excluded after randomisation: NR

Number of participants (eyes) analysed: 42(42)

Average age: 74 years (range 45 to 92 )

Sex: $57 \%$ women.

Inclusion criteria:

- Age 45+ years

- Classic/occult subfoveal CNV

- Informed consent 
Eter 2002 (Continued)

- No prior radiation treatment to head

- No vascular eye disease

- Neovascularisation as a results of AMD alone

- No prior treatment of AMD.

Exclusion criteria: NR

Interventions

Intervention: $(\mathrm{n}=27)^{*}$

- Exernal beam radiation therapy (10 fractions of $2 \mathrm{~Gy}$ )

- Duration: "3 times a week" so assume duration is approximately 3 weeks

Comparator: $(n=15)^{\star}$

- Observation

* This is the number followed up. Original allocation not reported; 3 participants lost to follow-up.

\begin{tabular}{ll}
\hline Outcomes & Primary: NR \\
Secondary: NR \\
Reported: \\
- Visual acuity (logMAR) \\
- Membrane size \\
Follow-up: 6 months
\end{tabular}

$\begin{array}{ll}\text { Notes } & \text { Date conducted: NR } \\ & \text { Sources of funding: NR } \\ & \text { Declaration of interest: NR } \\ & \text { Trial id: NR }\end{array}$

\section{Risk of bias}

Bias Authors' judgement Support for judgement

Random sequence genera- Unclear risk tion (selection bias)

Quote: "Forty-five eyes of 45 patients [...] were assigned randomly in a ratio of 2:1 to either radiation treatment or observation." Page 14

Judgement comment: authors did not describe how the allocation sequence was generated.

Allocation concealment Unclear risk Judgement comment: not reported.

(selection bias)

\begin{tabular}{|c|c|c|}
\hline $\begin{array}{l}\text { Blinding of participants } \\
\text { and personnel (perfor- } \\
\text { mance bias) } \\
\text { Visual acuity }\end{array}$ & High risk & $\begin{array}{l}\text { Judgement comment: masking was not mentioned in the report. We judged } \\
\text { that participants and personnel were probably not masked which may have af- } \\
\text { fected the visual acuity outcome. }\end{array}$ \\
\hline
\end{tabular}

\begin{tabular}{|c|c|c|}
\hline $\begin{array}{l}\text { Blinding of participants } \\
\text { and personnel (perfor- } \\
\text { mance bias) } \\
\text { Lesion size on fluorescein } \\
\text { angiography }\end{array}$ & Low risk & $\begin{array}{l}\text { Judgement comment: the control group was observation only so we have as- } \\
\text { sumed that participants and personnel were not masked. We felt that lack of } \\
\text { masking was unlikely to lead to performance bias for this outcome. }\end{array}$ \\
\hline
\end{tabular}


Eter 2002 (Continued)

$\begin{array}{ll}\begin{array}{l}\text { Blinding of outcome as- } \\ \text { sessment (detection bias) }\end{array} & \text { High risk }\end{array}$

Visual acuity

\begin{tabular}{|c|c|c|}
\hline $\begin{array}{l}\text { Blinding of outcome as- } \\
\text { sessment (detection bias) } \\
\text { Lesion size on fluorescein } \\
\text { angiography }\end{array}$ & Low risk & $\begin{array}{l}\text { Judgement comment: control group was observation only we have assumed } \\
\text { participants and personnel were not masked. We felt that lack of masking was } \\
\text { unlikely to lead to performance bias for this outcome. }\end{array}$ \\
\hline
\end{tabular}

Incomplete outcome data High risk

(attrition bias)

All outcomes
Quote: "Although 45 patients were randomized to either treatment or follow-up, 27 patients in the radiation group and 15 patients in the control group could be enrolled in the study. Three patients were lost to follow-up because motivation for further examinations was low and because they needed to be accompanied by relatives due to their age and visual acuity." Page 14.

Judgement comment: no information was given as to which group the excluded participants belonged. No information was given as to numbers examined at six month follow-up.

Selective reporting (re- Unclear risk Judgement comment: no access to study protocol or trial registry entry.
porting bias)

INTREPID 2013

\section{Study characteristics}

\begin{tabular}{|c|c|}
\hline Methods & $\begin{array}{l}\text { Parallel group RCT } \\
\text { One eye per person, unclear how selected }\end{array}$ \\
\hline Participants & $\begin{array}{l}\text { Country: Europe, multi-centre } \\
\text { Number of participants (eyes) randomised: } 230 \text { (230) } \\
\text { Number of participants (eyes) excluded after randomisation: } 0 \\
\text { Number of participants (eyes) analysed: } 230 \text { (230) } \\
\text { Average age: } 74 \text { years (range NR) } \\
\text { Sex: } 69 \% \text { women } \\
\text { Inclusion criteria: } \\
\text { - Neovascular age-related macular degeneration (AMD) diagnosed within the previous } 3 \text { years, have } \\
\text { received at least three injections with Lucentis }{ }^{\circledR} \text { (ranibizumab) or Avastin }{ }^{\circledR} \text { (bevacizumab) within the } \\
\text { previous year, and have the need for treatment with anti-vascular endothelial growth factor (VEGF) } \\
\text { therapy due to increased fluid or persistent cysts on optical coherence tomography (OCT), or leakage } \\
\text { on fluorescein angiography (FA). } \\
\text { - Total lesion size of <12 disc areas and a CNV lesion with the greatest linear dimension of <6 mm, but } \\
\text { not greater than } 3 \text { mm from the centre of the fovea to the furthest point on the lesion perimeter. } \\
\text { - Distance from the cent er of the fovea to the nearest edge of the optic disc should be not less than } \\
3 \text { mm. } \\
\text { - At least } 50 \text { years of age } \\
\text { - Women must be post-menopausal for } \geq 1 \text { year or surgically sterilized, or a pregnancy screen must be } \\
\text { performed prior to the study and a reliable form of contraception approved by the investigator must } \\
\text { be maintained during the study } \\
\text { - Best corrected visual acuity of } 75 \text { to } 25 \text { letters in the study eye and at least } 20 \text { letters in the fellow eye. }\end{array}$ \\
\hline
\end{tabular}




\section{Exclusion criteria:}

- CNV due to causes other than AMD, including ocular histoplasmosis syndrome, angioid streaks, multifocal choroiditis, choroidal rupture, or pathologic myopia (spherical equivalent $\geq-8$ diopters)

- Axial length of $<20 \mathrm{~mm}$ or $>26 \mathrm{~mm}$

- Previously diagnosed with diabetes mellitus and/or a haemoglobin A1c ( $\mathrm{HbA1c}$ ) value of $>6.5 \%$, and with retinal findings consistent with diabetic retinopathy

- Prior or concurrent therapies for AMD, including submacular surgery, subfoveal thermal laser photocoagulation (with or without photographic evidence), transpupillary thermotherapy (TTT), ocular photodynamic therapy, radiation therapy to the head or neck in the study eye.

- Previous posterior vitrectomy, or any surgery in the study eye within 6 months or YAG (yttrium-aluminum-garnet) capsulotomy within 3 months prior to the screening visit.

- Intravitreal device in the study eye.

- Concomitant disease in the study eye including uveitis, acute ocular or periocular infection, retinal vasculopathies (including retinal vein occlusions, etc.) or intraocular pressure $\geq 30 \mathrm{mmHg}$ uncontrollable with medications.

- History of rhegmatogenous retina detachment, optic neuritis, or intraocular tumours in the study eye.

- Inadequate pupillary dilation or significant media opacities in the study eye, including cataract, which may interfere with visual acuity or the evaluation of the posterior segment.

- Likely to need cataract surgery during the 2-year study period

Interventions Intervention 1: $(\mathrm{n}=75)$

- External beam (stereotactic) radiation therapy (1 fraction of $16 \mathrm{~Gy}$ )

- Ranibizumab (0.5mg) day 0 and as needed (pro re nata, PRN)

Intervention 1: $(n=75)$

- External beam (stereotactic) radiation therapy (1 fraction of $24 \mathrm{~Gy}$ )

- Ranibizumab $(0.5 \mathrm{mg})$ day 0 and PRN

Comparator: $(n=80)$

- Sham radiation

- Ranibizumab $(0.5 \mathrm{mg})$ day 0 and PRN

External beam radiation therapy was delivered by the IRay Radiotherapy System (Oraya Therapeutics, Newark, CA)).

"To be eligible for additional ranibizumab injections, participants had to meet 1 or more of the following retreatment criteria: a 100-m increase in central subfield thickness from the lowest previous OCT measurement, new or increased macular hemorrhage documented by fundus photographs, or a 5-letter or more decrease in BCVA since the last visit or the baseline BCVA, with disease activity, for example, persistent or increased fluid on OCT or leakage on FA."

Outcomes Primary outcome:

- Number of PRN ranibizumab injections administered over 52 weeks.

Secondary were:

- Mean change in best-corrected visual acuity (BCVA) based

- Loss of fewer than 15 letters,

- Gain of 15 letters or more

- Gain of 0 letters or more,

- Time from mandatory ranibizumab injection at day 0 to the first PRN ranibizumab injection

- Change in total lesion size on fluorescein angiography, and change in CNV lesion size on FA. S

- Adverse events (AEs) and serious AEs (SAEs). 
Declaration of interest: Quote "Oraya Therapeutics participated in the design of the study, conducting the study, data collection, data management, data analysis, and review of the manuscript." All authors report support from Oraya therapeutics

Trial id: NCT01016873

\section{Risk of bias}

\section{Bias \\ Authors' judgement Support for judgement}

Random sequence genera- Low risk tion (selection bias)

Quote: "A dynamic randomization algorithm was used to balance for the following: whether the patient exhibited a dry macula at any time after previous anti-VEGF therapy, whether the diagnosis of wet AMD was fewer than 6 months, or 6 months or more before study entry, and whether the baseline (day 0 ) visual acuity score was 54 letters or fewer, or 55 letters or more." Page 1894

Quote: "A stochastic minimization algorithm,25 using a minimization probability parameter of 0.80 , was used for dynamic randomization. The balance used for the minimization algorithm changed 3 times in the study, but the final intended ratio at the end of enrolment achieved the intended 2:1:2:1 distribution." Page 1894

\begin{tabular}{|c|c|c|}
\hline $\begin{array}{l}\text { Allocation concealment } \\
\text { (selection bias) }\end{array}$ & Low risk & $\begin{array}{l}\text { Quote: "Treatment assignment and dose were acquired through a secure, } \\
\text { password-protected website." Page } 1894\end{array}$ \\
\hline $\begin{array}{l}\text { Blinding of participants } \\
\text { and personnel (perfor- } \\
\text { mance bias) }\end{array}$ & Low risk & $\begin{array}{l}\text { Quote: "All patients and study personnel, including personnel from the spon- } \\
\text { sor, were masked to active or sham treatments." Page } 1894\end{array}$ \\
\hline Visual acuity & & $\begin{array}{l}\text { Quote "The operator of the SRT device was not masked to whether the partic- } \\
\text { ipant was receiving the } 16 \text {-Gy or } 24-G y \text { dose because the treatment times dif- } \\
\text { fered. However, all study personnel, including the operator, were masked to } \\
\text { whether active or sham treatment was delivered for the chosen dose." Page } \\
1895\end{array}$ \\
\hline
\end{tabular}

Blinding of participants Low risk and personnel (performance bias) Lesion size on fluorescein angiography
Quote: "All patients and study personnel, including personnel from the sponsor, were masked to active or sham treatments." Page 1894

Quote: "The operator of the SRT device was not masked to whether the participant was receiving the $16-G y$ or $24-G y$ dose because the treatment times differed. However, all study personnel, including the operator, were masked to whether active or sham treatment was delivered for the chosen dose." Page 1895

\begin{tabular}{|c|c|c|}
\hline $\begin{array}{l}\text { Blinding of outcome as- } \\
\text { sessment (detection bias) }\end{array}$ & Low risk & $\begin{array}{l}\text { Quote: "All patients and study personnel, including personnel from the spon } \\
\text { sor, were masked to active or sham treatments." Page } 1894\end{array}$ \\
\hline
\end{tabular}

Low risk

Blinding of outcome assessment (detection bias) Lesion size on fluorescein angiography
Quote: "All patients and study personnel, including personnel from the sponsor, were masked to active or sham treatments." Page 1894 
INTREPID 2013 (Continued)

Incomplete outcome data (attrition bias)

Low risk

All outcomes
Judgement comment: similar numbers followed up to one year: 16Gy 74/75 24 Gy $72 / 75$ and sham $79 / 80$.

Selective reporting (re- Low risk Judgement comment: outcomes on trial register same as in published report
porting bias)

\section{Jaakkola 2005}

\section{Study characteristics}

$\begin{array}{ll}\text { Methods } & \text { Parallel group RCT } \\ \text { One eye per person for most participants, } 2 \text { participants had } 2 \text { eyes enrolled }\end{array}$

Participants

Country: Finland.

Number of participants (eyes) randomised: 86 (88)

Number of participants (eyes) excluded after randomisation: 0

Number of participants (eyes) analysed: 82 (84) (at 12 months) 76 (78) at 3 years

Average age: 76 years .

Sex: $60 \%$ women

Inclusion criteria:

- Recent angiographically proven exudative AMD with subfoveal CNV

- Best-corrected visual acuity (VA) of 20/200 or better

- Size of the lesion had to be no larger than 6 disc areas and not exceed the boundaries of the active area of the plaque to be used

- At least ambulatory vision had to be present in the other eye

Exclusion criteria:

- Age 55 years or younger

- Uncontrolled or advanced glaucoma, diabetes, cataract precluding angiography, or

- estimation that surgery would be required within 3 years

\begin{tabular}{|c|c|}
\hline Interventions & $\begin{array}{l}\text { Intervention: ( } \mathrm{n}=43,43 \text { eyes) } \\
\text { - Episceral brachytherapy ( } \mathrm{Sr} 90 \text { plaques }{ }^{\star} \text { ) } \\
\text { Comparator: ( } \mathrm{n}=43,45 \text { eyes) } \\
\text { - Observation } \\
\text { *"Two different plaque types were used. Plaque I had a diameter of } 8 \mathrm{~mm} \text { and delivered a dose of } 15 \mathrm{~Gy} \\
\text { at a depth of } 1.75 \mathrm{~mm} \text { in } 54 \text { minutes. With plaque II, the corresponding values were } 4 \mathrm{~mm}, 12.6 \mathrm{~Gy} \text {, and } 11 \\
\text { minutes" }\end{array}$ \\
\hline Outcomes & $\begin{array}{l}\text { Primary: } \\
\text { - Visual acuity (ETDRS) } \\
\text { Secondary: } \\
\text { - Contrast sensitivity }\end{array}$ \\
\hline
\end{tabular}


Jaakkola 2005 (Continued)

\section{- Changes in the macula}

Follow-up: 6, 12, 24 and 36 months

Date conducted: 1996 to 2000
Sources of funding: Eye Foundation, Helsinki, Finland, and Friends of the Blind (De Blindas Vänner-
Sokeain Ystävät ry), Helsinki, Finland.
Declaration of interest: Reported "none".
Trial id: NR

\section{Risk of bias}

\begin{tabular}{lll}
\hline Bias & Authors' judgement & Support for judgement \\
\hline $\begin{array}{l}\text { Random sequence genera- } \\
\text { tion (selection bias) }\end{array}$ & Unclear risk & Judgement comment: not reported. \\
\hline $\begin{array}{l}\text { Allocation concealment } \\
\text { (selection bias) }\end{array}$ & Unclear risk & $\begin{array}{l}\text { Quote: "Treatment allocation was performed by envelope randomization with- } \\
\text { in CNV categories, as described below." Page 568. }\end{array}$ \\
& $\begin{array}{l}\text { Judgement comment: not really enough information to judge whether this } \\
\text { was done properly. }\end{array}$
\end{tabular}

\begin{tabular}{ll}
\hline $\begin{array}{l}\text { Blinding of participants } \\
\text { and personnel (perfor- }\end{array}$ & High risk \\
$\begin{array}{l}\text { mance bias) } \\
\text { Visual acuity }\end{array}$ & $\begin{array}{l}\text { Quote: "Visual acuity was measured [...] by an examiner masked against the } \\
\text { treatment given to the patient." Page } 569\end{array}$ \\
& $\begin{array}{l}\text { Judgement comment: participants were probably not masked which may have } \\
\text { affected the visual acuity outcome. }\end{array}$
\end{tabular}

\begin{tabular}{ll}
\hline $\begin{array}{l}\text { Blinding of participants } \\
\text { and personnel (perfor- }\end{array}$ & Low risk \\
$\begin{array}{l}\text { mance bias) } \\
\text { Lesion size on fluorescein } \\
\text { angiography }\end{array}$ & $\begin{array}{l}\text { Judgement comment: participants were unmasked but performance bias un- } \\
\text { likely to affect the lesion size }\end{array}$
\end{tabular}

\section{Blinding of outcome as- High risk} sessment (detection bias)

Visual acuity Judgement comment: participants were not masked which may have affected measurement of visual acuity.

\begin{tabular}{|c|c|c|}
\hline $\begin{array}{l}\text { Blinding of outcome as- } \\
\text { sessment (detection bias) } \\
\text { Lesion size on fluorescein } \\
\text { angiography }\end{array}$ & Low risk & Quote: "The angiograms were evaluated in a masked manner...." Page 569 \\
\hline $\begin{array}{l}\text { Incomplete outcome data } \\
\text { (attrition bias) } \\
\text { All outcomes }\end{array}$ & Unclear risk & $\begin{array}{l}\text { Judgement comment: } 43 / 43 \text { participants in radiotherapy group seen at } 12 \\
\text { months however it was also reported that two participants had died in the in- } \\
\text { terim. } 39 / 43 \text { participants in the control group ( } 91 \%) \text { seen at } 12 \text { months. Flow } \\
\text { chart was confusing because at } 6 \text { months it was reported that four participants } \\
\text { refused and at } 12 \text { months it was reported one participant refused. However } \\
\text { same numbers } 39 / 43 \text { seen at both time points. Page } 569 \text {, figure } 1 \text {. }\end{array}$ \\
\hline
\end{tabular}

Selective reporting (re- Unclear risk Judgement comment: no access to study protocol or trial registry entry.
porting bias)


Kacperek 2001

\section{Study characteristics}

\begin{tabular}{|c|c|}
\hline Methods & $\begin{array}{l}\text { Parallel group RCT } \\
\text { Unclear how many eyes }\end{array}$ \\
\hline Participants & $\begin{array}{l}\text { Country: UK } \\
\text { Number of participants (eyes) randomised: } 58 \text { (?) } \\
\text { Number of participants (eyes) excluded after randomisation: NR } \\
\text { Number of participants (eyes) analysed: unclear } \\
\text { Average age: } 76 \text { years (range } 56 \text { to } 86 \text { ) } \\
\text { Sex: } 61 \% \text { women (but reported for intervention arm only) } \\
\text { Inclusion criteria: } \\
\text { - Aged } 50+\text { with subfoveal CNV (classic) and evidence of AMD e.g. drusen } \\
\text { - Visual acuity > } 6 / 60 \\
\text { Exclusion criteria: } \\
\text { - Diabetes } \\
\text { - Severe hypertension } \\
\text { - Retinal vascular disease } \\
\text { - Myopia }\end{array}$ \\
\hline Interventions & $\begin{array}{l}\text { Intervention: }(n=38) \\
\text { - External beam radiation therapy (4 fractions of } 4.5 \mathrm{~Gy}) \\
\text { - Duration: } N R \\
\text { Comparator: }(n=20) \\
\text { - Observation. }\end{array}$ \\
\hline
\end{tabular}

Outcomes

Primary: NR

Secondary: NR

Reported:

- Visual acuity (ETDRS)

- Contrast sensitivity and angiography mentioned but not reported

Follow-up: 3, 6 and 12 months

\begin{tabular}{ll}
\hline Notes & Date conducted: NR \\
& Sources of funding: NR \\
& Declaration of interest: NR \\
& Trial id: NR \\
\hline Risk of bias & \\
\hline Bias & Authors' judgement Support for judgement \\
\hline \hline
\end{tabular}


Kacperek 2001 (Continued)

Random sequence genera- Unclear risk Quote:"Patients [...] were randomised to between treatment and control". tion (selection bias)

\section{Page 7}

Judgement comment: authors did not describe how the allocation schedule was generated.

Allocation concealment Unclear risk Judgement comment: not reported.

(selection bias)

\begin{tabular}{|c|c|c|}
\hline $\begin{array}{l}\text { Blinding of participants } \\
\text { and personnel (perfor- } \\
\text { mance bias) } \\
\text { Visual acuity }\end{array}$ & High risk & $\begin{array}{l}\text { Judgement comment: masking was not mentioned in the report. We judged } \\
\text { that participants and personnel were probably not masked which may have af- } \\
\text { fected the visual acuity outcome. }\end{array}$ \\
\hline
\end{tabular}

Visual acuity

$\begin{array}{ll}\begin{array}{l}\text { Blinding of participants } \\ \text { and personnel (perfor- }\end{array} & \text { Low risk }\end{array}$

mance bias)

Lesion size on fluorescein

angiography

\begin{tabular}{|c|c|c|}
\hline $\begin{array}{l}\text { Blinding of outcome as- } \\
\text { sessment (detection bias) } \\
\text { Visual acuity }\end{array}$ & High risk & $\begin{array}{l}\text { Judgement comment: no masking was reported and there was no sham inter- } \\
\text { vention in the control group. }\end{array}$ \\
\hline
\end{tabular}

Blinding of outcome as-

High risk

Judgement comment: no masking was reported and there was no sham intersessment (detection bias) vention in the control group.

Lesion size on fluorescein angiography

\begin{tabular}{|c|c|c|}
\hline $\begin{array}{l}\text { Incomplete outcome data } \\
\text { (attrition bias) } \\
\text { All outcomes }\end{array}$ & High risk & $\begin{array}{l}\text { Judgement comment: initial allocation was } 38 \text { participants in the treatment } \\
\text { arm and } 20 \text { for the control arm. } 27 \text { participants in treatment arm versus } 20 \text { in } \\
\text { control arm reported at } 12 \text { months. No information on people not seen. }\end{array}$ \\
\hline
\end{tabular}

\begin{tabular}{l}
$\begin{array}{l}\text { Selective reporting (re- Unclear risk Judgement comment: no access to study protocol or trial registry entry. } \\
\text { porting bias) }\end{array}$ \\
\hline
\end{tabular}

Kobayashi 2000

\section{Study characteristics}

\begin{tabular}{ll}
\hline Methods & Parallel group RCT \\
& One eye per person, chosen by participant and clinician
\end{tabular}

Country: Japan
Number of participants (eyes) randomised: 101 (101)
Number of participants (eyes) excluded after randomisation: NR
Number of participants (eyes) analysed: 85 (85) at all time points to 24 months
Average age: 72 years (range 60 to 89 )
Sex: $64 \%$ women
Inclusion criteria:


Kobayashi 2000 (Continued)

- Unsuitable for laser photocoagulation under the Macular Photocoagulation Study criteria, (2) newly formed or exacerbated choroidal neovascular membranes (e.g., within 3 months)

- Visual acuity of $0.5(25 / 50)$ or worse

- Age of 60 years of more

Exclusion criteria:

- Pre-existing ocular disease (i.e., glaucoma, severe myopia, chronic inflammatory disease, or neoplastic disorders)

- Systemic disorders (diabetes, uncontrolled hypertension) or a known life-threatening disease.

Interventions
- External beam radiation therapy $(10$ fractions of $2 \mathrm{~Gy})$
- Duration: 14 days
Comparator: $(n=50)$
- Observation

$\begin{array}{ll}\text { Outcomes } & \text { Primary: NR } \\ \text { Secondary: NR } \\ \text { Reported: } \\ \text { - Visual acuity (ETDRS) } \\ \text { - Area of CNV (FFA) } \\ \text { - Safety } \\ \text { Follow-up: } 2 \text { weeks, } 1,3,6,9,12,18 \text { and } 24 \text { months }\end{array}$

Notes

Date conducted: NR

Sources of funding: Hyogo Prefecture and Hyogo Medical Society, Hyogo, Japan.

Declaration of interest: NR

Trial id: NR

\section{Risk of bias}

Bias Authors' judgement Support for judgement

Random sequence genera- Low risk tion (selection bias)
Quote: "One eye of each of the 101 patients was prospectively randomized to receive radiotherapy or no treatment." and "Within 24 hours after enrollment, the patients were randomized by means of computer-generated numbers; patients assigned 0 received low-dose radiotherapy and those assigned 1 received no treatment." Page 618

\begin{tabular}{lll}
\hline $\begin{array}{l}\text { Allocation concealment } \\
\text { (selection bias) }\end{array}$ & Low risk & $\begin{array}{l}\text { Quote: "The treating physician (HK) was unaware of the patients' randomiza- } \\
\text { tion state". Page } 618\end{array}$ \\
\hline $\begin{array}{l}\text { Blinding of participants } \\
\begin{array}{l}\text { and personnel (perfor- } \\
\text { mance bias) }\end{array}\end{array}$ & High risk & $\begin{array}{l}\text { Judgement comment: masking of participants was not mentioned in the re- } \\
\text { port. We judged that participants were probably not masked which may have } \\
\text { affected the visual acuity outcome. }\end{array}$ \\
\hline $\begin{array}{l}\text { Blinding of participants } \\
\text { and personnel (perfor- } \\
\text { mance bias) }\end{array}$ & Low risk & $\begin{array}{l}\text { Judgement comment: } \text { masking of participants was not mentioned in the re- } \\
\text { port. We judged that participants were probably not masked but performance } \\
\text { bias unlikely to affect the lesion size. }\end{array}$ \\
\hline
\end{tabular}

Radiotherapy for neovascular age-related macular degeneration (Review) 
Kobayashi 2000 (Continued) Lesion size on fluorescein angiography

\begin{tabular}{lll}
\hline $\begin{array}{l}\text { Blinding of outcome as- } \\
\text { sessment (detection bias) } \\
\text { Visual acuity }\end{array}$ & High risk & $\begin{array}{l}\text { Quote: "Assessment of outcomes, including visual acuity, angiographic in- } \\
\text { terpretation, and assessment of complications and adverse events, was per- } \\
\text { formed in a masked fashion." Page } 618\end{array}$ \\
& $\begin{array}{l}\text { Judgement comment: participants were not masked which may have affected } \\
\text { measurement of visual acuity. }\end{array}$
\end{tabular}

\begin{tabular}{|c|c|c|}
\hline $\begin{array}{l}\text { Blinding of outcome as- } \\
\text { sessment (detection bias) } \\
\text { Lesion size on fluorescein }\end{array}$ & Low risk & $\begin{array}{l}\text { Quote: "Assessment of outcomes, including visual acuity, angiographic in- } \\
\text { terpretation, and assessment of complications and adverse events, was per- } \\
\text { formed in a masked fashion." Page } 618\end{array}$ \\
\hline
\end{tabular}
angiography

Incomplete outcome data Unclear risk (attrition bias)

All outcomes
Quote: "The overall complete follow-up rate was $84.1 \%$ (85/101) (Table 1 and Figure 1). there was no significant difference between the two groups; the complete follow-up rate was $88.2 \%(45 / 51)$ and $80.0 \%(40 / 50)$ in the treatment group and control group, respectively. Six treated patients and 10 untreated patients were not evaluated, because five patients died with intercurrent disease, six patients were to ill or frail to attend, and it was not possible to contact five patients. Page 619, results.

Judgement comment: although follow-up was over $80 \%$ there were some differences between the intervention and comparator group. porting bias) Judgement comment: no access to study protocol or trial registry entry.

\section{Marcus 2001}

\section{Study characteristics}

\begin{tabular}{ll}
\hline Methods & Parallel group RCT \\
& One eye per person, unclear how eye selected
\end{tabular}

\section{Participants}

Country: USA.

Number of participants (eyes) randomised: 83 (83)

Number of participants (eyes) excluded after randomisation: NR

Number of participants (eyes) analysed: 70 (70) (at 12 months)

Average age: 76 years (range NR)

Sex: $61 \%$ women

Inclusion criteria:

Active subfoveal CNV secondary AMD

Older than 48 years of age

Visual acuity $\geq 20 / 400$

Clinical and angiographic evidence of a choroidal neovascular membrane

Exclusion criteria:

Previous laser treatment 
Retinal vascular diseases e.g. diabetes; previous ocular, orbital or periorbital radiation; likely candidates for chemotherapeutic agents

Interventions
- External beam radiation therapy (7 fractions of $2 \mathrm{~Gy}$ )
- Duration: 7 working days
Comparator: $(\mathrm{n}=42)$
- Sham treatment ( 1 session)
- Duration: 1 day

$\begin{array}{ll}\text { Outcomes } & \text { Primary: } \\ \text { - Distance visual acuity (logMAR, ETDRS) } \\ \text { Secondary: } \\ \text { - Contrast sensitivity (Pelli-Robson chart) } \\ \text { - Appearance of fundus } \\ \text { Follow-up: specified as } 3,6,12,24 \text { weeks, and every } 6 \text { months to } 4 \text { years but only data up to } 12 \text { months } \\ \text { reported. }\end{array}$

Notes

Date conducted: February 1995 to September 1998

Sources of funding: Grant from Research to Prevent Blindness, New York and grants from the Knights Templar Educational Foundation of Georgia.

Declaration of interest: NR

Trial id: NR

\section{Risk of bias}

\begin{tabular}{lll}
\hline Bias & Authors' judgement & Support for judgement \\
\hline $\begin{array}{ll}\text { Random sequence genera- } \\
\text { tion (selection bias) }\end{array}$ & Low risk & $\begin{array}{l}\text { Quote: "The randomization incorporated blocking, which is recommended any } \\
\text { time patient recruitment extends for a long period of time. Blocks of size } 2 \text { or } 4 \\
\text { were assigned randomly, and a separate random permutation was used to as- } \\
\text { sign the } 2 \text { treatments to the blocks." Page } 172\end{array}$ \\
\hline
\end{tabular}

\begin{tabular}{ll}
\hline $\begin{array}{l}\text { Allocation concealment } \\
\text { (selection bias) }\end{array}$ & High risk \\
& $\begin{array}{l}\text { Quote "A randomization schedule was printed and sent to the radiology team, } \\
\text { who then sequentially allocated the patients to the sham or actual radiation } \\
\text { treatments". Page } 172\end{array}$ \\
& Judgement comment: allocation schedule was clearly not concealed.
\end{tabular}

\begin{tabular}{ll}
\hline $\begin{array}{l}\text { Blinding of participants } \\
\begin{array}{l}\text { and personnel (perfor- } \\
\text { mance bias) }\end{array}\end{array}$ & $\begin{array}{l}\text { Quote: "The patient, examining ophthalmologist, and ophthalmic techni- } \\
\text { vian were unaware of the assignment to observation or radiation treatment } \\
\text { gisual acuity }\end{array}$ \\
& $\begin{array}{l}\text { groups." Page } 172 \\
\text { Judgement comment: study was sham-controlled. }\end{array}$
\end{tabular}

\begin{tabular}{|c|c|c|}
\hline $\begin{array}{l}\text { Blinding of participants } \\
\text { and personnel (perfor- } \\
\text { mance bias) }\end{array}$ & Low risk & $\begin{array}{l}\text { Quote: "The patient, examining ophthalmologist, and ophthalmic techni- } \\
\text { cian were unaware of the assignment to observation or radiation treatment } \\
\text { groups." Page } 172\end{array}$ \\
\hline
\end{tabular}


Marcus 2001 (Continued) Lesion size on fluorescein angiography

\begin{tabular}{|c|c|c|}
\hline $\begin{array}{l}\text { Blinding of outcome as- } \\
\text { sessment (detection bias) } \\
\text { Visual acuity }\end{array}$ & Low risk & $\begin{array}{l}\text { Quote: "The patient, examining ophthalmologist, and ophthalmic techni- } \\
\text { cian were unaware of the assignment to observation or radiation treatment } \\
\text { groups." Page } 172\end{array}$ \\
\hline
\end{tabular}

\begin{tabular}{|c|c|c|}
\hline $\begin{array}{l}\text { Blinding of outcome as- } \\
\text { sessment (detection bias) } \\
\text { Lesion size on fluorescein } \\
\text { angiography }\end{array}$ & Low risk & $\begin{array}{l}\text { Quote: "The patient, examining ophthalmologist, and ophthalmic techni- } \\
\text { cian were unaware of the assignment to observation or radiation treatment } \\
\text { groups." Page } 172\end{array}$ \\
\hline $\begin{array}{l}\text { Incomplete outcome data } \\
\text { (attrition bias) } \\
\text { All outcomes }\end{array}$ & High risk & $\begin{array}{l}\text { Judgement comment: differences in follow-up between groups and follow-up } \\
\text { less than } 80 \% \text { in the control group. Radiation group } n=41.37(90 \%) \text { seen at one } \\
\text { year, } 4 \text { with missing data. Control } n=42.33(79 \%) \text { seen at one year, } 6 \text { with miss- } \\
\text { ing data, } 3 \text { withdrawn. Page } 175 \text {, table } 2 \text {. }\end{array}$ \\
\hline
\end{tabular}

\begin{tabular}{|c|c|c|}
\hline $\begin{array}{l}\text { Selective reporting (re- } \\
\text { porting bias) }\end{array}$ & High risk & $\begin{array}{l}\text { Judgement comment: follow-up to } 4 \text { years but only data up to } 12 \text { months re- } \\
\text { ported. }\end{array}$ \\
\hline
\end{tabular}

\section{MERLOT 2016}

\section{Study characteristics}

$\begin{array}{ll}\text { Methods } & \text { Parallel group RCT } \\ \text { One eye per person, if both eyes eligible participant chose which eye would be treated }\end{array}$

Participants

Country: UK (24 hospitals)

Number of participants (eyes) enrolled: 363 (363)

Number of participants (eyes) excluded after randomisation:

Age: 77 years (range 56 to 96 )

Sex: $60 \%$ women

Inclusion criteria:

- Subfoveal choroidal neovascularisation associated with wet age-related macular degeneration.

- Retinal Angiomatous Proliferation (RAP) lesions not directly involving the fovea must be associated with contiguous foveal leakage demonstrated on fundus examination, OCT, or fluorescein angiography

- Received anti-VEGF induction treatment, defined as the first three months of anti-VEGF therapy. Following this induction period, participants must have received at least 4 additional injections of Lucentis $^{\circledast}$ in no more than 12 months preceding enrolment, or 2 additional injections of Lucentis ${ }^{\circledR}$ in no more than 6 months preceding enrolment, given on an as needed basis

- Aged 50 years or older and met the NICE treatment criteria for Lucentis ${ }^{\circledR}$ therapy, i.e. all of the following circumstances must apply in the eye to be treated: the best-corrected visual acuity is between $6 / 12$ and 6/96 (24 to 69 ETDRS letters) there is no permanent structural damage to the central fovea the lesion size is less than or equal to 12 disc areas in greatest linear dimension there is evidence of recent presumed disease progression (blood vessel growth, as indicated by fluorescein angiography, or recent visual acuity changes)

Exclusion criteria:

- Has not been treated in accordance with NICE guidance

- Visual acuity worse than $6 / 96$ at the time of study enrolment 
- Prior or concurrent subfoveal CNV therapy with agents, surgery or devices (other than Macugen ${ }^{\circledR}$, Avastin $^{\circledR}$, or Lucentis $^{\circledast}$ ) including thermal laser photocoagulation (with or without photographic evidence), photodynamic therapy, intravitreal or subretinal steroids, and transpupillary thermotherapy (TTT)

- Subfoveal scarring

- Active concomitant disease in the study eye, including uveitis, presence of pigment epithelial tears or rips, acute ocular or periocular infection;

- Previously diagnosed with Type 1 or Type 2 Diabetes Mellitus or retinal findings consistent with Type 1 or Type 2 Diabetes Mellitus;

- Advanced glaucoma (greater than 0.8 cup:disk) or intraocular pressure $\geq 30 \mathrm{mmHg}$ in the study eye

- Previous glaucoma filtering surgery in the study eye

- Inadequate pupillary dilation or significant media opacities in the study eye, including cataract, which may interfere with visual acuity or the evaluation of the posterior segment;

- Current vitreous haemorrhage in the study eye

- History of rhegmatogenous retinal detachment or macular hole in the study eye;

- CNV due to causes other than AMD, including known or suspected idiopathic polypoidal choroidal vasculopathy (IPCV), ocular histoplasmosis syndrome, angioid streaks, multifocal choroiditis, choroidal rupture, or pathologic myopia (spherical equivalent $\geq 8$ Dioptre or axial length $\geq 25 \mathrm{~mm}$ );

- Any intraocular surgery in the study eye within 12 weeks prior to the screening visit, with the exception of cataract surgery

- Previous cataract surgery within 2 months prior to enrolment into the study;

- Known serious allergies to fluorescein dye used in angiography;

- Known sensitivity or allergy to Lucentis ${ }^{\circledast}$;

- Previous radiation therapy to the eye, head or neck;

- An intravitreal device or drug in the study eye;

- Any other condition, which in the judgment of the investigator would prevent completing the study (e.g. documented diagnosis of dementia or serious mental illness);

- Current participation in another drug or device clinical trial, or participation in such a clinical trial within the last year;

- History of use of drugs with known retinal toxicity, including: chloroquine (Aralen - an anti-malarial drug), hydroxychloroquine (Plaquenil), phenothiazines, chlorpromazine (Thorazine), thioridazine (Mellaril), fluphenazine (Prolixin), perphenazine (Trilafon), and trifluoperazine (Stelazine)

- Unwilling or unable to return for scheduled treatment and follow-up examinations for three years

- Women must be post-menopausal more than 1 year unless surgically sterilised

Interventions

Intervention: $(\mathrm{n}=244)$

- Epimacular brachytherapy, Strontium-90 (24 Gy)

- Ranibizumab (0.5mg) monthly as required

Comparator: $(n=119)$

- Ranibizumab $(0.5 \mathrm{mg})$ monthly as required

Outcomes

Primary:

- Mean change in ETDRS best-corrected visual acuity at 24 months

- Number of re-treatment injections of Lucentis ${ }^{\circledR}$ per participant, per year

Secondary:

- Percentage losing $<15$ ETDRS letters

- Percentage gaining $\geq 0$ ETDRS letters

- Percentage gaining $\geq 15$ ETDRS letters

- Change in total lesion size by fluorescein angiography

- Change in total CNV size by fluorescein angiography

- Foveal thickness measured using OCT. 
MERLOT 2016 (Continued)

Follow-up: 24 months

Information from clinicaltrials.gov

Notes Date conducted: November 2009 to January 2012

Sources of funding: Quote "NeoVista (Fremont, CA) provided unrestricted research funding but had no role in data collection, analysis, or in the preparation or review of this manuscript"

Declaration of interest: Authors reported financial support from NeoVista

Trial id: NCT01006538

\section{Risk of bias}

\begin{tabular}{lll}
\hline Bias & Authors' judgement & Support for judgement \\
\hline $\begin{array}{ll}\text { Random sequence genera- } \\
\text { tion (selection bias) }\end{array}$ & Low risk & $\begin{array}{l}\text { Quote: "Online electronic randomization was undertaken immediately af- } \\
\text { ter eligibility was confirmed by recruiting sites using a commercial system } \\
\text { (MedSciNet, Stockholm, Sweden)." }\end{array}$
\end{tabular}

\begin{tabular}{|c|c|c|}
\hline $\begin{array}{l}\text { Allocation concealment } \\
\text { (selection bias) }\end{array}$ & Low risk & $\begin{array}{l}\text { Quote: "Online electronic randomization was undertaken immediately af- } \\
\text { ter eligibility was confirmed by recruiting sites using a commercial system } \\
\text { (MedSciNet, Stockholm, Sweden)." }\end{array}$ \\
\hline
\end{tabular}

\begin{tabular}{|c|c|c|}
\hline $\begin{array}{l}\text { Blinding of participants } \\
\text { and personnel (perfor- }\end{array}$ & High risk & $\begin{array}{l}\text { Judgement comment: participants and personnel were not masked which } \\
\text { may have affected the visual acuity outcome. }\end{array}$ \\
\hline
\end{tabular}
mance bias)

Visual acuity

Blinding of participants Unclear risk
and personnel (perfor-
mance bias)
Lesion size on fluorescein
angiography

Judgement comment: participants and personnel were not masked and it is unclear whether this would have affected lesion size (for example, by differential treatment with anti-VEGF).

\begin{tabular}{|c|c|c|}
\hline $\begin{array}{l}\text { Blinding of outcome as- } \\
\text { sessment (detection bias) } \\
\text { Visual acuity }\end{array}$ & Low risk & $\begin{array}{l}\text { Quote: "VA testing and macular imaging (which were the most commonly used } \\
\text { criteria to necessitate ranibizumab retreatment) were undertaken by masked } \\
\text { assessors." }\end{array}$ \\
\hline
\end{tabular}

\begin{tabular}{lll}
\hline $\begin{array}{l}\text { Blinding of outcome as- } \\
\text { sessment (detection bias) } \\
\text { Lesion size on fluorescein } \\
\text { angiography }\end{array}$ & Low risk & $\begin{array}{l}\text { Quote: "VA testing and macular imaging (which were the most commonly used } \\
\text { criteria to necessitate ranibizumab retreatment) were undertaken by masked } \\
\text { assessors." }\end{array}$ \\
\hline $\begin{array}{l}\text { Incomplete outcome data } \\
\text { (attrition bias) }\end{array}$ & Low risk & $\begin{array}{l}\text { Judgement comment: at } 12 \text { months, } 13 / 363(3.3 \%) \text { participants were missing } \\
\text { visual acuity measurements. These were imputed using multiple imputation. } \\
\text { The ranibizumab retreatment injection analysis also included all participants } \\
\text { but no correction was made for participants who withdrew early. Fluorescein } \\
\text { angiography and OCT data were not available for } 26(7.2 \%) \text { and } 19(5.2 \%) \text { of } \\
\text { eyes respectively. }\end{array}$
\end{tabular}

Selective reporting (re- Low risk Judgement comment: outcomes on trials registry entry were reported


Osmanovic 2017

\section{Study characteristics}

Methods $\quad$ Parallel group RCT

One eye included in study; if both eyes were eligible, then the eye with the worse VA was treated.

Participants

Country: USA

Number of participants (eyes) randomised: 30 (30)

Number of participants (eyes) excluded after randomisation: 8 (8)

Number of participants (eyes) analysed: 22 (22)

Average age: 77 years (range not reported)

Sex: $59 \%$ women

Inclusion criteria:

- newly diagnosed neovascular AMD or evidence of recurrent active neovascular AMD.

- subfoveal or juxtafoveal choroidal neovascularization identified by fundus fluorescein angiography

- best-corrected visual acuity of $6 / 12$ to $6 / 120$ (20/40 to $20 / 400)$

Exclusion criteria:

- additional macular or optic nerve comorbidities,

- history of diabetes mellitus

- history of prior head and neck radiation

- intravitreal anti-VEGF treatment in the study eye within the 6 weeks before enrolment

Eyes with newly diagnosed neovascular AMD were recruited preferentially, but eyes with less than three prior intravitreal anti-VEGF therapies and with recurrent active neovascular AMD were considered for study enrolment.

- External beam radiation therapy (2 fractions of $12 \mathrm{~Gy}$ )

Intervention 2: $(n=7)$

- External beam radiation therapy (2 fractions of $8 \mathrm{~Gy}$ )

Comparator: $(n=8)$

- Sham radiation therapy (2 sessions)

Duration: 24 hours apart.

Radiation was administered 2 weeks to 6 weeks after enrolment and administration of the first study intravitreal anti-VEGF therapy. All participants received anti-VEGF therapy (either ranibizumab 0.5mg or bevacizumab $1.25 \mathrm{mg}$ in $0.05 \mathrm{~mL}$ ).

Quote "For sham radiation, a thermoplastic head mask was used to immobilize the head and eyelid retractors were used to remove the eyelids from the sham radiation field. Eye fixation was monitored and maintained for the sham radiation. The sham treatment was identical to the actual proton beam treatment except no treatment planning was performed and no radiation was administered." 
Primary outcome:

- Incidence of severe vision loss from radiation retinopathy or other causes defined as number of eyes with 3 or more lines of vision loss from baseline at 12 and 24 months

Secondary (12 and 24 months):

- number of anti-VEGF therapy [ Time Frame: Month 12 and 24 ]

- number of eyes with 3 or more lines of visual acuity gain from baseline

- number of eyes with radiation retinopathy or papillopathy

Outcomes reported in the publication (12 months)

- Mean best-corrected visual acuity

- Cataract progression

- Lesion area of CNV membrane

- Resolution of leakage on FA

- OCT measurements, mean CRT

- Size of PED

- Number of intravitreal anti-VEGF treatments

- Radiation retinopathy or papillopathy

- Severe vision loss (loss of BCVA of 3 or more Snellen lines)

- Adverse arteriothromboembolic events Age-related Macular Degeneration (AMD) (PBAMD2)

Date conducted: September 2010 to January 2015

Sources of funding: Quote: "Supported in part by a Strategic CTSI grant from UCSF (K.M.) and Research to Prevent Blindness Unrestricted Grant."

Declaration of interest: Quote: "The authors made the following disclosures: L.M.: Contracted researchGenentech, Allergan, Roche/Novartis. A.M.: Contracted research Genentech, Allergan, Roche/Novartis; Honoraria Genentech. S.S.P.: Contracted research e Genentech, Allergan, Roche/Novartis; Honoraria Genentech."

Trial id: NCT01213082

\section{Risk of bias}

\begin{tabular}{lll}
\hline Bias & Authors' judgement & Support for judgement \\
\hline $\begin{array}{l}\text { Random sequence genera- } \\
\text { tion (selection bias) }\end{array}$ & Low risk & $\begin{array}{l}\text { Quote: "The randomization was conducted by the unmasked study coordina- } \\
\text { tor using a sequential coin toss, first to determine sham versus PBT, then } 1 \text { of } 2 \\
\text { doses of PBT if subject was randomized to PBT." }\end{array}$ \\
\hline $\begin{array}{l}\text { Allocation concealment } \\
\text { (selection bias) }\end{array}$ & High risk & $\begin{array}{l}\text { Quote: "The randomization was conducted by the unmasked study coordina- } \\
\text { tor using a sequential coin toss, first to determine sham versus PBT, then } 1 \text { of } \\
\text { 2 doses of PBT if subject was randomized to PBT. Because this is a small study, } \\
\text { the total enrollment of each study group was roughly equal throughout the } \\
\text { study with variations in enrollment number limited to within } 2 \text { subjects rela- } \\
\text { tive to the other study groups during the study after accounting for any sub- } \\
\text { jects who } \\
\text { were excluded from the study after study enrollment." }\end{array}$ \\
\hline
\end{tabular}


Judgement comment: Allocation was unmasked.

Blinding of participants Low risk and personnel (perfor-

mance bias)

Visual acuity
Quote: "Both the examining study ophthalmologist and study subject were masked to study group randomization until study completion. The radiation oncologist and the randomizing study coordinator were unmasked to study randomization and did not participate in follow-up study examination and anti-VEGF retreatment decision making. For the interim 1-year data analysis, 1 investigator (E.M.) not involved in follow-up study eye examination and anti-VEGF retreatment decision making was unmasked."

Judgement comment: sham radiation in the control group.
Blinding of participants Low risk and personnel (performance bias) Lesion size on fluorescein angiography
Quote: "Both the examining study ophthalmologist and study subject were masked to study group randomization until study completion. The radiation oncologist and the randomizing study coordinator were unmasked to study randomization and did not participate in follow-up study examination and anti-VEGF retreatment decision making. For the interim 1-year data analysis, 1 investigator (E.M.) not involved in follow-up study eye examination and anti-VEGF retreatment decision making was unmasked."

Judgement comment: sham radiation in the control group.

\section{Blinding of outcome as- Low risk sessment (detection bias)} Visual acuity
Quote: "Both the examining study ophthalmologist and study subject were masked to study group randomization until study completion. The radiation oncologist and the randomizing study coordinator were unmasked to study randomization and did not participate in follow-up study examination and anti-VEGF retreatment decision making. For the interim 1-year data analysis, 1 investigator (E.M.) not involved in follow-up study eye examination and anti-VEGF retreatment decision making was unmasked."

Judgement comment: sham radiation in the control group.
Blinding of outcome as- Low risk sessment (detection bias) Lesion size on fluorescein angiography
Quote: "Both the examining study ophthalmologist and study subject were masked to study group randomization until study completion. The radiation oncologist and the randomizing study coordinator were unmasked to study randomization and did not participate in follow-up study examination and anti-VEGF retreatment decision making. For the interim 1-year data analysis, 1 investigator (E.M.) not involved in follow-up study eye examination and anti-VEGF retreatment decision making was unmasked."

Judgement comment: sham radiation in the control group.

Incomplete outcome data High risk
(attrition bias)

All outcomes
Judgement comment: 22/30 participants followed up to one year (73\%) and not clear follow-up by group in published study report. On clinical trials registry follow-up was lower in the control group: at 24 months 6/12 (50\%) in 24Gy group, $7 / 11$ (64\%) and 4/11 (in sham irradiation group (36\%). Reason for loss to follow-up given on trials registry was "lost to follow-up".
Judgement comment: differences between outcomes pre-specified on the

clinical trials registry and outcomes reported in the paper.

Selective reporting (re- High risk porting bias)

\section{Study characteristics}

Methods $\quad$ Parallel group RCT


RAD 1999 (Continued)

One eye per person, unclear how selected

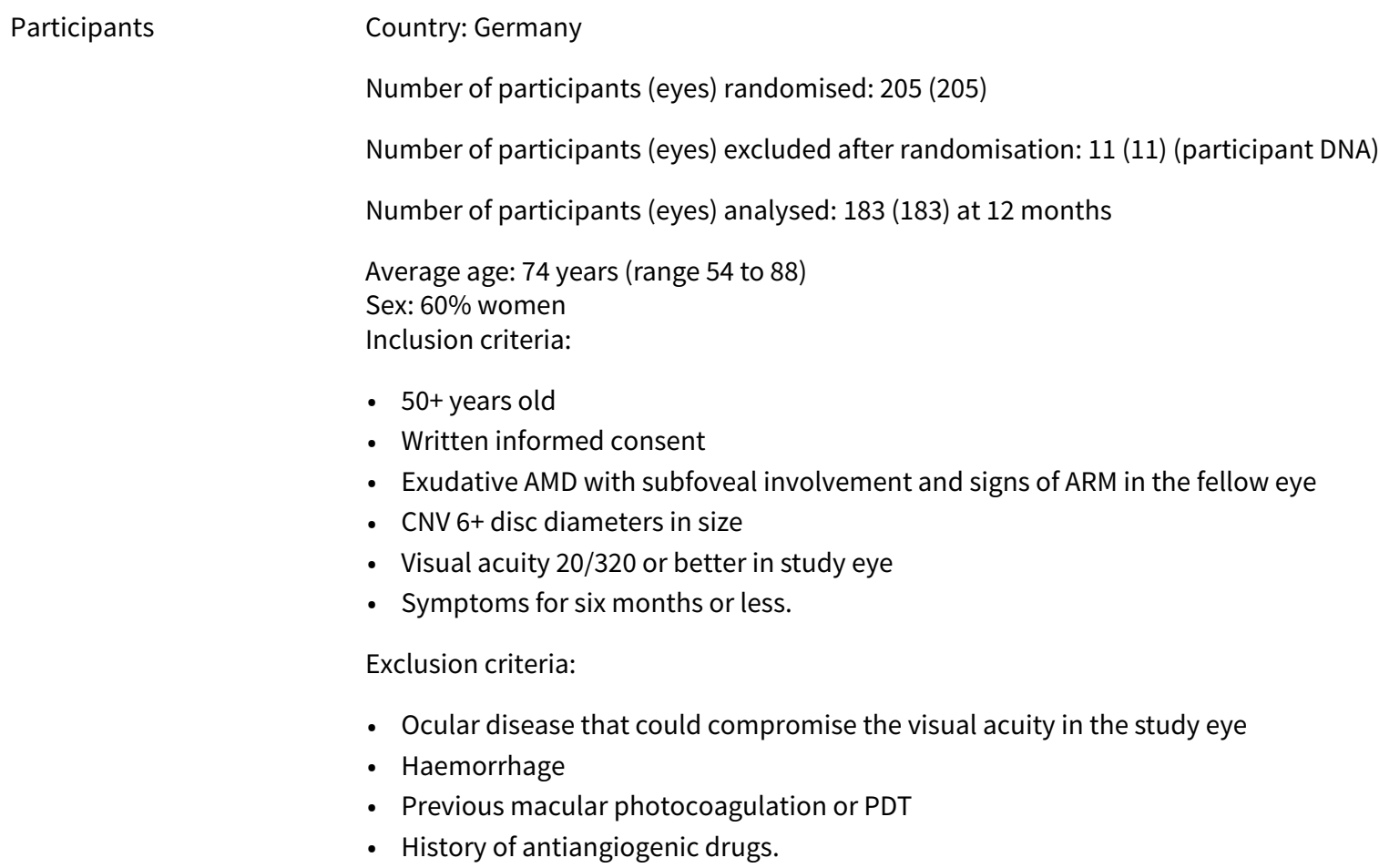

Participants

Country: Germany

Number of participants (eyes) randomised: 205 (205)

Number of participants (eyes) excluded after randomisation: 11 (11) (participant DNA)

Number of participants (eyes) analysed: 183 (183) at 12 months

Average age: 74 years (range 54 to 88 )

Sex: $60 \%$ women

Inclusion criteria:

- 50+ years old

- Written informed consent

- Exudative AMD with subfoveal involvement and signs of ARM in the fellow eye

- CNV 6+ disc diameters in size

- Visual acuity $20 / 320$ or better in study eye

- Symptoms for six months or less.

Exclusion criteria:

- Ocular disease that could compromise the visual acuity in the study eye

- Haemorrhage

- Previous macular photocoagulation or PDT

- History of antiangiogenic drugs.

- External beam radiation therapy (8 fraction of $2 \mathrm{~Gy}$ )

- Duration: 10 days

Comparator: $(n=104)$

- Sham irradiation (8 fractions of $0 \mathrm{~Gy}$ )

Primary outcome:
- Change in visual acuity between baseline and 12 months (logMAR, ETDRS)
Secondary: NR
Reported:
- Safety
Follow-up: 6 and 12 months
Full study name: The Radiation Therapy for Age-related Macular Degeneration (RAD) Study
Date conducted: February 1996 to October 1997
Sources of funding: Deutsche Forschungsgemeinschaft (DFG), Bonn, Germany (grant \# Vo 437/3-1), and
by the State of Baden-Wu "rttemberg, Heidelberg, Germany (grant \# 88/94).
Declaration of interest: NR
Trial id: NR

\section{Risk of bias}


RAD 1999 (Continued)

Bias Authors' judgement Support for judgement

Random sequence genera- Low risk tion (selection bias)

Allocation concealment Low risk
(selection bias)
Quote: "The randomization list was compiled generating random numbers using the statistical analysis system SAS, version 6.12." Page 2240

Blinding of participants Low risk
and personnel (perfor-
mance bias)
Visual acuity

Quote: "To ensure concealment, external randomization by telephone was performed by the Biostatistics and Data Centre, Heidelberg, Germany." Page 2240

Quote:"Patients in the placebo group were similarly planed and placed at the linear accelerator for 8 fractions with a dose of $8 \times 0 G y$. The machine noise during irradiation was simulated, and the technicians were instructed not to inform the patient about the mode of treatment. The sham treatment method was spread out over an identical time course as the radiation treatment." Page 2240

Quote "To ensure masking of patients and ophthalmologists, only the respective departments of radiation therapy were informed about treatment allocation." Page 2240

Blinding of participants Low risk
and personnel (perfor-
mance bias)
Lesion size on fluorescein
angiography

Quote "To ensure masking of patients and ophthalmologists, only the respective departments of radiation therapy were informed about treatment allocation." Page 2240

Quote: "All angiograms were read by reviewers masked to treatment assignments." Page 2240

\begin{tabular}{ll}
\hline $\begin{array}{l}\text { Blinding of outcome as- } \\
\text { sessment (detection bias) }\end{array}$ & Low risk \\
$\begin{array}{l}\text { Visual acuity } \\
\text { Quote: "Patients in the placebo group were similarly planed and placed at the } \\
\text { linear accelerator for } 8 \text { fractions with a dose of } 8 \times 0 \mathrm{~Gy} \text {. The machine noise dur- } \\
\text { ing irradiation was simulated, and the technicians were instructed not to in- } \\
\text { form the patient about the mode of treatment. The sham treatment method } \\
\text { was spread out over an identical time course as the radiation treatment." Page } \\
2240\end{array}$ \\
$\begin{array}{l}\text { Quote: "To ensure masking of patients and ophthalmologists, only the respec- } \\
\text { tive departments of radiation therapy were informed about treatment alloca- } \\
\text { tion." Page } 2240\end{array}$
\end{tabular}

\begin{tabular}{|c|c|c|}
\hline $\begin{array}{l}\text { Blinding of outcome as- } \\
\text { sessment (detection bias) } \\
\text { Lesion size on fluorescein }\end{array}$ & Low risk & $\begin{array}{l}\text { Quote: "All angiograms were read by reviewers masked to treatment assign- } \\
\text { ments." Page } 2240\end{array}$ \\
\hline
\end{tabular}
Lesion size on fluorescein angiography

\begin{tabular}{|c|c|c|}
\hline $\begin{array}{l}\text { Incomplete outcome data } \\
\text { (attrition bias) } \\
\text { All outcomes }\end{array}$ & Low risk & $\begin{array}{l}\text { Judgement comment: radiation group } 88 / 101(87.1 \%) \text { completed study } 7 \text { of } \\
\text { these protocol deviations. Sham therapy group } 95 / 104(91.3 \%) \text { completed } \\
\text { study. Detailed information given on loss to follow-up. Page } 2241 \text {, figure } 1 \text {. }\end{array}$ \\
\hline
\end{tabular}

Selective reporting (re- Unclear risk Judgement comment: no access to study protocol or trial registry entry.
porting bias)

\section{SFRADS 2002}

\section{Study characteristics}

Methods Parallel group RCT




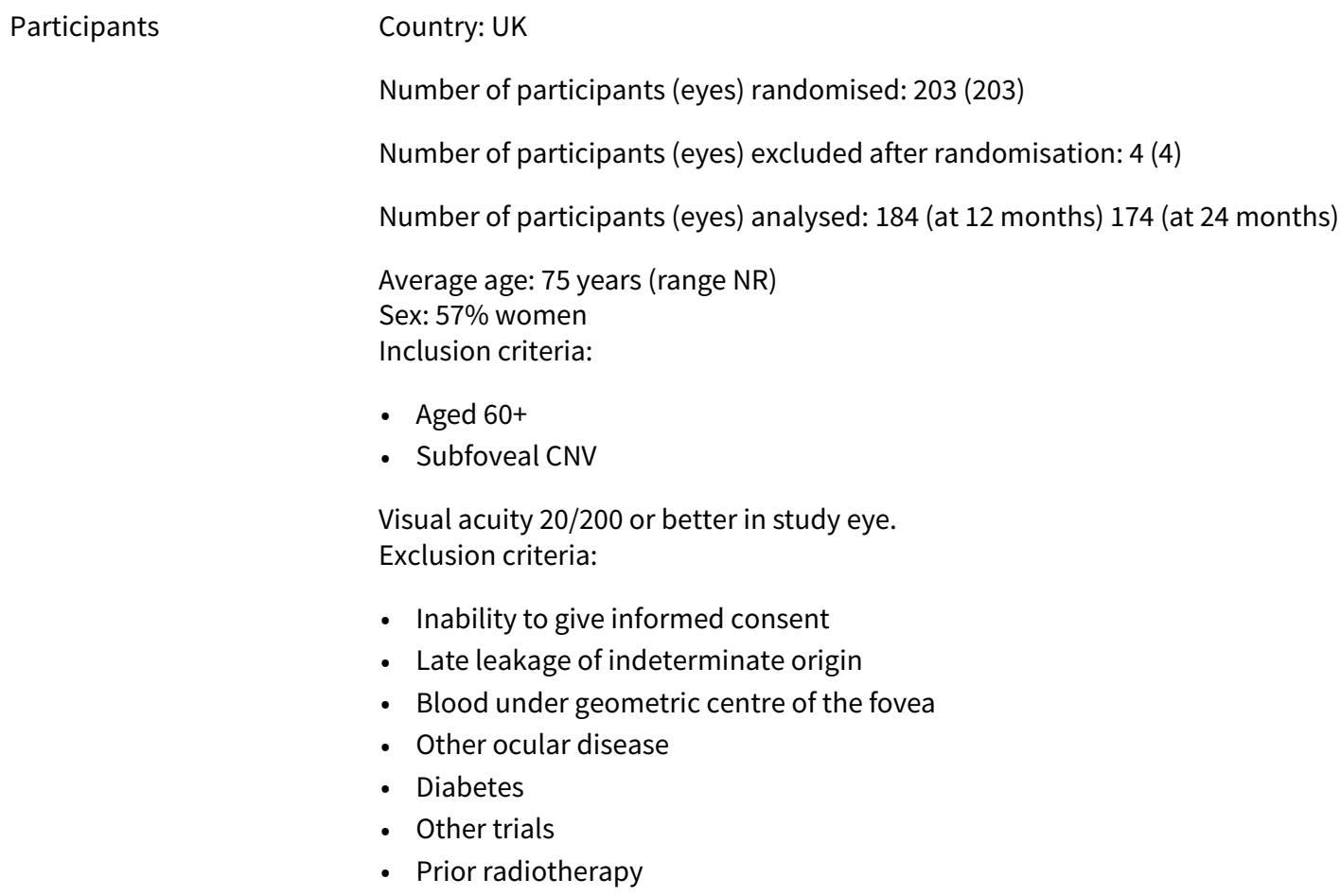

Participants

Country: UK

Number of participants (eyes) randomised: 203 (203)

Number of participants (eyes) excluded after randomisation: 4 (4)

Number of participants (eyes) analysed: 184 (at 12 months) 174 (at 24 months)

Average age: 75 years (range NR)

Sex: $57 \%$ women

Inclusion criteria:

- Aged 60+

- Subfoveal CNV

Visual acuity 20/200 or better in study eye.

Exclusion criteria:

- Inability to give informed consent

- Late leakage of indeterminate origin

- Blood under geometric centre of the fovea

- Other ocular disease

- Diabetes

- Other trials

- Prior radiotherapy

- External beam radiation therapy (6 fractions of $2 \mathrm{~Gy}$ )

- Duration: 6 consecutive working days

Comparator: $(n=100)^{\star}$

- Observation

Duration:

${ }^{\star}$ One control participant treated and included in intervention group; 4 protocol violations excluded.

\section{Outcomes}

Primary outcome:

- Loss of visual acuity at 12 and 24 months (logMAR, EDTRS)

Secondary:

- Near visual acuity (Bailey-Lovie chart)

- Contrast sensitivity

- Complications

- Quality of life

Follow-up: 3, 6, 12 and 24 months

Date conducted: November 1995 to July 1998

Sources of funding: Project grant G9404235 from Medical Research Council of the UIK.

Declaration of interest: NR 


\section{Risk of bias}

\begin{tabular}{|c|c|c|}
\hline Bias & Authors' judgement & Support for judgement \\
\hline $\begin{array}{l}\text { Random sequence genera- } \\
\text { tion (selection bias) }\end{array}$ & Low risk & $\begin{array}{l}\text { Quote: "To ensure balance within each of the } 3 \text { centers, the randomization was } \\
\text { blocked." Hart et al, page } 1031 \text {. }\end{array}$ \\
\hline $\begin{array}{l}\text { Allocation concealment } \\
\text { (selection bias) }\end{array}$ & Low risk & $\begin{array}{l}\text { Quote: "The randomization code was kept at the coordinating center (Belfast) } \\
\text { and released by telephone on receipt of patient details."Hart et al, page } \\
\text { 1030/1031. }\end{array}$ \\
\hline \multirow{2}{*}{$\begin{array}{l}\text { Blinding of participants } \\
\text { and personnel (perfor- } \\
\text { mance bias) } \\
\text { Visual acuity }\end{array}$} & High risk & $\begin{array}{l}\text { Quote: "The optometrists who undertook visual assessments were unaware of } \\
\text { the treatment status of the patients; however, neither the treating physicians } \\
\text { nor the patients were masked". Hart et al, page } 1030\end{array}$ \\
\hline & & $\begin{array}{l}\text { Judgement comment: participants and personnel were not masked which } \\
\text { may have affected the visual acuity outcome. }\end{array}$ \\
\hline $\begin{array}{l}\text { Blinding of participants } \\
\text { and personnel (perfor- } \\
\text { mance bias) } \\
\text { Lesion size on fluorescein } \\
\text { angiography }\end{array}$ & Unclear risk & Judgement comment: outcome not reported so far. \\
\hline \multirow[t]{2}{*}{$\begin{array}{l}\text { Blinding of outcome as- } \\
\text { sessment (detection bias) } \\
\text { Visual acuity }\end{array}$} & High risk & $\begin{array}{l}\text { Quote: "The optometrists who undertook visual assessments were unaware of } \\
\text { the treatment status of the patients; however, neither the treating physicians } \\
\text { nor the patients were masked". Hart et al, page } 1030\end{array}$ \\
\hline & & $\begin{array}{l}\text { Judgement comment: although visual acuity assessment was masked to treat- } \\
\text { ment group, physicians and patients were not. It is possible that an individ- } \\
\text { ual's performance on the visual acuity test could be influenced by their per- } \\
\text { ceptions as to which treatment they received. }\end{array}$ \\
\hline
\end{tabular}

Blinding of outcome as- Unclear risk Judgement comment: outcome not reported so far.
sessment (detection bias) Lesion size on fluorescein angiography

\begin{tabular}{|c|c|c|}
\hline $\begin{array}{l}\text { Incomplete outcome data } \\
\text { (attrition bias) } \\
\text { All outcomes }\end{array}$ & Unclear risk & $\begin{array}{l}\text { Judgement comment: } 101 \text { allocated to treatment } 102 \text { to observation. 93/101 } \\
\text { and } 91 / 100 \text { seen at } 12 \text { months. Not very good documentation for reasons for } \\
\text { no follow-up. }\end{array}$ \\
\hline
\end{tabular}

Selective reporting (re- Low risk Judgement comment: trials registry outcomes reported
porting bias)

\section{Valmaggia 2002}

\section{Study characteristics}

\begin{tabular}{ll}
\hline Methods & Parallel group RCT \\
& One eye per person, unclear how selected
\end{tabular}

Participants

Country: Switzerland. 
Number of participants (eyes) randomised: 161 (161)

Number of participants (eyes) excluded after randomisation: NR

Number of participants (eyes) analysed: 150 (6 months) 139 (12 months) 137 (18 months)

Average age: 75 years (range NR)

Sex: $58 \%$ women

Inclusion criteria:

- Subfoveal CNV in AMD

- Rapid worsening of visual acuity, a central scotoma, or metamorphopsia

Exclusion criteria:

- Foveal haemorrhage

- Severe haemorrhage or serous PED impeding measurement of CNV

- Preexisting ocular disease (glaucoma, severe myopia, diabetic retinopathy).

Interventions Intervention 1: $(n=52)$

- External beam radiation therapy (4 fractions of $4 \mathrm{~Gy}$ )

Intervention 2: $(\mathrm{n}=57)$

- External beam radiation therapy (4 fractions of $2 \mathrm{~Gy}$ )

Comparator: $(n=52)$

- External beam radiation therapy (4 fractions of $0.25 \mathrm{~Gy}$ )

Duration: 4 days.

Outcomes

Primary: NR

Secondary: NR

Reported:

- BCVA (logmAR)

- Reading ability

- Radiation-associated side effects (ocular irritation, conjunctivitis, cataract, radiation retinopathy, radiation optic neuropathy)

Follow-up: 6, 12 and 18 months

Sources of funding: NR

Declaration of interest: NR

Trial id: NR

\section{Risk of bias}

\section{Bias}

Authors' judgement Support for judgement

Random sequence genera- Unclear risk tion (selection bias)
Quote: "The patients were stratified in four different subgroups according to the CNV type, size and duration of the symptoms" Page 522

Quote: "According to the stratification, patients were randomized and treated in the Department of Radiation-Oncology." Page 522 
Valmaggia 2002 (Continued)

Judgement comment: not clear how the allocation schedule was generated.

$\begin{array}{ll}\text { Allocation concealment } \quad \text { Low risk } & \text { Quote: "The collaborators in the Department of Ophthalmology and patients } \\ \text { (selection bias) } & \text { were not aware of the applied radiation dose. Colleagues in the Department of } \\ & \text { Radiation-Oncology were only informed about the eye to be treated and the } \\ & \text { stratification code." Page 522. }\end{array}$

$\begin{array}{ll}\text { Blinding of participants } & \text { Low risk } \\ \text { and personnel (perfor- } & \text { were not aware of the applied radiation dose." Page } 522\end{array}$

mance bias)

Visual acuity

\begin{tabular}{|c|c|c|}
\hline $\begin{array}{l}\text { Blinding of participants } \\
\text { and personnel (perfor- } \\
\text { mance bias) } \\
\text { Lesion size on fluorescein } \\
\text { angiography }\end{array}$ & Low risk & $\begin{array}{l}\text { Quote: "The collaborators in the Department of Ophthalmology and patients } \\
\text { were not aware of the applied radiation dose." Page } 522\end{array}$ \\
\hline $\begin{array}{l}\text { Blinding of outcome as- } \\
\text { sessment (detection bias) } \\
\text { Visual acuity }\end{array}$ & Low risk & $\begin{array}{l}\text { Quote: "The collaborators in the Department of Ophthalmology and patients } \\
\text { were not aware of the applied radiation dose." Page } 522\end{array}$ \\
\hline $\begin{array}{l}\text { Blinding of outcome as- } \\
\text { sessment (detection bias) } \\
\text { Lesion size on fluorescein } \\
\text { angiography }\end{array}$ & Low risk & $\begin{array}{l}\text { Quote: "The collaborators in the Department of Ophthalmology and patients } \\
\text { were not aware of the applied radiation dose." Page } 522\end{array}$ \\
\hline $\begin{array}{l}\text { Incomplete outcome data } \\
\text { (attrition bias) } \\
\text { All outcomes }\end{array}$ & Unclear risk & $\begin{array}{l}\text { Judgement comment: control group } 44 / 52(85 \%) \text { seen at } 12 \text { months; } 8 \text { Gy } \\
\text { group } 52 / 57(91 \%) \text { seen at } 12 \text { months; } 16 \text { Gy group } 43(83 \%) \text { seen at } 12 \text { months. } \\
\text { Page } 524 \text {, table } 2 .\end{array}$ \\
\hline $\begin{array}{l}\text { Selective reporting (re- } \\
\text { porting bias) }\end{array}$ & Unclear risk & Judgement comment: no access to study protocol or trial registry entry. \\
\hline
\end{tabular}

AMD: age-related macular degeneration

ARM: age-related maculopathy

CNV: choroidal neovascularisation

CRT: central retinal thickness

ETDRS: Early Treatment of Diabetic Retinopathy Study

FFA: fundus fluorescein angiography

Gy: gray

NR: Not reported

OCT: optical coherence tomography

PDT: photodynamic therapy

PED: pigment epithelial detachment

PRN: pro re nata

Characteristics of excluded studies [ordered by study ID]

\begin{tabular}{ll}
\hline Study & Reason for exclusion \\
\hline Avila 2009 & Not a randomised controlled trial. \\
\hline Barak 2005 & No control group. \\
\hline Bergink 1995 & Treatment groups probably not randomly allocated. \\
\hline \hline
\end{tabular}

Radiotherapy for neovascular age-related macular degeneration (Review) 


\begin{tabular}{|c|c|}
\hline Study & Reason for exclusion \\
\hline Brown 1997 & Treatment groups allocated sequentially. \\
\hline Churei 2004 & Treatment groups not randomly allocated. \\
\hline Eter 2001 & One eye treated and fellow eye served as a control. Unclear whether first eye treated randomly. \\
\hline Friedrichsen 1996 & Abstract only reporting two different doses of radiotherapy \\
\hline Heier 2008 & Avastin but not radiotherapy allocated randomly. \\
\hline Honjo 1997 & Treatment groups probably not randomly allocated. \\
\hline Jackson 2012 & Not a report of a randomised controlled trial \\
\hline Mandai 1998 & Treatment groups probably not randomly allocated. \\
\hline Mandai 2000 & Retrospective study - groups not allocated randomly. \\
\hline Marcus 2004 & Non-randomised dose escalation study. \\
\hline Matsuhashi 1996 & Treatment groups not allocated randomly. \\
\hline Matsuhashi 2000 & $\begin{array}{l}\text { Treatment groups not allocated randomly. Control group consisted of people who had refused ra- } \\
\text { diation or laser treatment. }\end{array}$ \\
\hline NCT01833325 & Single group assignment \\
\hline Postgens 1997 & Retrospective study - groups not allocated randomly. \\
\hline Reichel 2007 & All participants received radiotherapy, different regimen for anti-VEGF compared. \\
\hline Saric 2001 & Control group consisted of participants who had refused treatment. \\
\hline Taniguchi 1996 & Treatment and control groups probably not randomly allocated. \\
\hline Tholen 2000 & $\begin{array}{l}\text { This study initially began as an RCT but the trial was stopped because of radiogenic complications } \\
\text { in the high dose group ( } 36 \mathrm{~Gy} \text { ). The study was continued as a non-randomised study and the re- } \\
\text { ports did not distinguish randomised and non-randomised comparisons. }\end{array}$ \\
\hline Zambarakji 2006 & No untreated control group. \\
\hline
\end{tabular}

Characteristics of ongoing studies [ordered by study ID]

\section{STAR (NCT02243878)}

\begin{tabular}{ll}
\hline Study name & Stereotactic Radiotherapy for Wet AMD (STAR) \\
\hline Methods & Parallel group RCT \\
\hline Participants & Country: UK (10 hospitals) \\
& Estimated number of participants: 411 \\
& Ages: 50 years and above
\end{tabular}


Inclusion Criteria

1. Participants must have neovascularAMD in the study eye, for which they have received at least 3 prior intravitreal injections of either bevacizumab (Avastin), aflibercept (Eylea), ranibizumab (Lucentis), or pegaptanib (Macugen).

2. Participants must have received an anti-VEGF injection in the study eye within 3 months prior to enrolment.

3. Participants must require treatment with anti-VEGF therapy at the time of enrolment, due to OCT evidence of subretinal fluid and/or cystoid macular oedema, and a macular volume that is greater than the 95th percentile of normal for the SD-OCT machines used in the investigational sites.

4. Participants must be at least 50 years of age.

\section{Exclusion Criteria}

1. Disciform scarring that involves the fovea, in the study eye.

2. Geographic atrophy that involves the fovea, or an area of geographic atrophy that is more than 500 microns in greatest diameter, immediately adjacent to the fovea, in the study eye.

3. Visual acuity worse than 6/96 (24 ETDRS letters) in the study eye.

4. Lesion size greater than $4 \mathrm{~mm}$ in greatest linear dimension, or greater than $2 \mathrm{~mm}$ from the centre of the fovea to the furthest point on the lesion perimeter.

5. Distance from the centre of the fovea to the nearest edge of the optic disc less than $3 \mathrm{~mm}$ in the study eye (this distance is confirmed by the Oraya SRT device software immediately prior to treatment).

6. An axial length of less than $20 \mathrm{~mm}$, or greater than $26 \mathrm{~mm}$, in the study eye.

7. Contraindication or sensitivity to contact lens application, including recurrent corneal erosions, in the study eye.

8. Type 1 or Type 2 diabetes mellitus.

9. Retinopathy in the study eye.

10.Prior or current therapies in the study eye for age-related macular degeneration, other than anti-VEGF agents, including submacular surgery, subfoveal thermal laser photocoagulation, photodynamic therapy (PDT), or transpupillary thermotherapy (TTT).

11.Presence of an intravitreal device in the study eye.

12.Previous radiation therapy to the study eye, head, or neck with the exception of radio-iodine treatment for hyperthyroidism, epimacular brachytherapy to the non-study eye, or Oraya SRT to the nonstudy eye.

13.Inadequate pupillary dilation or significant media opacities in the study eye, including cataract, which may interfere with visual acuity testing, the clinical evaluation of the posterior segment, or fundus imaging.

14. Likely to need cataract surgery in the study eye, within two years of enrolment.

15.Study eyes with CNV due to causes other than AMD, including presumed ocular histoplasmosis syndrome $(\mathrm{POH})$, angioid streaks, multifocal choroiditis, choroidal rupture, and pathological myopia (greater than 8 Dioptres spherical equivalent). Participants with retinal angiomatous proliferation (RAP) or idiopathic polypoidal choroidal vasculopathy (IPCV) are not excluded.

16.Known allergy to intravenous fluorescein, ICG or intravitreal ranibizumab.

17.Intraocular surgery or laser-assisted in situ keratomileusis (LASIK) in the study eye within 12 weeks prior to enrolment.

18. Prior pars plana vitrectomy in the study eye.

19.Current participation in another interventional clinical trial, or participation in such a clinical trial within the last six months.

20.Unwilling, unable, or unlikely to return for scheduled follow-up for the duration of the trial.

21. Women who are pregnant at the time of radiotherapy.

22.Participants with an implantable cardioverter defibrillator (ICD) or pacemaker implant (or any implanted device) where the device labelling specifically contraindicates patients undergoing X-ray. 
STAR (NCT02243878) (Continued)

23.Any other condition, which in the judgment of the investigator, would prevent the participant from granting informed consent or completing the study, such as dementia, and mental illness (including generalized anxiety disorder and claustrophobia)

\begin{tabular}{|c|c|}
\hline Interventions & $\begin{array}{l}\text { Intervention: } \\
\text { - Stereotactic radiotherapy ( } 16 \mathrm{~Gy}) \\
\text { - Intravitreal injections of } 0.5 \mathrm{mg} \text { ranibizumab ( } 1 \text { dose at baseline, then as needed up to monthly, } \\
\text { if predefined retreatment criteria are met) } \\
\text { Comparator: } \\
\text { - Sham stereotactic radiotherapy ( } 0 \text { Gy) } \\
\text { - Intravitreal injections of } 0.5 \mathrm{mg} \text { ranibizumab ( } 1 \text { dose at baseline, then as needed up to monthly, } \\
\text { if predefined retreatment criteria are met) }\end{array}$ \\
\hline Outcomes & $\begin{array}{l}<\text { from clnicaltrials.gov> } \\
\text { - Primary Outcome Measures: Number of as required (prn) ranibizumab injections during the first } 24 \\
\text { months } \\
\text { - Secondary Outcome Measures: Mean Early Treatment of Diabetic Retinopathy Study (ETDRS) visual } \\
\text { acuity (VA) at } 24 \text { months. }\end{array}$ \\
\hline Starting date & December 2014 to October 2022 \\
\hline Contact information & Timothy Jackson t.jackson1@nhs.net \\
\hline Notes & $\begin{array}{l}\text { www.starstudy.org.uk } \\
\text { www.clinicaltrials.gov/ct2/show/NCT02243878 } \\
\text { www.isrctn.com/ISRCTN12884465 }\end{array}$ \\
\hline
\end{tabular}

\section{DATA AND ANALYSES}

\section{Comparison 1. Radiation therapy versus control}

\begin{tabular}{|c|c|c|c|c|}
\hline Outcome or subgroup title & $\begin{array}{l}\text { No. of } \\
\text { studies }\end{array}$ & $\begin{array}{l}\text { No. of } \\
\text { partici- } \\
\text { pants }\end{array}$ & Statistical method & Effect size \\
\hline $\begin{array}{l}1.1 \text { Loss of } 3 \text { or more lines best-corrected } \\
\text { visual acuity lost at } 12 \text { months }\end{array}$ & 8 & 811 & Risk Ratio (M-H, Random, 95\% Cl) & $0.82[0.64,1.04]$ \\
\hline $\begin{array}{l}\text { 1.2 Three or more lines visual acuity lost } \\
\text { at } 24 \text { months }\end{array}$ & 4 & 654 & Risk Ratio (M-H, Random, 95\% Cl) & $0.78[0.63,0.97]$ \\
\hline 1.3 Change in BCVA at 12 months & 10 & 883 & $\begin{array}{l}\text { Mean Difference (IV, Random, 95\% } \\
\mathrm{CI} \text { ) }\end{array}$ & $-0.10[-0.17,-0.03]$ \\
\hline 1.3.1 Change in visual acuity & 7 & 771 & $\begin{array}{l}\text { Mean Difference (IV, Random, 95\% } \\
\mathrm{CI})\end{array}$ & $-0.09[-0.16,-0.02]$ \\
\hline 1.3.2 Final value & 3 & 112 & $\begin{array}{l}\text { Mean Difference (IV, Random, 95\% } \\
\mathrm{CI} \text { ) }\end{array}$ & $-0.17[-0.41,0.08]$ \\
\hline
\end{tabular}




\begin{tabular}{llllll}
\hline Outcome or subgroup title & $\begin{array}{l}\text { No. of } \\
\text { studies }\end{array}$ & $\begin{array}{l}\text { No. of } \\
\text { partici- } \\
\text { pants }\end{array}$ & Statistical method & Effect size \\
\hline 1.4 Change in BCVA at 24 months & 6 & 516 & $\begin{array}{l}\text { Mean Difference (IV, Random, 95\% } \\
\text { Cl) }\end{array}$ & -0.09 [-0.15, -0.03] \\
\hline 1.5 Change in contrast sensitivity & 2 & Mean Difference (IV, Fixed, 95\% Cl) & Subtotals only \\
\hline 1.5 .112 months & 2 & 267 & Mean Difference (IV, Fixed, 95\% Cl) & $0.15[0.05,0.25]$ \\
\hline 1.5 .2 24 months & 2 & 257 & Mean Difference (IV, Fixed, 95\% Cl) & $0.11[0.00,0.22]$ \\
\hline 1.6 Contrast sensitivity raw data & 1 & & Mean Difference (IV, Fixed, 95\% Cl) & Subtotals only \\
\hline 1.6 .112 months & 1 & 83 & Mean Difference (IV, Fixed, 95\% Cl) & $-0.22[-0.38,-0.06]$ \\
\hline 1.6 .2 24 months & 1 & 82 & Mean Difference (IV, Fixed, 95\% Cl) & $-0.22[-0.41,-0.03]$ \\
\hline
\end{tabular}

\section{Analysis 1.1. Comparison 1: Radiation therapy versus control, Outcome 1: Loss of 3 or more lines best-corrected visual acuity lost at 12 months}

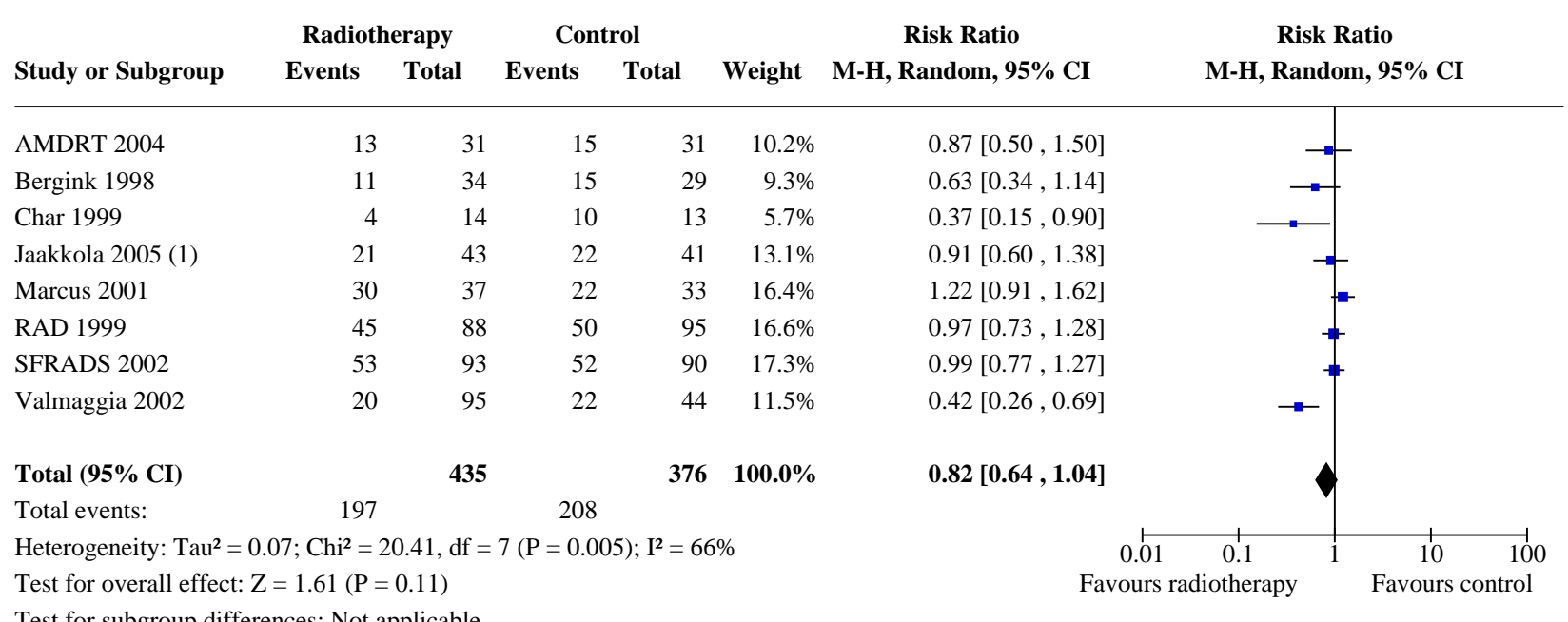

Footnotes

(1) Brachytherapy 
Analysis 1.2. Comparison 1: Radiation therapy versus control, Outcome 2: Three or more lines visual acuity lost at 24 months

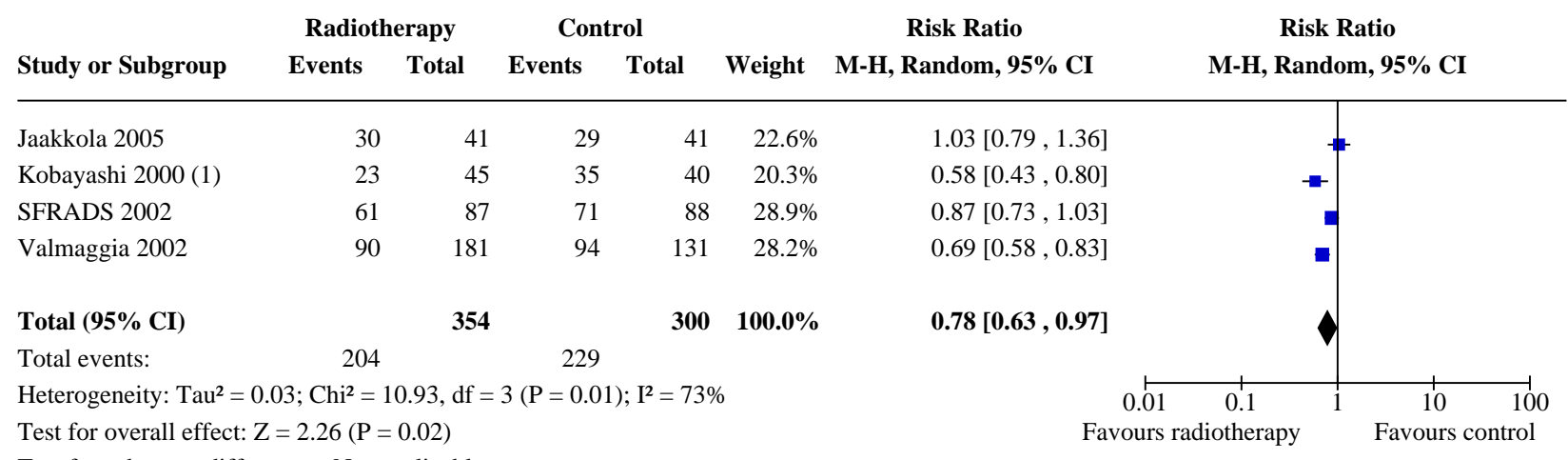

Footnotes

(1) Brachytherapy

\section{Analysis 1.3. Comparison 1: Radiation therapy versus control, Outcome 3: Change in BCVA at 12 months}

\begin{tabular}{|c|c|c|c|c|c|c|c|}
\hline Study or Subgroup & MD & SE & $\begin{array}{c}\text { Radiation therapy } \\
\text { Total }\end{array}$ & $\begin{array}{c}\text { Control } \\
\text { Total }\end{array}$ & Weight & $\begin{array}{c}\text { Mean Difference } \\
\text { IV, Random, 95\% CI }\end{array}$ & $\begin{array}{c}\text { Mean Difference } \\
\text { IV, Random, 95\% CI }\end{array}$ \\
\hline
\end{tabular}

1.3.1 Change in visual acuity

$\begin{array}{lrrrrrr}\text { Char 1999 } & -0.32 & 0.1696 & 14 & 13 & 3.7 \% & -0.32[-0.65,0.01] \\ \text { Jaakkola 2005 (1) } & -0.137 & 0.077816 & 42 & 41 & 10.8 \% & -0.14[-0.29,0.02] \\ \text { Kobayashi 2000 } & -0.196 & 0.063467 & 45 & 40 & 13.0 \% & -0.20[-0.32,-0.07] \\ \text { Marcus 2001 } & 0.075 & 0.079 & 37 & 33 & 10.6 \% & 0.07[-0.08,0.23] \\ \text { RAD 1999 } & -0.02 & 0.063484 & 88 & 95 & 13.0 \% & -0.02[-0.14,0.10] \\ \text { SFRADS 2002 } & -0.06 & 0.055 & 93 & 91 & 14.5 \% & -0.06[-0.17,0.05] \\ \text { Valmaggia 2002 } & -0.1213 & 0.0579 & 95 & 44 & 14.0 \% & -0.12[-0.23,-0.01] \\ \text { Subtotal (95\% CI) } & & & \mathbf{4 1 4} & \mathbf{3 5 7} & \mathbf{7 9 . 5 \%} & \mathbf{- 0 . 0 9}[-\mathbf{0 . 1 6}, \mathbf{- 0 . 0 2}]\end{array}$

Heterogeneity: $\mathrm{Tau}^{2}=0.00 ; \mathrm{Chi}^{2}=11.16, \mathrm{df}=6(\mathrm{P}=0.08) ; \mathrm{I}^{2}=46 \%$

Test for overall effect: $\mathrm{Z}=2.45(\mathrm{P}=0.01)$

\subsubsection{Final value}

Anders 1998

$\begin{array}{rr}-0.287 & 0.1195 \\ 0.02 & 0.0753\end{array}$

0.1195

$-0.33-0.1883$

19

Ciulla 2002

Subtotal $(\mathbf{9 5 \%}$ CI)

Heterogeneity: $\mathrm{Tau}^{2}=0.03 ; \mathrm{Chi}^{2}=6.47, \mathrm{df}=2(\mathrm{P}=0.04) ; \mathrm{I}^{2}=69 \%$

Test for overall effect: $\mathrm{Z}=1.33(\mathrm{P}=0.18)$

Total $(95 \%$ CI $)$

479

Heterogeneity: $\mathrm{Tau}^{2}=0.01 ; \mathrm{Chi}^{2}=17.64, \mathrm{df}=9(\mathrm{P}=0.04) ; \mathrm{I}^{2}=49 \%$

Test for overall effect: $\mathrm{Z}=2.77(\mathrm{P}=0.006)$

Test for subgroup differences: $\mathrm{Chi}^{2}=0.35, \mathrm{df}=1(\mathrm{P}=0.55), \mathrm{I}^{2}=0 \%$

$404-100.0 \% \quad-0.10[-0.17,-0.03]$

$$
\begin{array}{r}
-0.29[-0.52,-0.05] \\
0.02[-0.13,0.17] \\
-0.33[-0.70,0.04] \\
\mathbf{- 0 . 1 7}[\mathbf{- 0 . 4 1 , 0 . 0 8}]
\end{array}
$$

\section{Footnotes}

(1) Brachytherapy 
Analysis 1.4. Comparison 1: Radiation therapy versus control, Outcome 4: Change in BCVA at 24 months

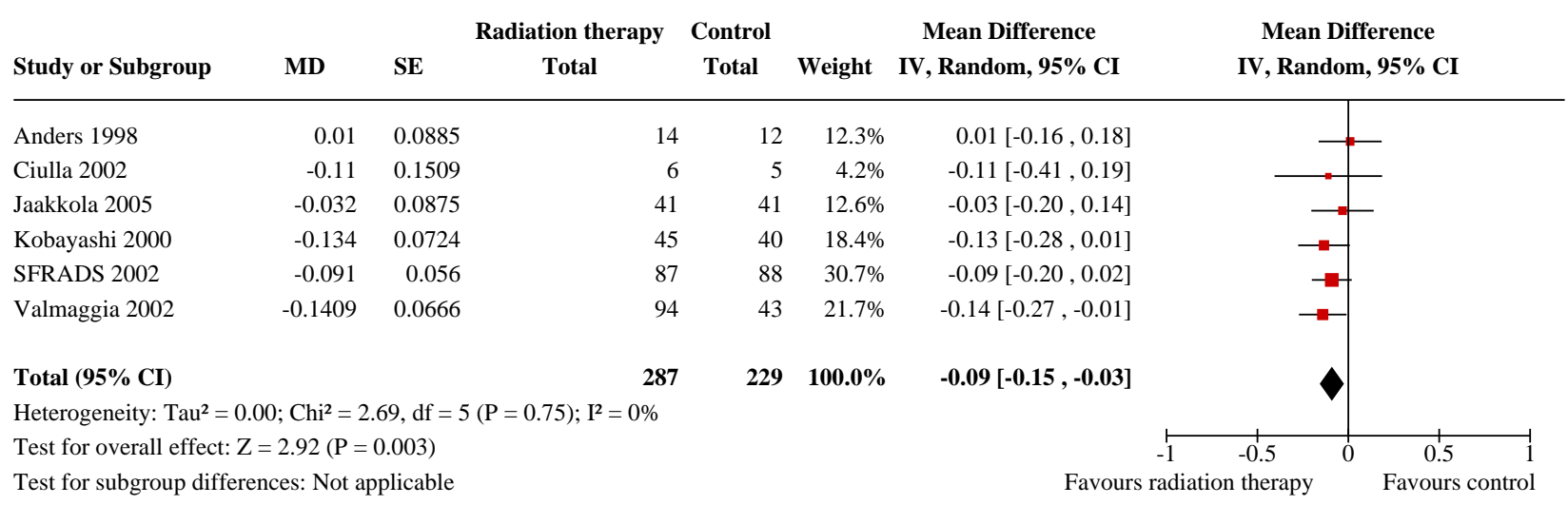

\section{Analysis 1.5. Comparison 1: Radiation therapy versus control, Outcome 5: Change in contrast sensitivity}

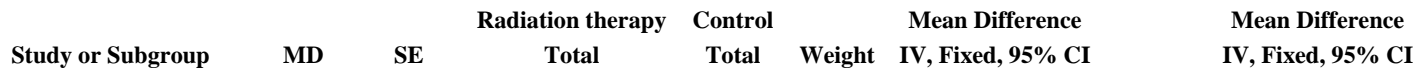

\begin{tabular}{lrrrrrr}
\hline $\mathbf{1 . 5 . 1} 12$ months & & & & & & \\
Jaakkola 2005 & 0.22 & 0.08235 & 42 & 41 & $38.4 \%$ & $0.22[0.06,0.38]$ \\
SFRADS 2002 & 0.102 & 0.065 & 93 & 91 & $61.6 \%$ & $0.10[-0.03,0.23]$ \\
Subtotal (95\% CI) & & & $\mathbf{1 3 5}$ & $\mathbf{1 3 2}$ & $\mathbf{1 0 0 . 0 \%}$ & $\mathbf{0 . 1 5}[\mathbf{0 . 0 5}, \mathbf{0 . 2 5}]$
\end{tabular}

Subtotal (95\% CI)

Heterogeneity: $\mathrm{Chi}^{2}=1.27, \mathrm{df}=1(\mathrm{P}=0.26) ; \mathrm{I}^{2}=21 \%$

Test for overall effect: $\mathrm{Z}=2.89(\mathrm{P}=0.004)$

\subsubsection{4 months}

SFRADS 2002

Subtotal $(95 \%$ CI $)$

df $=1(\mathrm{P}=0.15) ; \mathrm{I}^{2}=53 \%$

Heterogeneity: $\mathrm{Chi}^{2}=2.11, \mathrm{df}=1(\mathrm{P}=0.15) ; \mathrm{I}^{2}=53 \%$

Test for overall effect: $\mathrm{Z}=1.98(\mathrm{P}=0.05)$

Test for subgroup differences: $\mathrm{Chi}^{2}=0.27, \mathrm{df}=1(\mathrm{P}=0.60), \mathrm{I}^{2}=0 \%$

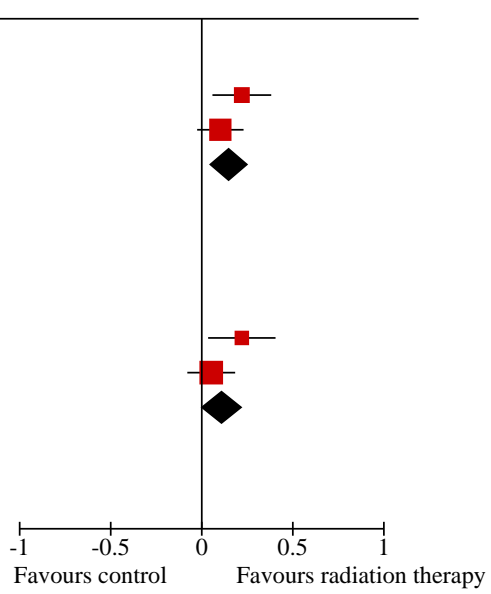

Analysis 1.6. Comparison 1: Radiation therapy versus control, Outcome 6: Contrast sensitivity raw data

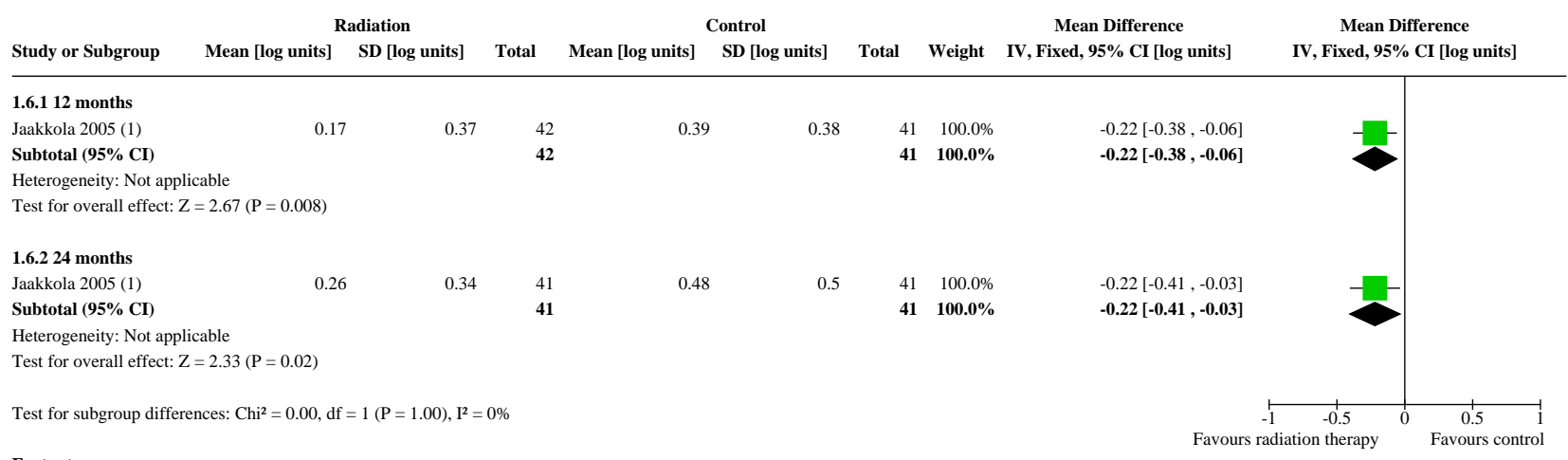

Footnotes

(1) Change (decrease) in mean contrast sensitivity from baseline (nb Mann Whitney U test) 
Comparison 2. Radiation therapy with anti-VEGF versus anti-VEGF alone

\begin{tabular}{|c|c|c|c|c|}
\hline Outcome or subgroup title & $\begin{array}{l}\text { No. of } \\
\text { studies }\end{array}$ & $\begin{array}{l}\text { No. of } \\
\text { partici- } \\
\text { pants }\end{array}$ & Statistical method & Effect size \\
\hline $\begin{array}{l}2.1 \text { Three or more lines visual acuity } \\
\text { lost at } 12 \text { months }\end{array}$ & 3 & 1050 & Risk Ratio (M-H, Fixed, 95\% Cl) & $2.11[1.40,3.17]$ \\
\hline 2.1.1 Epimacular brachytherapy & 2 & 820 & Risk Ratio (M-H, Fixed, 95\% Cl) & $2.36[1.49,3.74]$ \\
\hline 2.1.2 Stereotactic radiotherapy & 1 & 230 & Risk Ratio (M-H, Fixed, 95\% Cl) & $1.24[0.50,3.11]$ \\
\hline $\begin{array}{l}2.2 \text { Three or more lines visual acuity } \\
\text { lost at } 24 \text { months }\end{array}$ & 2 & 820 & Risk Ratio (M-H, Fixed, 95\% Cl) & $2.39[1.68,3.39]$ \\
\hline 2.3 Change in BCVA at 12 months & 4 & 1072 & Mean Difference (IV, Random, 95\% CI) & $0.05[-0.03,0.13]$ \\
\hline 2.3.1 Epimacular brachytherapy & 2 & 820 & Mean Difference (IV, Random, 95\% CI) & $0.10[0.05,0.15]$ \\
\hline 2.3.2 External beam radiotherapy & 2 & 252 & Mean Difference (IV, Random, 95\% CI) & $-0.03[-0.09,0.03]$ \\
\hline 2.4 Change in BCVA at 24 months & 2 & 819 & Mean Difference (IV, Random, 95\% CI) & $0.17[0.11,0.23]$ \\
\hline
\end{tabular}

Analysis 2.1. Comparison 2: Radiation therapy with anti-VEGF versus anti-
VEGF alone, Outcome 1: Three or more lines visual acuity lost at 12 months

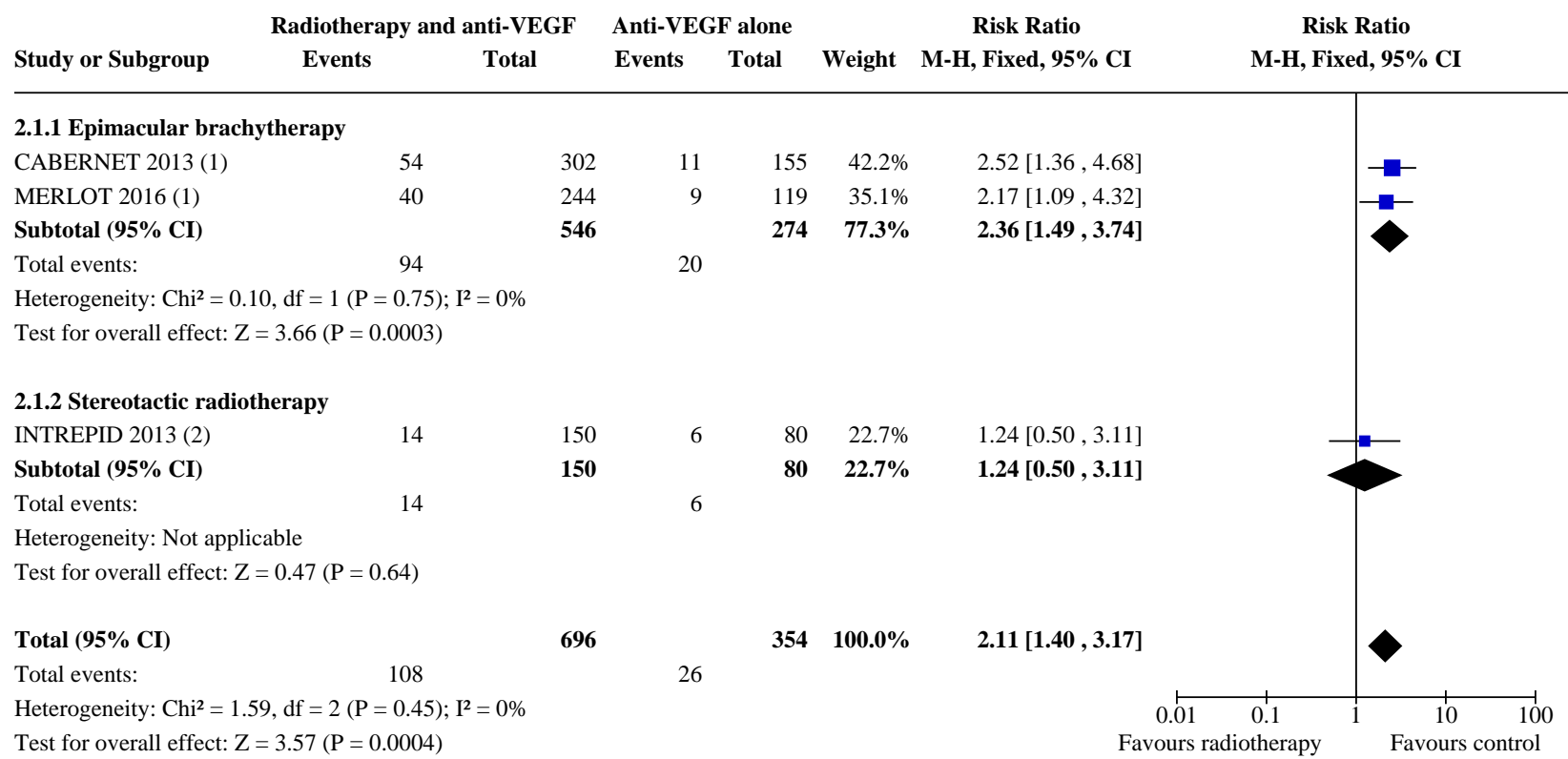

Test for subgroup differences: $\mathrm{Chi}^{2}=1.49, \mathrm{df}=1(\mathrm{P}=0.22), \mathrm{I}^{2}=33.1 \%$

Footnotes

(1) Epimacular brachytherapy

(2) Stereotactic radiotherapy 
Analysis 2.2. Comparison 2: Radiation therapy with anti-VEGF versus antiVEGF alone, Outcome 2: Three or more lines visual acuity lost at 24 months

\begin{tabular}{|c|c|c|c|c|c|c|c|}
\hline \multirow{2}{*}{ Study or Subgroup } & \multicolumn{2}{|c|}{ Radiotherapy and anti-VEGF } & \multicolumn{2}{|c|}{ Anti-VEGF alone } & \multicolumn{2}{|r|}{ Risk Ratio } & \multirow{2}{*}{$\begin{array}{c}\text { Risk Ratio } \\
\text { M-H, Fixed, 95\% CI }\end{array}$} \\
\hline & Events & Total & Events & Total & Weight & M-H, Fixed, 95\% CI & \\
\hline
\end{tabular}

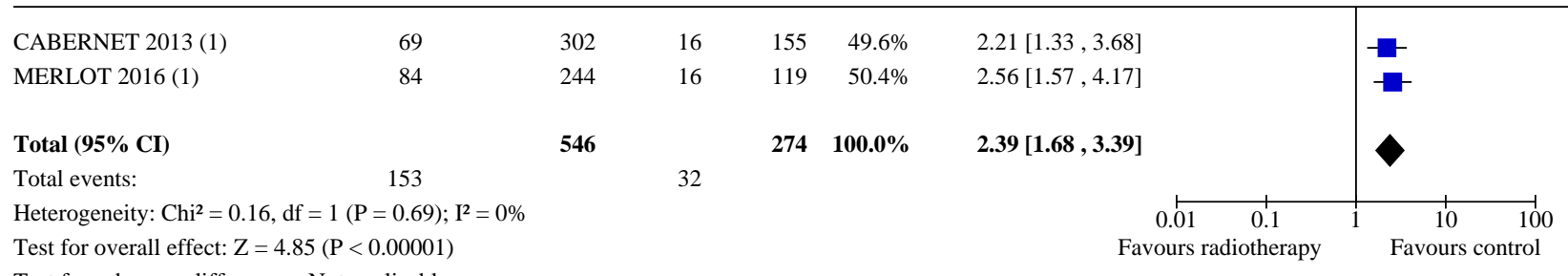

Test for subgroup differences: Not applicable

Footnotes

(1) Epimacular brachytherapy

Analysis 2.3. Comparison 2: Radiation therapy with anti-VEGF versus anti-VEGF alone, Outcome 3: Change in BCVA at 12 months

\begin{tabular}{|c|c|c|c|c|c|c|c|c|c|c|}
\hline Study or Subgroup & \multicolumn{3}{|c|}{ Radiotherapy and anti-VEGF } & \multicolumn{3}{|c|}{ Anti-VEGF alone } & Weight & Mean Difference & \multicolumn{2}{|c|}{$\begin{array}{c}\text { Mean Difference } \\
\text { IV, Random, 95\% CI [logMAR] }\end{array}$} \\
\hline \multicolumn{11}{|c|}{ 2.3.1 Epimacular brachytherapy } \\
\hline CABERNET 2013 & 0.01 & 0.326 & 302 & -0.12 & 0.278 & 155 & $29.6 \%$ & $0.13[0.07,0.19]$ & & $=$ \\
\hline MERLOT 2016 & 0.096 & 0.216 & 244 & 0.018 & 0.194 & 119 & $31.6 \%$ & $0.08[0.03,0.12]$ & & $=$ \\
\hline Subtotal $(95 \%$ CI $)$ & & & 546 & & & 274 & $61.2 \%$ & $0.10[0.05,0.15]$ & & $\Delta$ \\
\hline \multicolumn{11}{|c|}{$\begin{array}{l}\text { Heterogeneity: } \mathrm{Tau}^{2}=0.00 ; \mathrm{Chi}^{2}=1.99, \mathrm{df}=1(\mathrm{P}=0.16) ; \mathrm{I}^{2}=50 \% \\
\text { Test for overall effect: } \mathrm{Z}=3.90(\mathrm{P}<0.0001)\end{array}$} \\
\hline \multicolumn{11}{|c|}{ 2.3.2 External beam radiotherapy } \\
\hline INTREPID 2013 (1) & -0.0012 & 0.1911 & 150 & 0.0314 & 0.238 & 80 & $29.1 \%$ & $-0.03[-0.09,0.03]$ & & . \\
\hline Osmanovic 2017 & -0.175 & 0.25 & 14 & -0.14 & 0.25 & 8 & $9.7 \%$ & $-0.03[-0.25,0.18]$ & & + \\
\hline Subtotal $(95 \%$ CI $)$ & & & 164 & & & 88 & $38.8 \%$ & $-0.03[-0.09,0.03]$ & & 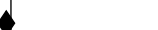 \\
\hline \multicolumn{11}{|c|}{$\begin{array}{l}\text { Heterogeneity: } \mathrm{Tau}^{2}=0.00 ; \mathrm{Ch}^{2}=0.00, \mathrm{df}=1(\mathrm{P}=0.98) ; \mathrm{I}^{2}=0 \% \\
\text { Test for overall effect: } \mathrm{Z}=1.10(\mathrm{P}=0.27)\end{array}$} \\
\hline Total $(95 \% \mathrm{CI})$ & & & 710 & & & 362 & $100.0 \%$ & $0.05[-0.03,0.13]$ & & 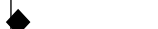 \\
\hline \multicolumn{11}{|c|}{ Heterogeneity: $\mathrm{Tau}^{2}=0.00 ; \mathrm{Chi}^{2}=16.11, \mathrm{df}=3(\mathrm{P}=0.001) ; \mathrm{I}^{2}=81 \%$} \\
\hline Test for overall effect & $\mathrm{Z}=1.24(\mathrm{P}=0.22)$ & & & & & & & & -0.5 & 0.5 \\
\hline Test for subgroup diff & ences: $\mathrm{Chi}^{2}=11.51, \mathrm{c}$ & $\mathrm{df}=1(\mathrm{P}=0.0007$ & $\mathrm{I}^{2}=91.3 \%$ & & & & & Favo & ours radiotherapy & Favours control \\
\hline
\end{tabular}

Analysis 2.4. Comparison 2: Radiation therapy with anti-VEGF versus anti-VEGF alone, Outcome 4: Change in BCVA at 24 months

\begin{tabular}{|c|c|c|c|c|c|c|c|c|c|c|}
\hline \multirow[b]{2}{*}{ Study or Subgroup } & \multicolumn{3}{|c|}{ Radiotherapy and anti-VEGF } & \multicolumn{3}{|c|}{ Anti-VEGF alone } & \multicolumn{2}{|r|}{ Mean Difference } & \multicolumn{2}{|c|}{ Mean Difference } \\
\hline & Mean [logMAR] & SD [logMAR] & Total & Mean [logMAR] & SD [logMAR] & Total & Weight & IV, Random, 95\% CI [logMAR] & IV, Random, & $5 \%$ CI [logMAR] \\
\hline CABERNET 2013 (1) & 0.05 & 0.328 & 302 & -0.088 & 0.35 & 155 & $44.9 \%$ & $0.14[0.07,0.20]$ & & 릅 \\
\hline MERLOT 2016 (1) & 0.224 & 0.314 & 243 & 0.028 & 0.218 & 119 & $55.1 \%$ & $0.20[0.14,0.25]$ & & $\square$ \\
\hline Total $(95 \% \mathrm{CI})$ & & & 545 & & & 274 & $100.0 \%$ & $0.17[0.11,0.23]$ & & $\Delta$ \\
\hline Heterogeneity: $\mathrm{Tau}^{2}=0$ & $00 ; \mathrm{Chi}^{2}=1.72, \mathrm{df}=$ & $=1(\mathrm{P}=0.19) ; \mathrm{I}^{2}=$ & & & & & & & & \\
\hline Test for overall effect: Z & $=5.89(\mathrm{P}<0.00001)$ & & & & & & & & -0.5 & 0.5 \\
\hline Test for subgroup differ & ences: Not applicable & & & & & & & Fav & surs radiotherapy & Favours control \\
\hline
\end{tabular}

\section{ADDITIONAL TABLES}




\begin{tabular}{|c|c|c|c|c|c|c|c|c|c|}
\hline & $\begin{array}{l}\text { Review edi- } \\
\text { tion study } \\
\text { first included }\end{array}$ & Study name & Country & Funding & $\begin{array}{l}\text { Number } \\
\text { of peo- } \\
\text { ple ran- } \\
\text { domised }\end{array}$ & $\begin{array}{l}\text { Num- } \\
\text { ber of } \\
\text { eyes ran- } \\
\text { domised }\end{array}$ & Note & $\begin{array}{l}\text { Aver- } \\
\text { age age } \\
\text { (years) }\end{array}$ & $\%$ female \\
\hline 1 & 2010 & AMDLTRSG 2003 & Japan & NR & 69 & 69 & Analysed & 72 & 30 \\
\hline 2 & 2010 & AMDRT 2004 & US & $\mathrm{NIH}$ & 88 & 88 & & 77 & 58 \\
\hline 3 & 2004 & Anders 1998 & Germany & NR & 76 & 76 & $\begin{array}{l}\text { unclear } \\
\text { how many } \\
\text { eyes }\end{array}$ & 77 & 67 \\
\hline 4 & 2004 & Bergink 1998 & The Netherlands & NR & 74 & 74 & & 75 & 56 \\
\hline 5 & 2019 & CABERNET 2013 & $\begin{array}{l}\text { US, Europe, Is- } \\
\text { rael, South Amer- } \\
\text { ica }\end{array}$ & $\begin{array}{l}\text { Manufac- } \\
\text { turer }\end{array}$ & 494 & 494 & & 77 & 68 \\
\hline 6 & 2004 & Char 1999 & US & NGO & 27 & 27 & & 76 & 52 \\
\hline 7 & 2004 & Ciulla 2002 & US & NGO & 37 & 37 & $\begin{array}{l}\text { unclear } \\
\text { how many } \\
\text { eyes }\end{array}$ & 71 & 38 \\
\hline 8 & 2004 & Eter 2002 & Germany & NR & 45 & 45 & & 74 & 57 \\
\hline 9 & 2019 & INTREPID 2013 & Europe & $\begin{array}{l}\text { Manufac- } \\
\text { turer }\end{array}$ & 230 & 230 & & 74 & 69 \\
\hline 10 & 2010 & Jaakkola 2005 & Finland & NGO & 86 & 88 & & 76 & 60 \\
\hline 11 & 2004 & Kacperek 2001 & UK & $N R$ & 58 & 58 & $\begin{array}{l}\text { unclear } \\
\text { how many } \\
\text { eyes }\end{array}$ & 76 & 61 \\
\hline 12 & 2004 & Kobayashi 2000 & Japan & NGO & 101 & 101 & & 72 & 64 \\
\hline 13 & 2004 & Marcus 2001 & US & NGO & 83 & 83 & & 76 & 61 \\
\hline 14 & 2019 & MERLOT & UK & $\begin{array}{l}\text { Manufac- } \\
\text { turer }\end{array}$ & 363 & 363 & & 77 & 60 \\
\hline
\end{tabular}




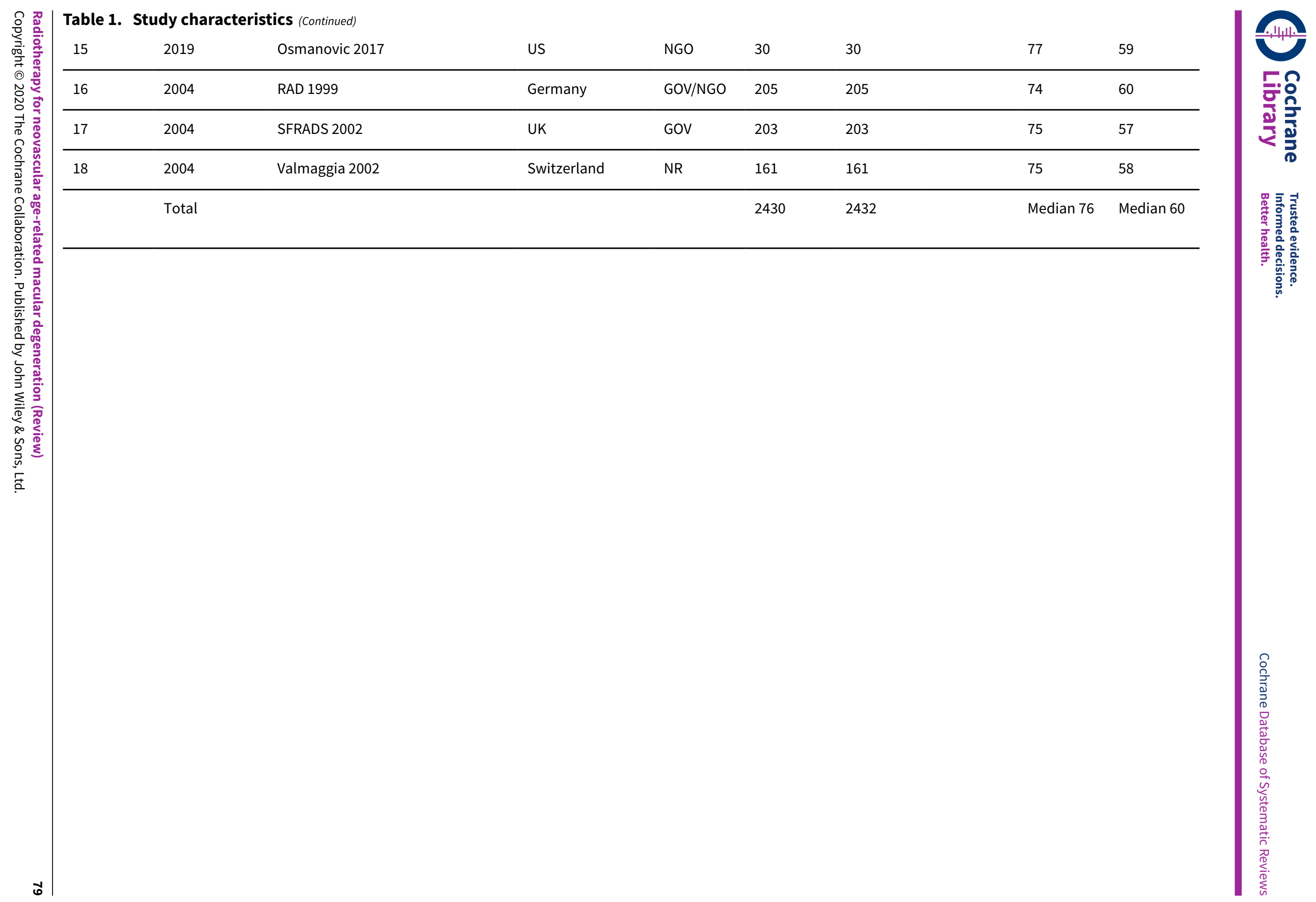


Table 2. Type of choroidal neovascularisation

\begin{tabular}{|c|c|c|c|c|}
\hline & Study & $\%$ classic & $\%$ occult & $\%$ mixed \\
\hline 1 & AMDLRTSG 2003 & NR & & \\
\hline 2 & AMDRT 2004 & 18 (predominantly classic) & 21 & $\begin{array}{l}61 \text { (min- } \\
\text { imally } \\
\text { classic) }\end{array}$ \\
\hline 3 & Anders 1998 & NR & & \\
\hline 4 & Bergink 1998 & 52 & 24 & 25 \\
\hline 5 & CABERNET 2013 & 39 (predominantly classic) & 35 & 25 \\
\hline 6 & Char 1999 & 48 & 52 & \\
\hline 7 & Ciulla 2002 & 46 & 14 & 39 \\
\hline 8 & Eter 2002 & 37 & Mixed/occult $=$ & 63.0 \\
\hline 9 & INTREPID 2013 & NR & & \\
\hline
\end{tabular}

\begin{tabular}{|c|c|c|c|c|}
\hline 10 & Jaakkola 2005 & 40 ("a classic component") & \multicolumn{2}{|c|}{$\begin{array}{l}52 \text { ("occult no } \\
\text { classic") }\end{array}$} \\
\hline 11 & Kacperek 2001 & NR & & \\
\hline 12 & Kobayashi 2000 & 51 & 13 & 21 \\
\hline 13 & Marcus 2001 & 12 & 42 & 43 \\
\hline 14 & MERLOT 2016 & 12 & 75 & 12 \\
\hline 15 & Osmanovic 2017 & 50 & 50 & \\
\hline 16 & RAD 1999 & 38 & 62 & \\
\hline 17 & SFRADS 2002 & 52 & 2 & 43 \\
\hline 18 & Valmaggia 2002 & 57 & 43 & \\
\hline
\end{tabular}

NR: Not reported

Table 3. Characteristics of the intervention and comparator

\begin{tabular}{lllll}
\hline Study & $\begin{array}{l}\text { Total } \\
\text { dose (Gy) }\end{array}$ & $\begin{array}{l}\text { Number } \\
\text { of frac- } \\
\text { tions }\end{array}$ & Control & Comments \\
\hline
\end{tabular}


Table 3. Characteristics of the intervention and comparator (Continued)

\section{Trials of external beam radiotherapy}

\begin{tabular}{|c|c|c|c|c|}
\hline $\begin{array}{l}\text { INTREPID } \\
2013\end{array}$ & 24 and 16 & 1 & $\begin{array}{l}\text { Sham radiotherapy, } \\
\text { ranibizumab ( } 0.5 \mathrm{mg} \text { and } \mathrm{PRN})\end{array}$ & $\begin{array}{l}\text { Stereotactic radiotherapy; two arms receiving differ- } \\
\text { ent radiation dose; all groups received ranibizumab } \\
(0.5 \mathrm{mg} \text { and } \mathrm{PRN})\end{array}$ \\
\hline $\begin{array}{l}\text { Osmanovic } \\
2017\end{array}$ & 24 and 16 & 2 & $\begin{array}{l}\text { Sham radiotherapy, } \\
\text { ranibizumab or bevacizumab }\end{array}$ & $\begin{array}{l}\text { Two arms receiving different radiation dose; all } \\
\text { groups received ranibizumab or bevacizumab }\end{array}$ \\
\hline Bergink 1998 & 24 & 4 & Observation & \\
\hline AMDRT 2004 & 20 & 5 & $\begin{array}{l}\text { Observation and sham radio- } \\
\text { therapy }\end{array}$ & \\
\hline Eter 2002 & 20 & 10 & Observation & \\
\hline $\begin{array}{l}\text { Kobayashi } \\
2000\end{array}$ & 20 & 10 & Observation & \\
\hline $\begin{array}{l}\text { AMDLRTSG } \\
2003\end{array}$ & 20 & 10 & Observation & \\
\hline Kacperek 2001 & 18 & 4 & Observation & \\
\hline Ciulla 2002 & 16 & 2 & Sham irradiation & \\
\hline RAD 1999 & 16 & 8 & Sham irradiation (0 Gy) & \\
\hline Marcus 2001 & 14 & 7 & Sham irradiation & \\
\hline SFRADS 2002 & 12 & 6 & Observation & \\
\hline Anders 1998 & 12 & 6 & Observation & \\
\hline $\begin{array}{l}\text { Valmaggia } \\
2002\end{array}$ & 8 & 4 & Low dose irradiation (1 Gy) & \\
\hline Char 1999 & 7.5 & 1 & Observation & \\
\hline
\end{tabular}

\section{Trials of brachytherapy (radiation source placed near the lesion)}

$\begin{array}{llll}\begin{array}{l}\text { CABERNET } 24 \\ 2013\end{array} & 1 & \begin{array}{l}\text { Ranibizumab }(0.5 \mathrm{mg}) 3 \text { injec- } \\ \text { tions, over } 3 \text { months followed } \\ \text { by quarterly injections }\end{array} & \begin{array}{l}\text { Epimacular brachytherapy; pars plana vitrectomy and } \\ \text { placing of strontium 90/yttrium } 90 \text { applicator over } \\ \text { AMD lesion. Intervention group also received } 2 \text { intrav- } \\ \end{array} \\ & & \begin{array}{l}\text { itreal injections of 0.5mg ranibizumab, one at the end } \\ \text { of surgery and one 30 days later }\end{array}\end{array}$

$\begin{array}{llll}\text { MERLOT } 2016 \quad 24 & 1 & \begin{array}{l}\text { Ongoing PRN ranibizumab } \\ (0.5 \mathrm{mg})\end{array}\end{array}$

Epimacular brachytherapy; pars plana vitrectomy and placing of strontium 90 probe over AMD lesion to deliver required dose. All participants received PRN ranibizumab $(0.5 \mathrm{mg})$

Jaakkola $2005 \quad 12$ to $15 \quad 1 \quad$ Observation

Plaque brachytherapy. One strontium 90 plaque delivered a dose of $15 \mathrm{~Gy}$ at a depth of $1.75 \mathrm{~mm}$ for 54 minutes but as this took too long another plaque was used which delivered a dose of $12.6 \mathrm{~Gy}$ at $4 \mathrm{~mm}$ depth for 11 minutes 
PRN: pro re nata 


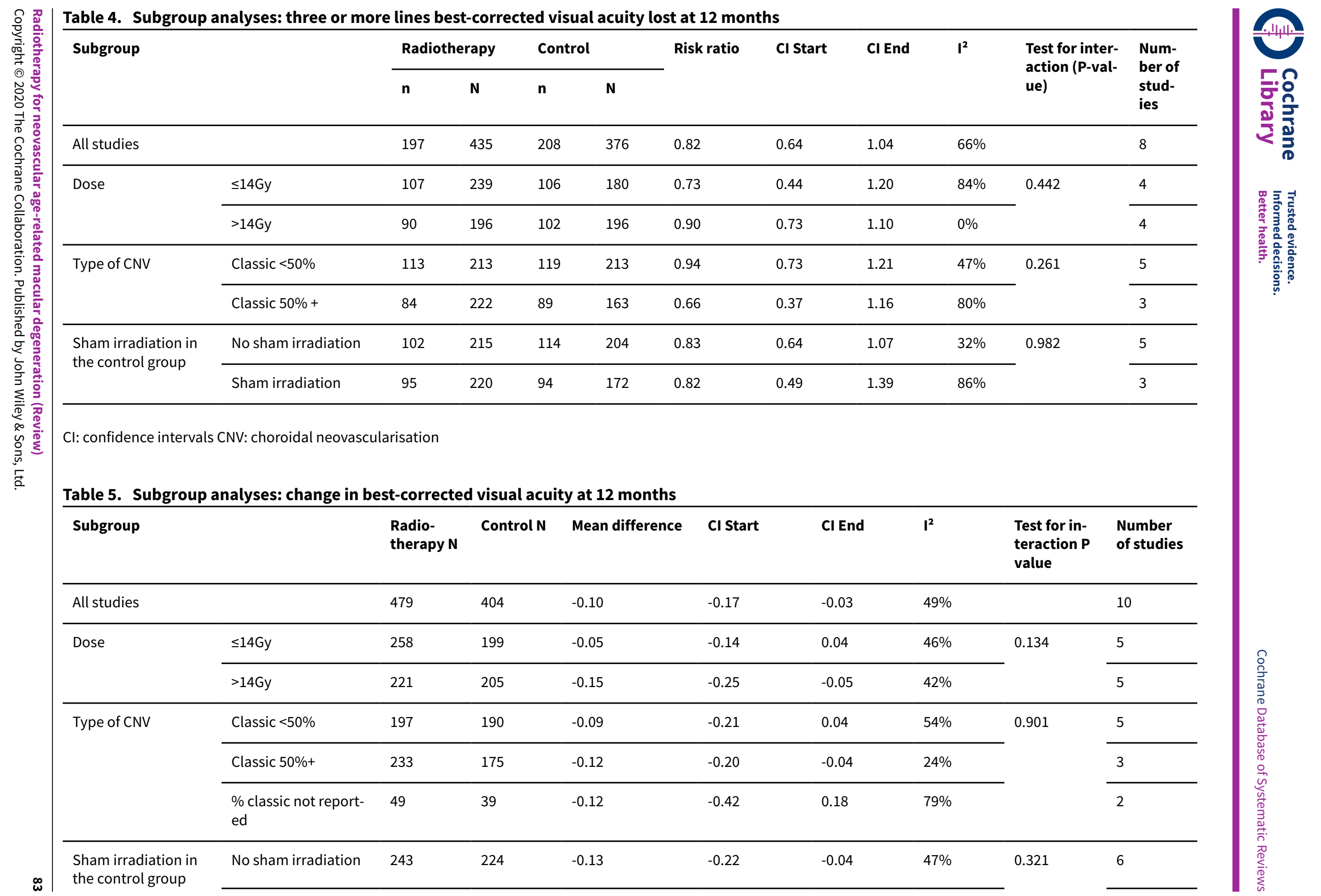




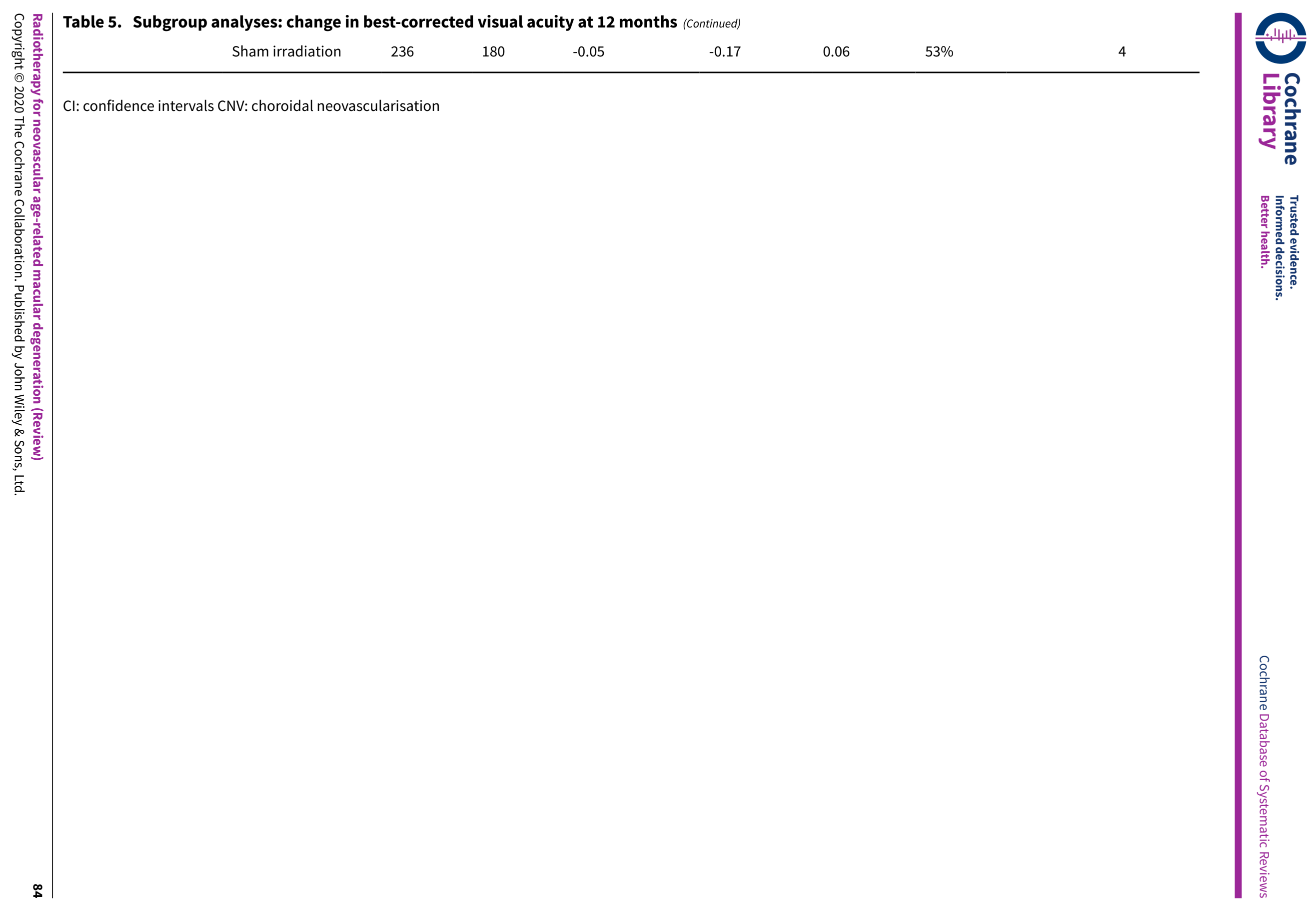


Table 6. Adverse outcomes

\begin{tabular}{|c|c|c|c|}
\hline & Study & $\begin{array}{l}\text { Number of } \\
\text { eyes ran- } \\
\text { domised }\end{array}$ & Report \\
\hline 1 & $\begin{array}{l}\text { AMDLRTSG } \\
2003\end{array}$ & 69 & No comment on adverse effects in the report \\
\hline 2 & AMDRT 2004 & 88 & $\begin{array}{l}\text { "Adverse events were infrequent.By } 12 \text { months, one treated patient devel- } \\
\text { oped multiple cotton wool spots and retinal nonperfusion adjacent to the } \\
\text { disc, possibly indicating radiation retinopathy. Visual acuity in this eye was } \\
20 / 80 \text { at baseline and } 20 / 80 \text { at } 12 \text { months. There were five deaths among AM- } \\
\text { DRT patients: four of which occurred among patients who did not receive } \\
\text { EBR. Cataract surgery was performed on two patients, one in each treatment } \\
\text { group. Six patients reported ocular dryness; four had not received EBR and } \\
\text { two had received EBR" }\end{array}$ \\
\hline
\end{tabular}

\begin{tabular}{lll}
\hline 3 & Anders $1998 \quad 76$ & $\begin{array}{l}\text { Subretinal haemorrhage in } 3 \text { cases in both treatment and control groups. } \\
\text { No other complications reported. }\end{array}$
\end{tabular}

$\begin{array}{ll}\text { CABERNET } 494 & \begin{array}{l}\text { A higher proportion of the treatment group had serious ocular adverse } \\ \text { event (54\%) compared to the control group (18\%). The majority of these } \\ \text { adverse events were cataract. Overall } 5 \% \text { of the treatment group had de- } \\ \text { vice-related adverse events (17 cases); } 10 \text { of these cases were radiation } \\ \text { retinopathy. }\end{array}\end{array}$

\begin{tabular}{|c|c|c|c|}
\hline 6 & Char 1999 & 27 & No comment on adverse effects in the report \\
\hline 7 & Ciulla 2002 & 37 & No comment on adverse effects in the report \\
\hline 8 & Eter 2002 & 45 & No comment on adverse effects in the report \\
\hline 9 & INTREPID 2013 & 230 & AEs similar across study arms and none attributed to radiation. \\
\hline 10 & Jaakkola 2005 & 88 & No comment on adverse effects in the report \\
\hline 11 & Kacperek 2001 & 58 & No comment on adverse effects in the report \\
\hline \multirow[t]{3}{*}{12} & Kobayashi 2000 & 101 & Reported no radiation-associated adverse effects. \\
\hline & & & $\begin{array}{l}2 \text { participants in treatment group "complained of transient conjunctival in- } \\
\text { jection that resolved within } 2 \text { weeks" }\end{array}$ \\
\hline & & & $\begin{array}{l}\text { Cataract observed in } 1 \text { participant in treatment group but otherwise no evi- } \\
\text { dence of cataract progression. }\end{array}$ \\
\hline
\end{tabular}

\begin{tabular}{lll}
\hline 13 & Marcus 2001 83 & $\begin{array}{l}\text { Reported no radiation-associated adverse effects. Cataract progression sim- } \\
\text { ilar to treatment and control. } 1 \text { case of retinal detachment and } 1 \text { case of vit- } \\
\text { reous haemorrhage seen in radiation group }\end{array}$ \\
\hline 14 & MERLOT 2016 363 & $\begin{array}{l}\text { In the radiotherapy plus ranibizumab group (n=244) there were } 4 \text { cases of } \\
\text { reduced visual acuity, } 1 \text { vitreous haemorrhage, } 3 \text { retinal haemorrhage, } 3 \\
\text { retinal detachment, } 1 \text { vision blurred, } 1 \text { endophthalmitis, } 1 \text { vitreous floaters, }\end{array}$
\end{tabular}


Table 6. Adverse outcomes (Continued)

2 postoperative uveitis. In the ranibizumab only group $(n=119)$ there was 1 case of reduced visual acuity and 1 case of retinal haemorrhage.

\begin{tabular}{|c|c|c|c|}
\hline 15 & $\begin{array}{l}\text { Osmanovic } \\
2017\end{array}$ & 30 & $\begin{array}{l}\text { Reported no cases of: } \\
\text { - severe vision loss } \\
\text { - adverse arteriothromboembolic events } \\
\text { - radiation retinopathy, neuropathy or anterior segment adverse effects. } \\
\text { Cataract progression: Among the } 13 \text { phakic eyes ( } 13 \text { people) who completed } \\
\text { the } 12 \text {-month study follow-up, } 4 \text { had cataract progression ( } 1 \text { control, } 2 \text { from } \\
16 \text { GyE, } 1 \text { from } 24 \text { GyE). One eye receiving } 16 \text { GyE PBT } \\
\text { underwent cataract extraction within the } 1 \text {-year follow-up; however, } \\
\text { this individual had moderately advanced cataract } \\
\text { at baseline. }\end{array}$ \\
\hline 16 & RAD 1999 & 205 & $\begin{array}{l}\text { Reported no radiation-associated adverse effects. Cataract developed in } 7 \\
(10.3 \%) \text { radiation group, } 12(16 \%) \text { control group) }(P=0.218) \text {. Dry eye symp- } \\
\text { toms in were recorded in } 30(40 \%) \text { radiation group and } 38(45.2 \%) \text { in control } \\
\text { group }(P=0.525) .4 \text { deaths unrelated to radiation treatment, } 3 \text { in radiation } \\
\text { group, } 1 \text { in control group }\end{array}$ \\
\hline 17 & SFRADS 2002 & 203 & $\begin{array}{l}\text { Reported no radiation-associated adverse effects but "transient disturbance } \\
\text { of the precorneal tear film" was noted in treated patients" }\end{array}$ \\
\hline 18 & Valmaggia 2002 & 161 & Reported no radiation-associated adverse effects. \\
\hline
\end{tabular}

\section{AP PE N DICES}

\section{Appendix 1. CENTRAL search strategy}

\#1 MeSH descriptor Macular Degeneration

\#2 MeSH descriptor Retinal Degeneration

\#3 MeSH descriptor Neovascularization, Pathologic

\#4 (macula* near degenerat ${ }^{\star}$ )

\#5 (macula* near neovasc ${ }^{\star}$ )

\#6 (retina* near degener $\left.{ }^{\star}\right)$

\#7 (retina* near neovasc $\left.{ }^{\star}\right)$

\#8 (choroid $^{*}$ near degener $\left.{ }^{\star}\right)$

\#9 (choroid $^{\star}$ near neovasc $\left.{ }^{\star}\right)$

$\# 10$ (maculopath ${ }^{\star}$ )

\#11 (\#1 OR \#2 OR \#3 OR \#4 OR \#5 OR \#6 OR \#7 OR \#8 OR \#9 OR \#10)

\#12 MeSH descriptor Radiotherapy

\#13 (radiotherap* or radiat $^{\star}$ or irradiat $^{\star}$ )

\#14 (teletherap* or tele-therap* ${ }^{\star}$ or proton* or plaque)

\#15 (external near beam)

\#16 (external-beam)

\#17 (\#12 OR \#13 OR \#14 OR \#15 OR \#16)

\#18 (\#11 AND \#17)

\section{Appendix 2. MEDLINE Ovid search strategy}

1 randomized controlled trial.pt.

2 (randomized or randomised).ab,ti.

3 placebo.ab,ti.

4 dt.fs.

5 randomly.ab,ti. 
6 trial.ab,ti.

7 groups.ab,ti.

8 or $/ 1-7$

9 exp animals/

10 exp humans/

119 not (9 and 10)

128 not 11

13 exp macular degeneration/

14 exp retinal degeneration/

15 exp retinal neovascularization/

16 exp choroidal neovascularization/

17 exp macula lutea/

18 (macula\$ adj2 lutea).tw.

19 maculopath\$.tw.

20 ((macul\$ or retina\$ or choroid\$) adj3 degener\$).tw.

21 ((macul\$ or retina\$ or choroid\$) adj3 neovasc\$).tw.

22 or/13-21

23 exp radiotherapy/

24 (radiotherap $\$$ or radiat\$ or irradiat\$ or teletherap\$ or proton\$ or plaque).tw.

25 (external adj3 beam).tw.

26 or/23- 25

2722 and 26

2812 and 27

The search filter for trials at the beginning of the MEDLINE strategy is from the published paper by Glanville 2006.

\section{Appendix 3. Embase Ovid search strategy}

1 exp randomized controlled trial/

2 exp randomization/

3 exp double blind procedure/

4 exp single blind procedure/

5 random $\$ . t w$.

6 or/ $1-5$

7 (animal or animal experiment).sh.

8 human.sh.

97 and 8

107 not 9

116 not 10

12 exp clinical trial/

13 (clin\$ adj3 trial\$).tw.

14 ((singl\$ or doubl\$ or trebl\$ or tripl\$) adj3 (blind\$ or mask\$)).tw.

15 exp placebo/

16 placebo\$.tw.

17 random $\$$.tw.

18 exp experimental design/

19 exp crossover procedure/

20 exp control group/

21 exp latin square design/

22 or $/ 12-21$

2322 not 10

2423 not 11

25 exp comparative study/

26 exp evaluation/

27 exp prospective study/

28 (control\$ or propspectiv\$ or volunteer\$).tw.

29 or $/ 25-28$

3029 not 10

3130 not (11 or 23$)$

3211 or 24 or 31

33 exp retina macula age related degeneration/

34 exp retina degeneration/ 
35 exp neovascularization pathology/

36 ((macul\$ or retina\$ or choroid\$) adj3 degener\$).tw.

37 ((macul\$ or retina\$ or choroid\$) adj3 neovasc\$).tw.

38 maculopath\$.tw.

39 or/33-38

40 exp radiotherapy/

41 (radiotherap\$ or radiat\$ or irradiat\$ or teletherap\$ or proton\$ or plaque).tw.

42 (external adj3 beam).tw.

43 or $/ 40-42$

4439 and 43

4532 and 44

\section{Appendix 4. LILACS search strategy}

macula\$ or retina\$ or choroid\$ and degenerat $\$$ or neovasc $\$$ and radiotherap $\$$ or radiat $\$$ or irradiat $\$$ or teletherap\$ or proton\$ or plaque

\section{Appendix 5. ISRCTN search strategy}

(Macular Degeneration OR AMD OR nAMD OR ARMD) AND (radiotherapy OR radiation OR irradiation OR teletherapy OR proton OR plaque)

\section{Appendix 6. ClinicalTrials.gov search strategy}

(Macular Degeneration OR AMD OR nAMD OR ARMD) AND (radiotherapy OR radiation OR irradiation OR teletherapy OR proton OR plaque)

\section{Appendix 7. WHO ICTRP search strategy}

macular degeneration $=$ Condition AND radiotherapy $=$ Intervention

\section{WHAT' S NEW}

\begin{tabular}{lll}
\hline Date & Event & Description \\
\hline 1 May 2020 & $\begin{array}{l}\text { New citation required and conclusions } \\
\text { have changed }\end{array}$ & $\begin{array}{l}\text { Issue 8 2020: Four new studies included in update (CABERNET } \\
\text { 2013; INTREPID 2013; MERLOT 2016; Osmanovic 2017) }\end{array}$ \\
\hline 1 May 2020 & New search has been performed & Issue 8 2020: Electronic searches updated \\
\hline
\end{tabular}

\section{H I S T OR Y}

Protocol first published: Issue 1, 2003

Review first published: Issue 4, 2004

\begin{tabular}{lll}
\hline Date & Event & Description \\
\hline 31 March 2010 & New search has been performed & Issue 5 2010: Updated searches yielded 3 new trials. \\
\hline 31 March 2010 & $\begin{array}{l}\text { New citation required but conclusions } \\
\text { have not changed }\end{array}$ & $\begin{array}{l}\text { Review substantially updated including new assessment of risk } \\
\text { of bias and preparation of summary of findings tables. }\end{array}$ \\
\hline 17 March 2008 & Amended & Converted to new review format. \\
\hline
\end{tabular}

\section{CONTRIBUTIONS OF AUTHORS}

Conceiving the review: VC

Designing the review, writing the protocol: $\mathrm{VC}$

Co-ordinating the review: VC, JE

Data collection for the review: JE, $\mathrm{Cl}$ 
Screening search results: JE, EP

Organising retrieval of papers: JE

Screening retrieved papers against inclusion criteria: JE, EP

Appraising quality of papers: $\mathrm{JE}, \mathrm{Cl}$

Abstracting data from papers: $\mathrm{JE}, \mathrm{Cl}$

Writing to authors of papers for additional information: VC, JE

Obtaining and screening data on unpublished studies: JE

Data management for the review: JE

Entering data into RevMan: JE

Analysis of data: JE

Interpretation of data: All authors

Providing a clinical perspective: VC, TJ, EP

Writing the review: JE, VC, TJ, EP

Guarantor for the review: JE

\section{DECLARATIONS OF INTEREST}

\section{JE: none known}

$\mathrm{Cl}$ : none known

TJ was a principal investigator and/or lead author in the CABERNET, MERLOT, MERITAGE and INTREPID studies. He leads an NIHR funded trial of the Oraya device. His employer received research payments for participants enrolled in commercial clinical trials of radiation devices used to treat wet AMD, and research grants or free use of radiation devices for investigator-initiated clinical trials of wet AMD. He is a consultant to Opthea and iLumens.

VC is consultant of Quantel Medical and is an employee of Boehringer Ingelheim. This publication expresses the opinion of the author (VC) and is not endorsed by Boehringer Ingelheim.

\section{SOURCES OF SUPPORT}

\section{Internal sources}

- No sources of support supplied

\section{External sources}

- Guide Dogs for the Blind Association, UK

- National Institute for Health Research (NIHR), UK

* Richard Wormald, Co-ordinating Editor for Cochrane Eyes and Vision (CEV) received financial support for his CEV research sessions (during this update) from the Department of Health through the award made by the National Institute for Health Research to Moorfields Eye Hospital NHS Foundation Trust and UCL Institute of Ophthalmology for a Specialist Biomedical Research Centre for Ophthalmology.

* This review update was supported by the NIHR, via Cochrane Infrastructure funding to the CEV UK editorial base.

The views and opinions expressed therein are those of the authors and do not necessarily reflect those of the Systematic Reviews Programme, NIHR, NHS or the Department of Health.

\section{DIFFERENCES BETWEEN PROTOCOL AND REVIEW}

The review has been substantially updated since the original protocol was written and new methods, such assessment of risk of bias, GRADE assessment and summary of findings table, have been incorporated.

In previous versions of this review we considered loss of 3 and 6 lines of visual acuity. We felt that loss of 6 or more lines of visual acuity was not such a relevant outcomes now with the advent of anti-VEGF treatments and therefore made the decision to drop this outcome in the current review update. We have included change in best-corrected visual acuity instead.

Recent trials have considered the combination of anti-VEGF and radiotherapy. As a result, we have added in a new comparison "Radiotherapy combined with anti-VEGF versus anti-VEGF alone" and one additional outcome "number of injections of anti-VEGF". We have considered this as an outcome because one of the potential aims of radiotherapy would be to reduce the number of anti-VEGF injections required.

We also dropped the 6 month follow-up period and have focused on 12 and 24 months only.

In previous version of this review (Evans 2010) we assessed the potential impact of missing data in some detail and assessed the potential for selective outcome reporting using the ORBIT classification (Kirkham 2010). As these analyses did not point to any major sources of bias we have not updated them for the current version of this review. 
INDEX TERMS

\section{Medical Subject Headings (MeSH)}

Eye [radiation effects]; Macular Degeneration [ ${ }^{\star}$ radiotherapy]; Radiation Injuries [complications]; Randomized Controlled Trials as Topic

\section{MeSH check words}

Humans 